\author{
UNIVERSIDADE DE SÃO PAULO \\ ESCOLA DE ENGENHARIA DE SÃO CARLOS \\ DEPARTAMENTO DE ENGENHARIA MECÂNICA
}

\title{
Algoritmo de Autoidentificação para o Controle Autônomo de Vibrações em Sistemas Rotativos
}

THIAGO MALTA BUTTINI

Orientador: Prof. Dr. Rodrigo Nicoletti

São Carlos

2011 


\title{
Algoritmo de Autoidentificação para o Controle Autônomo de Vibrações em Sistemas Rotativos
}

\author{
Dissertação apresentada à Escola de \\ Engenharia de São Carlos da Universidade de \\ São Paulo, como parte dos requisitos para a \\ obtenção do título de Mestre em Engenharia \\ Mecânica. Área de concentração: Dinâmica de \\ Máquinas e Sistemas.
}

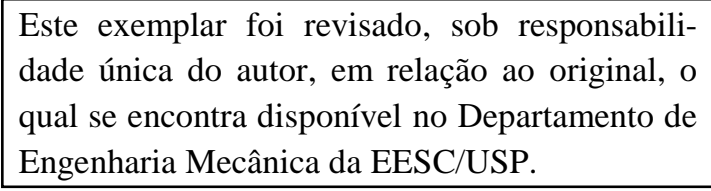

Orientador: Prof. Dr. Rodrigo Nicoletti

São Carlos 
AUTORIZO A REPRODUÇÃO E DIVULGAÇÃO TOTAL OU PARCIAL DESTE TRABALHO, POR QUALQUER MEIO CONVENCIONAL OU ELETRÔNICO, PARA FINS DE ESTUDO E PESQUISA, DESDE QUE CITADA A FONTE.

Ficha catalográfica preparada pela Seção de Tratamento da Informação do Serviço de Biblioteca - EESC/USP

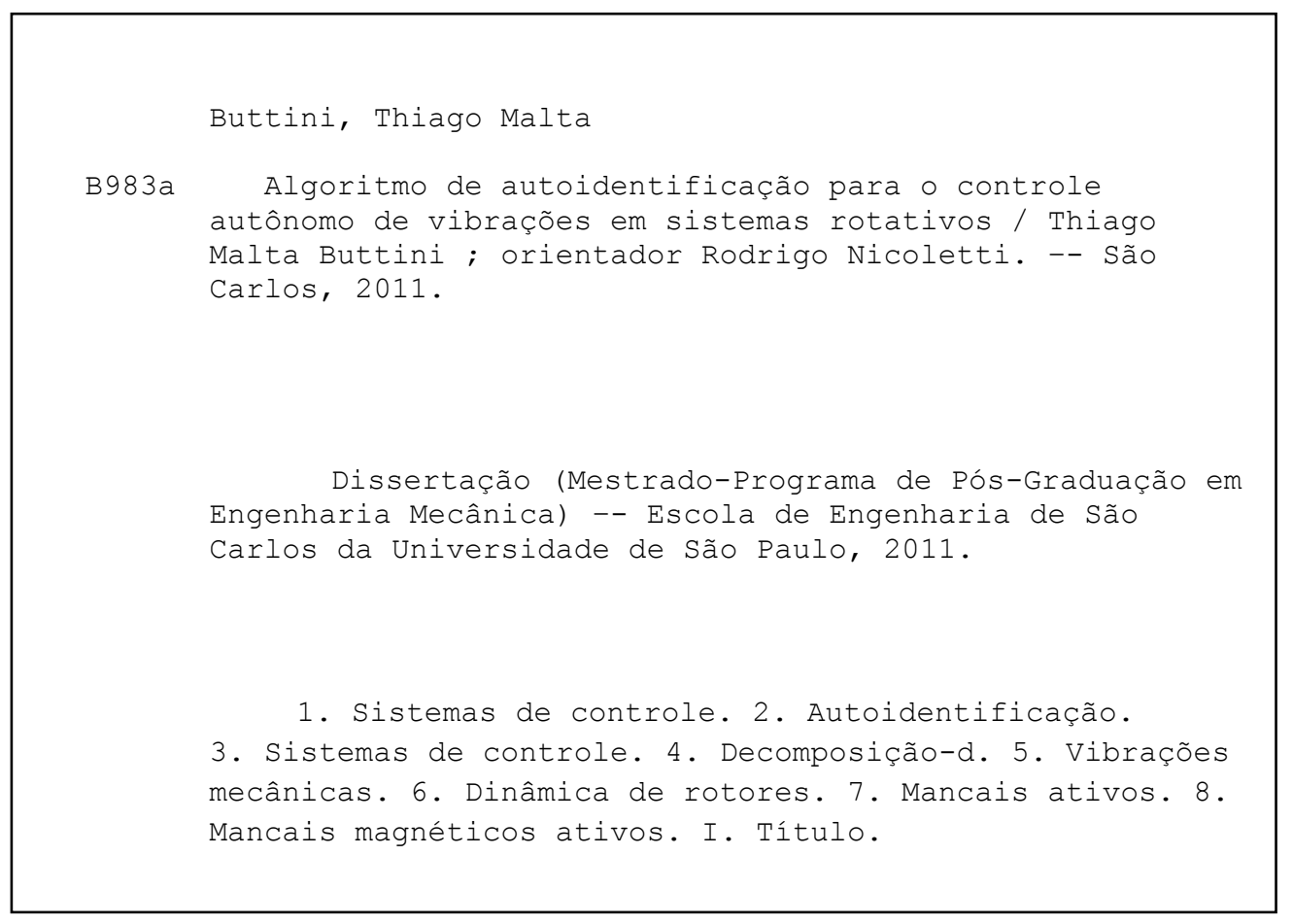




\section{FOLHA DE JULGAMENTO}

Candidato: Engenheiro THIAGO MALTA BUTTINI

Título da dissertação: Algoritmo de autoidentificação para o controle autônomo de vibrações em sistemas rotativos.

Data da defesa: 29/07/2011:

\section{Comissão Julgadlora:}

Prof. Dr. Rodrigo Nicoletti (Orientador)

(Escola de Engenharia de São Carlos/EESC)

Prof. Dr. Adriano Almeida Gonçalves Siqueira

(Escola de Engenharia de São Carlos/EESC)

Prof. Dr. Agenor de Toledo Fleury

(Escola Politécnica/USP)
Resultado:

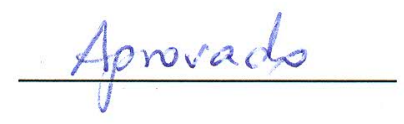

APROVADO

APROVADO

Coordenador do Programa de Pós-Graduação em Engenharia Mecânica:

Prof. Associado Marcelo Areias Trindade

Presidente da Comissão de Pós-Graduação:

Prof. Associado Paulo Cesar Lima Segantine 


\section{Dedicatória}

Dedico este trabalho aos meus pais, José Roberto e Maria Cleuza, e às minhas irmãs, Juliana e Heloísa, pelo amor incondicional e apoio. 


\section{Agradecimentos}

Ao Prof. Dr. Rodrigo Nicoletti pela amizade e confiança em mim depositada, além da orientação constante e entusiasmo ao longo do desenvolvimento deste trabalho.

Aos professores do departamento de Engenharia Mecânica da EESC/USP, em especial ao Prof. Dr. Adriano Almeida Gonçalves Siqueira pelos comentários e sugestões dados durante o desenvolvimento e implantação da técnica de controle.

Aos funcionários do Laboratório de Dinâmica, em especial aos técnicos Jair Diego Antonietti e Sérgio Donizete Carvalho Ferreira pelo auxílio na montagem da bancada de testes.

Aos colegas do Laboratório de Dinâmica Andreza, Carlos, Fábio, Heinsten, Henry, Jaime, Leonardo, Leopoldo, Meire, Tatiane e Vítor pelo companheirismo e bom ambiente de trabalho.

Aos pesquisadores Patrick Felscher e Nicklas Norrick da Technische Universität Darmstadt, Alemanha, pelo auxílio durante a execução dos testes experimentais.

Aos amigos Ana Gabriela, Bruna, Frederico, Guilherme, João Antônio, João Vítor, Juliano, Luiz Vítor, Patrícia, Rebeca e Thiago José pela amizade e excelente convivência.

À Rosana César pelo companheirismo e apoio.

Aos meus familiares pelo amor, incentivo constante e inestimável apoio. Em especial, aos meus avós Pedro (in memoriam), Aparecida, Expedito e Maria pelo carinho e valores a mim transmitidos.

À FAPESP, Fundação de Amparo à Pesquisa do Estado de São Paulo, pelo suporte financeiro.

A todos aqueles que, embora não tenham sido citados explicitamente, também contribuíram direta ou indiretamente e de forma não menos importante para a realização deste trabalho. 
“[...] Penso que cumprir a vida Seja simplesmente Compreender a marcha E ir tocando em frente Como um velho boiadeiro Levando a boiada Eu vou tocando os dias Pela longa estrada, eu vou [...]" Tocando em Frente (Almir Sater \& Renato Teixeira) 


\section{Resumo}

BUTTINI, T. M. (2011). Algoritmo de autoidentificação para o controle autônomo de vibrações em sistemas rotativos. Dissertação de Mestrado, Escola de Engenharia de São Carlos, Universidade de São Paulo, São Carlos.

Vibrações são intrínsecas às máquinas rotativas e, embora não possam ser completamente eliminadas, devem ser controladas de modo a se evitar fadiga e até mesmo falha da máquina. Neste contexto, devido à sua capacidade de alterar as características dinâmicas destas máquinas, os mancais ativos são uma solução efetiva a fim de se reduzir vibrações em rotores, permitindo não só maior ciclo de vida, mas também aumento de confiabilidade e desempenho. Frequentemente, o projeto do sistema de controle destes mancais baseia-se em um modelo matemático da planta, o qual pode ser de difícil obtenção e, devido à adoção de hipóteses simplificadoras (inerentes ao processo de modelagem), pode ser impreciso. Com base nestes conceitos, propõe-se a utilização de uma técnica de controle do tipo proporcionalderivativa baseada em medições de resposta em frequência (livre de modelos matemáticos) aplicada ao controle de vibrações em sistemas rotativos, contornando dificuldades de modelagem. Esta técnica é testada experimentalmente em uma bancada de testes cujos elementos de atuação são os eletromagnetos de um mancal ativo, e um algoritmo para a identificação automática das FRFs do sistema (algoritmo de autoidentificação) é desenvolvido e implementado, permitindo, de forma autônoma, o cálculo dos ganhos ótimos do controlador PD visando atenuação de vibrações. Com base nos resultados obtidos, tem-se que este trabalho é um estudo preliminar que pode viabilizar o desenvolvimento de um mancal ativo inteligente, o qual, a partir de medições do deslocamento do eixo, seria capaz de obter a resposta em frequência do sistema e determinar, de forma automática, os ganhos ótimos do controlador, possibilitando o controle autônomo de vibrações em sistemas rotativos, a partir de um algoritmo de autoidentificação e de uma metodologia de controle livre de modelos.

Palavras-chave: Autoidentificação, Sistemas de Controle, Decomposição-d, Vibrações Mecânicas, Dinâmica de Rotores, Mancais Ativos, Mancais Magnéticos Ativos. 


\section{Abstract}

BUTTINI, T. M. (2011). Self-identification algorithm for the autonomous control of vibrations in rotating systems. Master's dissertation, Escola de Engenharia de São Carlos, Universidade de São Paulo, São Carlos.

Vibrations are intrinsic to rotating machinery and, although they cannot be completely eliminated, it is important to control this kind of motion with the objective of avoiding fatigue and even failure of the machine. In this context, due to their capacity of changing the dynamic characteristics of these machines, active bearings are an effective solution to reduce vibration in rotors, allowing not only longer lifecycle, but also higher performance. Frequently, the design of the control system of these bearings is based on a mathematical model of the plant, whose obtainment can be hard and, due to the adoption of simplifying hypotheses (inherent to the modeling process), it may be imprecise. Keeping in mind these concepts, this dissertation proposes the use of a proportional-derivative control technique based on frequency response measurements (free of mathematical models) applied to the vibration control of rotating systems, overcoming modeling difficulties. This technique is experimentally tested in a test rig whose actuation elements are the electromagnets of an active bearing, and an algorithm for automatic identification of the system's FRFs (self-identification algorithm) is developed and implemented, allowing, in an autonomous way, the calculation of the optimum gains of the PD controller aiming at controlling vibration. Based on the results obtained, this work consists in a preliminary study that may enable the development of a smart active bearing, which, from measurements of the shaft's displacement, would be capable of obtaining the frequency response of the system and determine, automatically, the optimum gains of the controller, making it possible the autonomous vibration control in rotating systems, from a self-identification algorithm and a model-free control methodology.

Keywords: Self-identification, Control Systems, D-decomposition, Mechanical Vibrations, Rotor Dynamics, Active Bearings, Active Magnetic Bearings. 


\section{Lista de figuras}

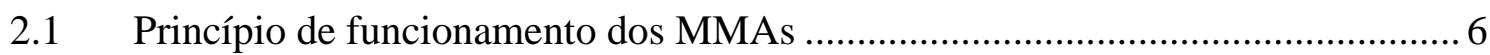

2.2 Configuração dos eletromagnetos de um MMA de 4 polos .................................. 7

2.3 Montagem da sapata móvel magnética .................................................... 8

2.4 Mancal hidrodinâmico segmentado com sapatas móveis magnéticas .................. 8

2.5 Exemplo de malha de controle adaptativo ....................................................... 13

3.1 Regiões cujos números de polos em malha fechada é invariável para o sistema da Equação (3.1) (a área hachurada corresponde à região de

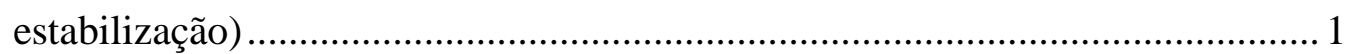

3.2 Configuração do sistema de controle realimentado ....................................... 18

3.3 Faixa de frequências a ser varrida a fim de minimizar o segundo pico de ressonância

4.1 Sistema com um disco: 1. mancais de rolamento, 2. sensores de posição, 3. discos rígidos, 4. atuadores eletromagnéticos, 5. motor elétrico

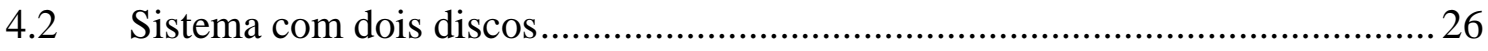

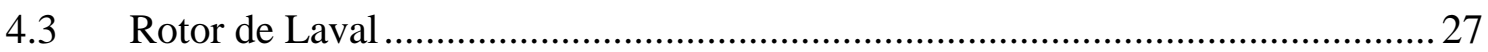

4.4 Vistas ampliadas dos sensores e atuadores (itens \#2 e \#4, respectivamente da Figura 4.1)

4.5 Sistema com um disco: dimensões e distâncias relativas entre os componentes 
4.6 Sistema com dois discos: distâncias e pontos considerados para a análise modal

4.7 Modos de vibrar da bancada de testes (a ressonância verificada em $\mathrm{f}=44,2$ $\mathrm{Hz}$, pela forma de seu modo de vibrar associado, não corresponde a um modo do eixo; acredita-se que ela seja devida a um modo de vibrar do motor)

4.8 Diagrama de blocos da planta: a FRF contém informações do sistema como um todo, incluindo sensores e atuadores

4.9 Esquematização do procedimento para excitação e aquisição dos dados de saída do sistema (inicialmente, o sinal de controle é zero, sendo somado ao de excitação quando da implantação da estratégia de controle)

4.10 Sinal de excitação do tipo chirp utilizado para excitar o sistema com um disco. (a) um período, (b) sinal replicado 4 vezes (perfazendo um tempo total de excitação de $40 \mathrm{~s}$ )

4.11 Sinal de excitação do tipo chirp utilizado para excitar o sistema com dois discos. (a) um período, (b) sinal replicado 4 vezes (perfazendo um tempo total de excitação de $40 \mathrm{~s}$ ).

4.12 Balanceamento da tensão de trabalho nos atuadores

4.13 Programa em MatLab Simulink para excitação e aquisição da resposta do sistema

4.14 Filtro Butterworth de segunda ordem passa alta (frequência de corte é 0,5 $\mathrm{Hz})$

4.15 Diagrama de cascata experimental do sistema com um disco em malha aberta. (a) deslocamento na horizontal, (b) deslocamento na vertical

4.16 FRF do sistema com um disco parado e girando a duas velocidades diferentes. (a) deslocamento na horizontal, (b) deslocamento na vertical

4.17 Função coerência ordinária para as FRFs da Figura 4.16. (a) coerência na horizontal, (b) coerência na vertical 
4.18 Diagrama de cascata experimental do sistema com dois discos em malha aberta. (a) deslocamento na horizontal (sensor \#1), (b) deslocamento na vertical (sensor \#2), (c) deslocamento na horizontal (sensor \#2), (d) deslocamento na vertical (sensor \#2)

4.19 FRF do sistema com dois discos parado e girando a duas velocidades diferentes. (a) deslocamento na horizontal (sensor \#1), (b) deslocamento na vertical (sensor \#2), (c) deslocamento na horizontal (sensor \#2), (d) deslocamento na vertical (sensor \#2)

4.20 Função coerência ordinária para as FRFs da Figura 4.19. (a) coerência na horizontal (sensor \#1), (b) coerência na vertical (sensor \#2), (c) coerência na horizontal (sensor \#2), (d) coerência na vertical (sensor \#2)

5.1 Regiões de ganhos invariáveis para $\Omega=880 \mathrm{rpm}$ (o pico observado para a frequência de $14,7 \mathrm{~Hz}$ é devido à harmônica da FRF - componente $\mathbf{B}$ na Figura 4.15 (a))

5.2 Regiões de ganhos invariáveis para $\Omega=0,560$ e $2080 \mathrm{rpm}$

5.3 Contornos de Nyquist para os conjuntos de ganhos selecionados na Figura 5.2. (a) ponto $\mathrm{A}$, (b) ponto $\mathrm{B}$, (c) ponto $\mathrm{C}$, (d) ponto $\mathrm{D}$, (e) ponto $\mathrm{E}$

5.4 Valores dos ganhos do controlador PD que garantem a estabilidade do sistema com um disco em malha fechada para uma faixa de velocidades de rotação de 0 a 2080 rpm. (a) região de estabilização, (b) ganhos estáveis selecionados

5.5 Valor esperado da amplitude do pico de ressonância em função dos valores dos ganhos do controlador. (a) $\Omega=560 \mathrm{rpm}$, (b) $\Omega=1180 \mathrm{rpm}$, (c) $\Omega=$ $1460 \mathrm{rpm}$, (d) $\Omega=2080 \mathrm{rpm}$

5.6 Programa em MatLab Simulink para excitação, controle e aquisição da resposta do sistema em malha fechada.

5.7 Comparação entre a amplitude do pico de ressonância na direção horizontal (sistema não controlado, controlado e valor esperado). (a) $\Omega=560 \mathrm{rpm}$, (b) $\Omega=1180 \mathrm{rpm}$, (c) $\Omega=1460 \mathrm{rpm},(\mathrm{d}) \Omega=2080 \mathrm{rpm}$ 
5.8 Comparação entre a amplitude do pico de ressonância na direção vertical (sistema não controlado e controlado). (a) $\Omega=560 \mathrm{rpm}$, (b) $\Omega=1180 \mathrm{rpm}$, (c) $\Omega=1460 \mathrm{rpm}$, (d) $\Omega=2080 \mathrm{rpm}$

5.9 Regiões de ganhos invariáveis para $\Omega=1770 \mathrm{rpm}$ (o pico observado para a frequência de 29,5 Hz é devido à harmônica da FRF - componente $\mathbf{B}$ na Figura 4.18 (a))

5.10 Regiões de ganhos invariáveis para $\Omega=0,740,1620$ e $2080 \mathrm{rpm}$

5.11 Contornos de Nyquist para os conjuntos de ganhos selecionados na Figura 5.10. (a) ponto $\mathrm{A}$, (b) ponto $\mathrm{B}$, (c) ponto $\mathrm{C}$, (d) ponto $\mathrm{D}$, (e) ponto $\mathrm{E}$, (f) ponto $\mathrm{F}$

5.12 Valores dos ganhos do controlador PD que garantem a estabilidade do sistema com dois discos em malha fechada para uma faixa de velocidades de rotação de 0 a 2080 rpm. (a) região de estabilização, (b) ganhos estáveis selecionados

5.13 Valor esperado da amplitude do maior dos dois picos correspondentes ao $1^{\circ}$ modo de vibrar do sistema em função dos valores dos ganhos do controlador. (a) $\Omega=560 \mathrm{rpm}$, (b) $\Omega=740 \mathrm{rpm}$, (c) $\Omega=1620 \mathrm{rpm}$, (d) $\Omega=$ $2080 \mathrm{rpm}$.

5.14 Comparação entre a amplitude do pico de ressonância na direção horizontal (sistema não controlado, controlado e valor esperado). (a) $\Omega=560 \mathrm{rpm}$, (b) $\Omega=740 \mathrm{rpm}$, (c) $\Omega=1620 \mathrm{rpm},(\mathrm{d}) \Omega=2080 \mathrm{rpm}$.

5.15 Amplitudes do primeiro e segundo picos de ressonância correspondentes ao $1^{\circ}$ modo de vibrar do sistema em função dos valores dos ganhos do controlador

5.16 Valor esperado para o maior dos dois picos correspondentes ao $1^{\mathrm{o}}$ modo de vibrar do sistema em função dos valores do ganho (controle do tipo P)

5.17 Comparação entre a amplitude do pico de ressonância na direção horizontal para o sistema não controlado e controlado (controle do tipo PD e P). (a) $\Omega$ $=560 \mathrm{rpm}$, (b) $\Omega=740 \mathrm{rpm}$, (c) $\Omega=1620 \mathrm{rpm}$, (d) $\Omega=2080 \mathrm{rpm}$. 
5.18 Comparação entre a amplitude do pico de ressonância na direção vertical para o sistema não controlado e controlado (controle do tipo PD e P) sensor \#1. (a) $\Omega=560 \mathrm{rpm}$, (b) $\Omega=740 \mathrm{rpm}$, (c) $\Omega=1620 \mathrm{rpm}$, (d) $\Omega=$ $2080 \mathrm{rpm}$

5.19 Comparação entre a amplitude do pico de ressonância na direção horizontal para o sistema não controlado e controlado (controle do tipo PD e P) sensor \#2. (a) $\Omega=560 \mathrm{rpm}$, (b) $\Omega=740 \mathrm{rpm}$, (c) $\Omega=1620 \mathrm{rpm}$, (d) $\Omega=$ $2080 \mathrm{rpm}$

5.20 Comparação entre a amplitude do pico de ressonância na direção vertical para o sistema não controlado e controlado (controle do tipo PD e P) sensor \#2. (a) $\Omega=560 \mathrm{rpm}$, (b) $\Omega=740 \mathrm{rpm}$, (c) $\Omega=1620 \mathrm{rpm}$, (d) $\Omega=$ $2080 \mathrm{rpm}$

5.21 Comparação entre a FRF experimental e modelo ajustado $(\Omega=880 \mathrm{rpm})$

5.22 Representação gráfica das condições necessárias e suficientes para estabilidade do sistema em malha fechada calculadas a partir do critério de estabilidade de Routh-Hurwitz (a área hachurada corresponde à região de estabilização)

5.23 Comparação entre o resultado obtido através da Decomposição-d (baseado na resposta em frequência experimental do sistema) e o obtido através do critério de Routh-Hurwitz (baseado em um modelo ajustado) para $\Omega=880$ rpm. (a) Decomposição-d, (b) Routh-Hurwitz

6.1 Fluxograma do algoritmo de autoidentificação

6.2 Fluxograma da sub-rotina FRF

6.3 Fluxograma da sub-rotina calculo_ganhos

6.4 Interface gráfica do algoritmo de autoidentificação desenvolvida através da ferramenta GUI do MatLab 
6.5 "Trajetória" realizada pelos ganhos do controlador (controle PD e P) a cada iteração realizada até que os valores máximos dos ganhos que não resultassem em saturação fossem atingidos $(\Omega=280 \mathrm{rpm})$.

6.6 Faixa de ganhos analisadas pela sub-rotina calcula_ganhos quando da implantação do controle PD para $\Omega=280 \mathrm{rpm}$ (quatro primeiras iterações)......83

6.7 Comparação entre a amplitude do pico de ressonância na direção horizontal para o sistema não controlado e controlado autonomamente (controle PD e P) para $\Omega=280 \mathrm{rpm}$

6.8 "Trajetória" realizada pelos ganhos do controlador (controle PD e P) a cada iteração realizada até que os valores máximos dos ganhos que não resultassem em saturação fossem atingidos $(\Omega=2080 \mathrm{rpm})$.

6.9 Comparação entre a amplitude do pico de ressonância na direção horizontal para o sistema não controlado e controlado autonomamente (controle PD e P) para $\Omega=2080 \mathrm{rpm}$ 


\section{Lista de tabelas}

2.1 Vantagens e desvantagens do uso de mancais hidrodinâmicos segmentados e mancais magnéticos.

5.1 Conjuntos de ganhos selecionados na Figura 5.2 para testar a estabilidade do sistema em malha fechada

5.2 Valores dos ganhos do controlador e amplitude do pico de ressonância

5.3 Redução percentual estimada e medida para o pico de ressonância e erro entre o valor medido em relação ao estimado

5.4 Amplitude do pico de ressonância (deslocamento na direção vertical)

5.5 Conjuntos de ganhos selecionados na Figura 5.10 para testar a estabilidade do sistema em malha fechada

5.6 Valores dos ganhos do controlador e amplitude do maior pico de ressonância

5.7 Redução percentual estimada e medida para o maior pico de ressonância e erro entre o valor medido em relação ao estimado

5.8 Amplitude do pico \#1: valores esperados e medidos

5.9 Amplitude do pico \#2: valores esperados e medidos 60

5.10 Valor do ganho proporcional adotado para o controle do sistema e amplitude do maior pico de ressonância 
5.11 Comparação entre a amplitude do maior pico de ressonância para o sistema não controlado e controlado (controle do tipo PD e P)

5.12 Redução percentual estimada e medida para o maior pico de ressonância e erro entre o valor medido em relação ao estimado (controle do tipo P)

5.13 Comparação entre a amplitude do maior pico de ressonância para o sistema não controlado e controlado (controle do tipo PD e P) - direção vertical (sensor \#1)

5.14 Comparação entre a amplitude do maior pico de ressonância para o sistema não controlado e controlado (controle do tipo PD e P) - direção horizontal (sensor \#2)

5.15 Comparação entre a amplitude do maior pico de ressonância para o sistema não controlado e controlado (controle do tipo PD e P) - direção vertical (sensor \#2)

5.16 Disposição de Routh-Hurwitz para o polinômio característico da Equação $(5.5)$

5.17 Vantagens e desvantagens do critério de estabilidade de Routh em relação à Decomposição-d para o cálculo dos ganhos estáveis de um sistema LTI.

6.1 Valores dos ganhos do controlador para cada iteração realizada ( $\Omega=280$ rpm)

6.2 Faixas de ganhos analisadas pela sub-rotina "calcula_ganhos" e valores ótimos para cada faixa quando da implantação do controle PD para $\Omega=280$ rpm (quatro primeiras iterações)

6.3 Valores dos ganhos do controlador para cada iteração realizada ( $\Omega=2080$ $\mathrm{rpm})$.

6.4 Comparação entre a amplitude do maior pico de ressonância para o sistema não controlado e controlado autonomamente (controle PD e P) 


\title{
Lista de abreviaturas e siglas
}

\author{
CRB complex root boundary (fronteira da raiz complexa) \\ FRF função de resposta em frequência \\ gdl grau-de-liberdade \\ IRB infinity root boundary (fronteira da raiz infnita) \\ LTI linear time invariant (linaer e invariante no tempo) \\ MIMO multiple-input, multiple-output (múltiplas entradas e múltiplas saídas) \\ MMA mancal magnético ativo \\ P proporcional \\ PD proporcional-derivativo \\ PID proporcional-integral-derivativo \\ rpm rotações por minuto \\ RRB real root boundary (fronteira da raiz real) \\ SISO single-input, single-output (uma entrada e uma saída)
}


xxiv 


\section{Nomenclatura}

$\mathrm{a}_{\mathrm{n}} \quad$ coeficiente dominante do polinômio característico do sistema em malha fechada

a polo real introduzido no controlador PD

$\mathrm{C}(\mathrm{j} \omega)$ função de resposta em frequência do controlador

$d_{n} \quad$ coeficiente dominante do denominador da planta em malha aberta

f frequência $[\mathrm{Hz}]$

$\mathrm{G}(j \omega)$ função de resposta em frequência da planta em malha fechada

j unidade imaginária $(\sqrt{-1})$

$\mathrm{K}_{\mathrm{D}} \quad$ ganho derivativo [V.s/mm]

$\mathrm{K}_{\mathrm{P}} \quad$ ganho proporcional $[\mathrm{V} / \mathrm{mm}]$

$\mathrm{M}_{\mathrm{r}} \quad$ amplitude do pico de ressonância $[\mathrm{mm} / \mathrm{V}]$

$\mathrm{n}_{\mathrm{n}} \quad$ coeficiente dominante do numerador da planta em malha aberta

$P(j \omega)$ função de resposta em frequência da planta em malha aberta

$\mathrm{P}(0) \quad$ valor de $\mathrm{P}(\mathrm{j} \omega)$ quando $\omega=0$

$\mathrm{P}(\infty) \quad$ valor de $\mathrm{P}(\mathrm{j} \omega)$ quando $\omega \rightarrow \infty$

$\mathrm{P}_{\mathrm{i}}(\omega)$ parte imaginária de $\mathrm{P}(\mathrm{j} \omega)$

$\mathrm{P}_{\mathrm{r}}(\omega)$ parte real de $\mathrm{P}(\mathrm{j} \omega)$ 
xxvi

$\pi(j \omega)$ polinômio característico

$\pi_{\mathrm{i}}(\omega)$ parte imaginária de $\pi(\mathrm{j} \omega)$

$\pi_{\mathrm{r}}(\omega) \quad$ parte real de $\pi(\mathrm{j} \omega)$

$\omega \quad$ frequência $[\mathrm{rad} / \mathrm{s}]$

$\Omega \quad$ velocidade angular do eixo [rpm] 


\section{Sumário}

Resumo $\quad$ xi

$\begin{array}{ll}\text { Abstract } & \text { xiii }\end{array}$

$\begin{array}{ll}\text { Lista de figuras } & \text { xv }\end{array}$

$\begin{array}{ll}\text { Lista de tabelas } & \text { xxi }\end{array}$

$\begin{array}{lc}\text { Lista de abreviaturas e siglas } & \text { xxiii }\end{array}$

$\begin{array}{ll}\text { Nomenclatura } & \mathbf{x x v}\end{array}$

1 Introdução 1

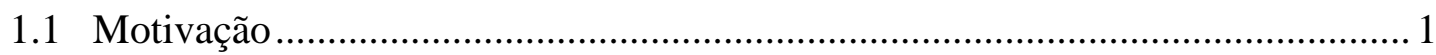

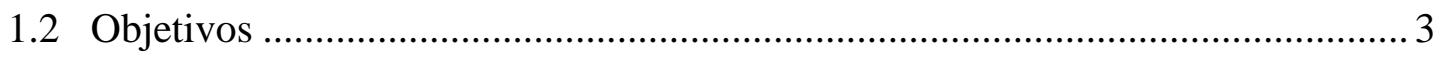

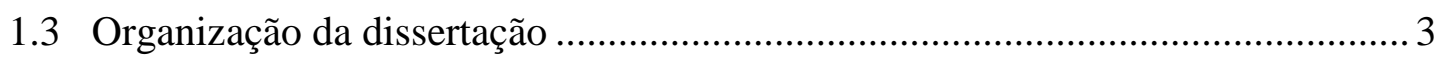

2 Revisão de literatura 5

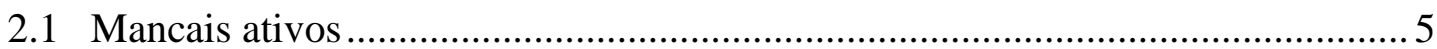

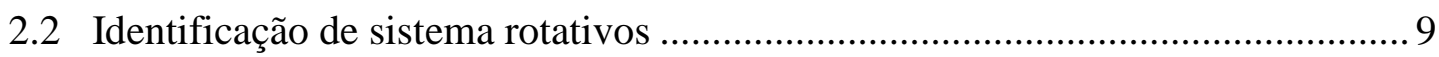

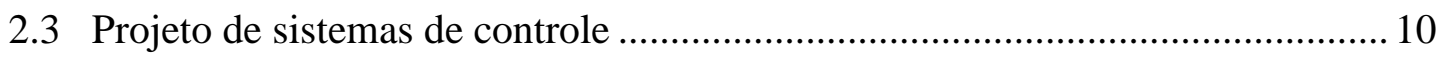

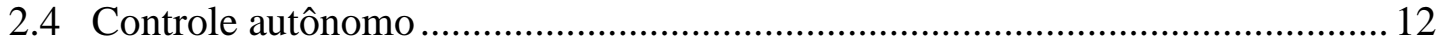

3 Projeto de controladores PD $\quad 15$

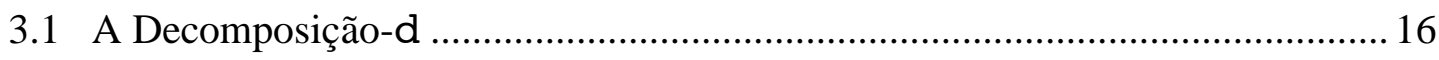

3.2 Teorema para cálculo das regiões de estabilização ......................................... 18

3.3 Amplitude do pico de ressonância..................................................................... 22 
4 Identificação dinâmica experimental do sistema rotativo 25

4.1 Montagem da bancada de testes.....................................................................25

4.2 Procedimento de identificação experimental das FRFs .....................................30

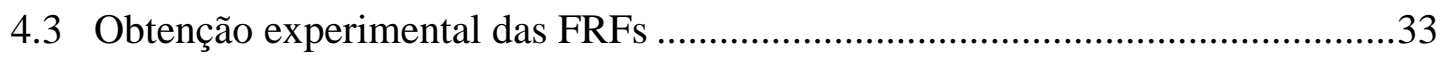

4.3.1 Sistema rotativo com um disco ........................................................... 33

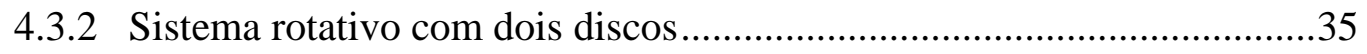

5 Implantação experimental da técnica de controle 39

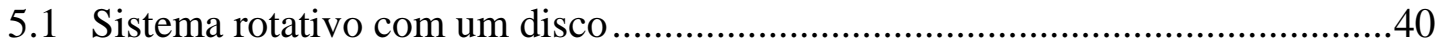

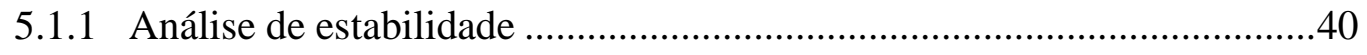

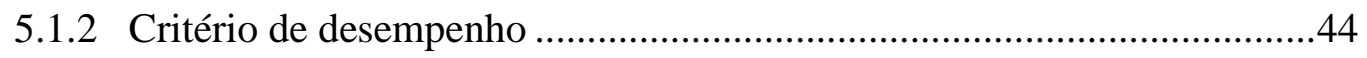

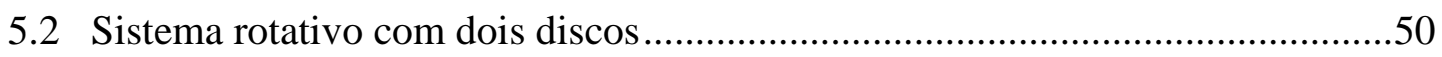

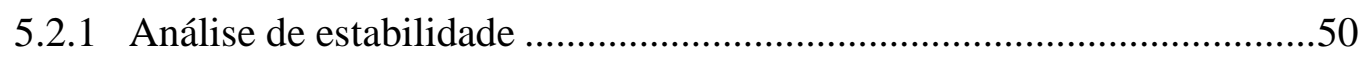

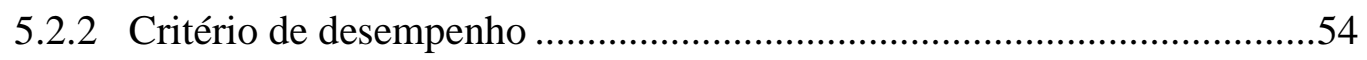

5.2.3 Comparação com um controle do tipo P.................................................61

5.3 Comparação com o critério de estabilidade de Routh-Hurwitz ..........................68

6 Algoritmo de autoidentificação $\quad 75$

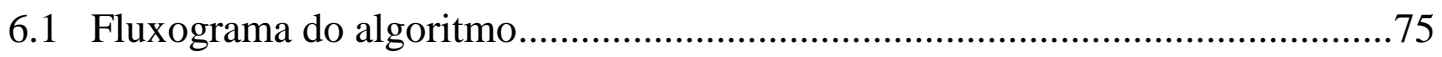

6.2 Controle autônomo de vibrações do sistema rotativo ........................................81

7 Conclusões $\quad 89$

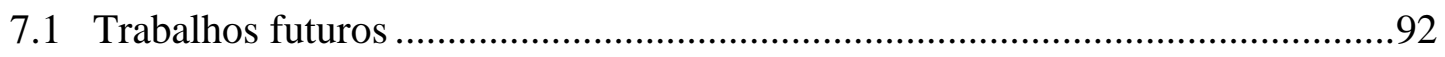

Referências bibliográficas 


\section{Capítulo 1}

\section{Introdução}

\subsection{Motivação}

Mancais ativos contam com atuadores capazes de exercer forças de controle em máquinas rotativas. Sendo assim, são utilizados para sustentar e, simultaneamente, controlar vibrações em rotores. Em relação à sua capacidade de controlar ativamente vibrações, ressalta-se que, tradicionalmente, os ganhos do controlador utilizado para tal fim são projetados a partir da tentativa e erro (estratégia que não conduz a um resultado ótimo) ou a partir do modelo matemático do sistema, que pode ser de difícil obtenção e impreciso, uma vez que a adoção de hipóteses simplificadoras é inerente ao processo de modelagem. Além disso, ao longo do tempo, os valores dos ganhos que tornam o sistema estável e otimizam seu desempenho não são os mesmos, pois as condições de operação da máquina variam (devido à mudança da velocidade de rotação do eixo e/ou ao carregamento a que ela está sujeita, por exemplo), fazendo-se necessário que o sistema de controle seja reprojetado a fim de garantir estabilidade e melhor desempenho.

Assim, um dos desafios no aperfeiçoamento dos mancais ativos é torná-los um componente "inteligente", i.e., eles devem contar com um sistema de aquisição e processamento de dados, que, a partir de informações como o deslocamento do eixo em relação a sua posição de equilíbrio, seja capaz, de forma automática, de determinar os ganhos ótimos do controlador, permitindo a sustentação e o controle autônomo de vibrações de sistemas rotativos sujeitos a diferentes condições de operação, assegurando estabilidade e desempenho, sem interferência humana. 
Neste sentido, este trabalho propõe a utilização de uma técnica de controle baseada em medições de resposta em frequência do sistema rotativo (a qual não requer modelos matemáticos), sendo um algoritmo (algoritmo de autoidentificação) responsável por excitar de forma autônoma o sistema utilizando atuadores eletromagnéticos de um mancal ativo, obtendo, assim, as suas respectivas FRFs e permitindo o projeto do controlador automaticamente através de uma estratégia de controle livre de modelos. Em estudos anteriores (Buttini e Nicoletti, 2009), verificou-se que um controlador da forma

$$
C(j \omega)=\frac{x_{1} j \omega+x_{2}}{j \omega+x_{3}}
$$

pode se comportar como um compensador de avanço ou atraso de fase e, a partir da FRF de dado sistema, é possível obter-se um volume de ganhos estáveis no espaço dos parâmetros $\left(x_{1}, x_{2}, x_{3}\right)$ do controlador em questão que garante estabilidade do sistema em malha fechada utilizando-se o teorema proposto por Keel e Bhattacharyya (2005). Dessa forma, a partir de uma metodologia de controle baseada em medições de resposta em frequência, tem-se que se tomando qualquer ponto (conjunto de ganhos) dentro de tal volume garante-se que o sistema em malha fechada será estável.

Entretanto, tratando-se de um sistema rotativo sujeito a diferentes velocidades de rotação, seriam obtidos diversos volumes de estabilização para cada velocidade, o que tornaria a análise de estabilidade para um sistema operando em condições distintas pouco prática. Além disso, pelo fato do controlador da Equação (1.1), assim como um controlador PID, ser de três termos, a investigação dos ganhos dentro do volume que permitem o sistema realimentado apresentar determinado desempenho desejado torna-se por demais complexa. Deste modo, por simplicidade, propõe-se a implementação de um controlador de dois termos do tipo proporcional-derivativo, cuja configuração é dada pela Equação (1.2).

$$
C(j \omega)=K_{P}+K_{D} j \omega
$$

Para o controlador PD, através da técnica apresentada por Li et al. (2008) é possível calcular seus ganhos estáveis a partir da FRF do sistema e, uma vez que este tipo de controlador possui dois termos, são obtidas regiões planas de estabilização em vez de volumes, simplificando a análise de estabilidade de um sistema sujeito a diferentes condições de operação, bem como a determinação dos ganhos ótimos em termos de desempenho, quando comparado ao controlador da Equação (1.1) ou a um controlador PID. 
Desta forma, a motivação deste trabalho é ter-se um estudo preliminar de conceitos que podem ser utilizados para o desenvolvimento de mancais ativos inteligentes: (i) validação de uma técnica de controle do tipo PD que não requer a modelagem do sistema aplicada a sistemas rotativos e a investigação de como se obter os ganhos apropriados a fim de se assegurar estabilidade e atenuação de vibrações e (ii) desenvolvimento e implementação de um algoritmo de autoidentificação capaz de determinar, de forma automática, as funções de resposta em freqüência do sistema e, a partir das mesmas, determinar os ganhos ótimos do controlador proporcional-derivativo para cada velocidade de rotação do eixo, fechando a malha de controle e garantindo estabilidade e o controle autônomo de vibrações em sistemas rotativos.

\subsection{Objetivos}

O presente trabalho propõe a utilização de uma técnica de controle PD que não requer o uso do modelo matemático do sistema a ser controlado para o projeto dos ganhos do controlador. Isto requer a validação desta técnica para sistemas rotativos e a investigação dos ganhos estáveis que otimizem o comportamento do sistema em malha fechada do ponto de vista de controle de vibrações, para que, por fim, um algoritmo de autoidentificação do sistema e cálculo dos ganhos do controlador possa ser desenvolvido e implementado. Como objetivos específicos, mencionam-se:

- investigar, a partir da região de ganhos estáveis do controlador proporcionalderivativo, como se determinar os valores dos ganhos $\left(K_{D}, K_{P}\right)$ que resultam em redução do nível de vibrações;

- identificar as FRFs do sistema rotativo a ser testado utilizando atuadores eletromagnéticos de um mancal magnético ativo e sensores de proximidade;

- implementar experimentalmente o controle em uma bancada de testes e o algoritmo de autoidentificação, de forma a se obter, automaticamente, as FRFs do sistema, bem como o cálculo dos ganhos ótimos do controlador PD.

\subsection{Organização da dissertação}

Após este capítulo introdutório, é apresentada uma revisão bibliográfica dos temas pertinentes a este projeto, sendo levantadas informações a respeito do estado da arte de mancais ativos, identificação de sistemas rotativos a partir de mancais magnéticos, projeto de sis- 
temas de controle baseados em medições de resposta em freqüência do sistema e controle autônomo (Capítulo 2). No Capítulo 3, o teorema para o cálculo das regiões de ganhos estáveis (regiões de estabilização) para o controlador PD é apresentado e é proposta uma metodologia para se determinar os ganhos ótimos do ponto de vista de controle de vibrações. As FRFs experimentais de uma bancada de testes utilizada neste trabalho são então obtidas por meio de excitação utilizando atuadores eletromagnéticos (Capítulo 4) e, assim, no Capítulo 5, são calculadas as regiões de estabilização do sistema para diferentes velocidades de rotação do eixo, os ganhos mais apropriados do ponto de vista de atenuação de vibrações são determinados, e a estratégia de controle é implantada. Em seguida, apresenta-se o desenvolvimento do algoritmo de autoidentificação (Capítulo 6), o qual, de forma automática, excita o sistema, de forma a obter sua resposta em frequência, sendo os ganhos ótimos do controlador determinados e implementados, permitindo o controle autônomo de vibrações. Por fim, apresentam-se as conclusões obtidas, bem como as limitações e perspectivas da técnica de controle estudada aplicada a sistemas rotativos e do algoritmo desenvolvido (Capítulo 7). 


\section{Capítulo 2}

\section{Revisão de literatura}

Neste capítulo, apresenta-se uma revisão bibliográfica dos principais temas relacionados a este trabalho: mancais ativos, identificação de sistemas rotativos utilizando-se mancais magnéticos ativos, projeto de sistemas de controle a partir de medições de resposta em frequência e o conceito de controle autônomo visando o desenvolvimento de sistemas inteligentes.

\subsection{Mancais ativos}

Máquinas rotativas, como turbogeradores, compressores, turbinas e bombas, são elementos vitais em produção e em outros processos da sociedade moderna. Dessa forma, estas máquinas devem apresentar não apenas alto desempenho, mas também grande disponibilidade, de forma a não comprometer o fluxo de produção (Nicoletti e Santos, 2008), sendo que os mancais das máquinas rotativas, como componentes que são destes equipamentos, formam um rico universo tanto para o estudo, como para o projeto de máquinas mais eficientes (Nicoletti, 2003).

Deste modo, a fim de se aumentar a eficiência destas máquinas, faz-se necessário diminuir o nível de vibrações laterais do rotor - definidas como sendo o movimento orbital da linha de centro do eixo no plano radial (Adams, 2001) e que resultam em baixo desempenho, perdas de energia, fadiga e até mesmo falha da máquina (Beards, 1996). Elas são causadas principalmente devido às condições de operação (vibrações forçadas) e ao desbalanço e desalinhamento do rotor. 
Embora seja inviável eliminar totalmente tais vibrações, é essencial que elas sejam controladas dentro de limites aceitáveis visando à operação de forma segura e confiável das máquinas rotativas (Silva, 2007). Neste contexto, devido aos elementos de atuação a eles incorporados, os mancais ativos são uma solução eficaz a fim de se modificarem as características dinâmicas destas máquinas, de forma a se satisfazerem requisitos desejados: estabilidade, alto desempenho, maior disponibilidade, redução do consumo energético e ciclo de vida mais longo.

Como exemplos destes tipos de mancais, citam-se os mancais magnéticos ativos (MMAs), os quais empregam eletroímãs para sustentação e controle do rotor; os hidrodinâmicos, em que um fino filme de óleo é responsável por suportar o eixo (lubrificação hidrodinâmica) e a variação da injeção radial do fluido permite o controle de vibrações; e os mancais acoplados a atuadores piezoelétricos e hidráulicos. Ulbrich (1998) define que, em geral, existem duas formas de se aplicar forças de controle em sistemas rotativos: através da ação direta sobre o rotor, que é o caso dos mancais magnéticos ativos e os hidrodinâmicos, e por meio de ação indireta, atuando-se na carcaça dos mancais (mancais acoplados a atuadores piezoelétricos e hidráulicos).

Os MMAs consistem em uma nova geração de mancais cuja aplicação tem crescido nos últimos anos. Seu princípio de funcionamento baseia-se na levitação do rotor (o qual deve ser de material ferro-magnético) através de atuadores eletromagnéticos, responsáveis também por controlar ativamente vibrações. Para isto, mede-se o deslocamento do eixo por meio de um sensor de posição, cujos sinais são enviados a um controlador e amplificados, de forma a realimentar o sistema, fechando a malha de controle (Figura 2.1).

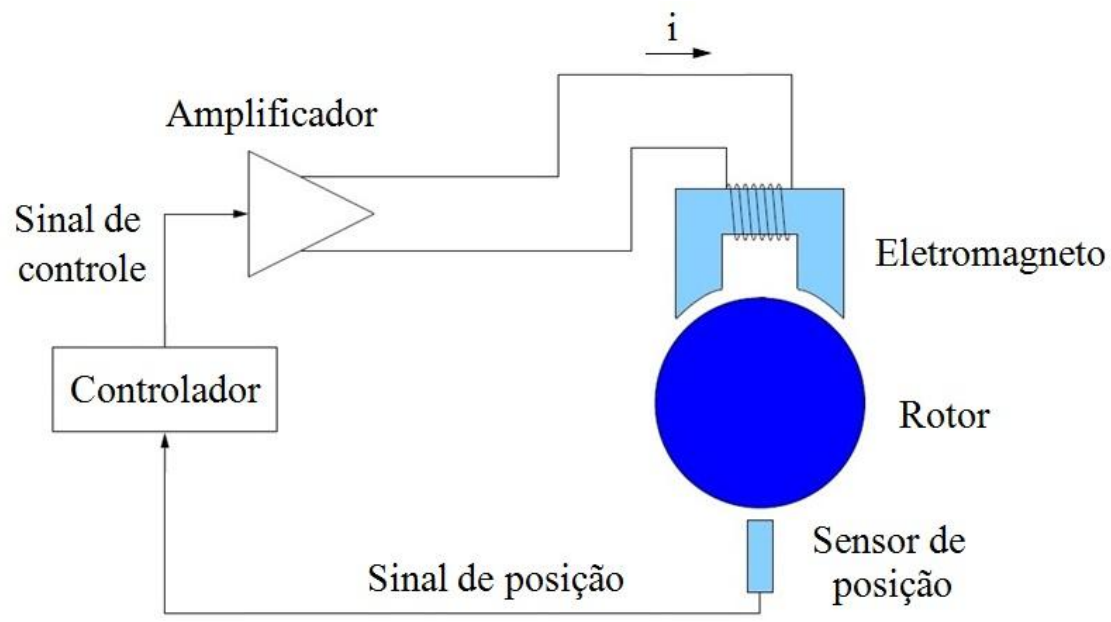

Figura 2.1: Princípio de funcionamento dos MMAs (Schweitzer e Maslen, 2009). 
Embora a Figura 2.1 ilustre apenas um atuador, neste tipo de mancal os eletromagnetos são dispostos em pares, permitindo-se atrair o rotor em sentidos opostos em uma mesma direção, sendo o uso de 4 polos uma configuração bastante utilizada, de forma a controlar-se o rotor em duas direções ortogonais, em ambos os sentidos (Burdet, 2006) - Figura 2.2.

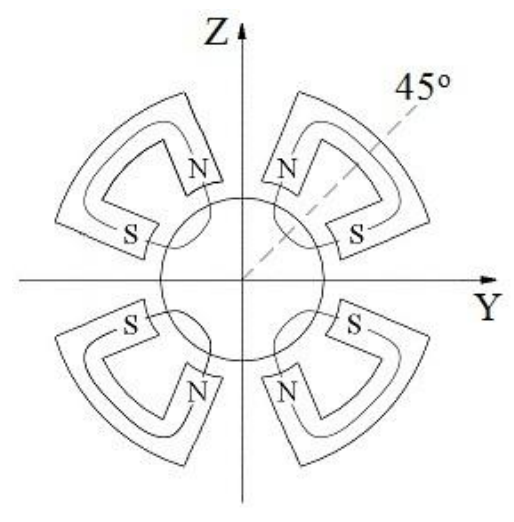

Figura 2.2: Configuração dos eletromagnetos de um MMA de 4 polos.

Em relação aos mancais convencionais, os MMAs apresentam vantagens como ausência de contato e, por conseguinte, de desgaste mecânico, possibilitando funcionamento em altas velocidades de rotação, e operação em uma ampla faixa de temperaturas (Duan et al., 2001). Além disso, por não haver atrito, estes mancais apresentam uma vida útil elevada e não requerem lubrificação, havendo apenas ar na interface entre o rotor e o mancal, sendo considerados limpos (Ulbrich, 1993). De acordo com Schweitzer e Maslen (2009), tendo-se em vista as características específicas dos mancais magnéticos e suas vantagens, citam-se como exemplos de sua aplicação:

- máquinas-ferramentas: permitem alta velocidade de rotação, o que é um requisito essencial para a retificação de precisão de pequenas peças;

- dispositivos médicos: por serem mancais limpos, são especialmente úteis na área médica. Um exemplo de aplicação é a sua utilização em uma bomba cardíaca artificial;

- turbomáquinas (bombas, geradores, compressores): principal área de aplicação dos MMAs. Permitem alterar as características dinâmicas destes sistemas, aumentando seu amortecimento e a faixa de velocidades em que podem operar. Além disso, tais mancais podem ser utilizados como elementos de diagnose da máquina (identificação de trincas e rachaduras no eixo, por exemplo) e contribuem para a redução dos custos com manutenção e consumo energético. 
Entretanto, apesar das vantagens citadas, este tipo de mancal não é apropriado para sistemas rotativos de grande porte, uma vez que a força requerida para a levitação do eixo é elevada, tornando o sistema magnético caro e pouco compacto. Outro fator a ser considerado é que o uso de mancais magnéticos ativos isoladamente não é recomendado, uma vez que uma eventual sobrecarga e/ou falha do sistema de atuação poderia comprometer o funcionamento e a integridade da máquina, fazendo-se necessária a utilização de sistemas de proteção, como mancais auxiliares (Kasarda, 2000).

Neste contexto, destaca-se o conceito de mancal híbrido proposto por Nicoletti (2006): um mancal hidrodinâmico segmentado em conjunto com sapatas móveis magnéticas, em que um fino filme de óleo formado entre o eixo e as sapatas é responsável por sustentar o eixo, e atuadores eletromagnéticos pelo controle das vibrações laterais (Figuras 2.3 e 2.4). Assim, tem-se um mancal híbrido em que as limitações do mancal magnético são atenuadas e suas vantagens são incorporadas às do mancal hidrodinâmico em uma única montagem (Tabela 2.1), o que se acredita poder permitir melhor desempenho e aumento da faixa de freqüências de operação das máquinas rotativas, incrementando sua disponibilidade (Viveros et al., 2011).
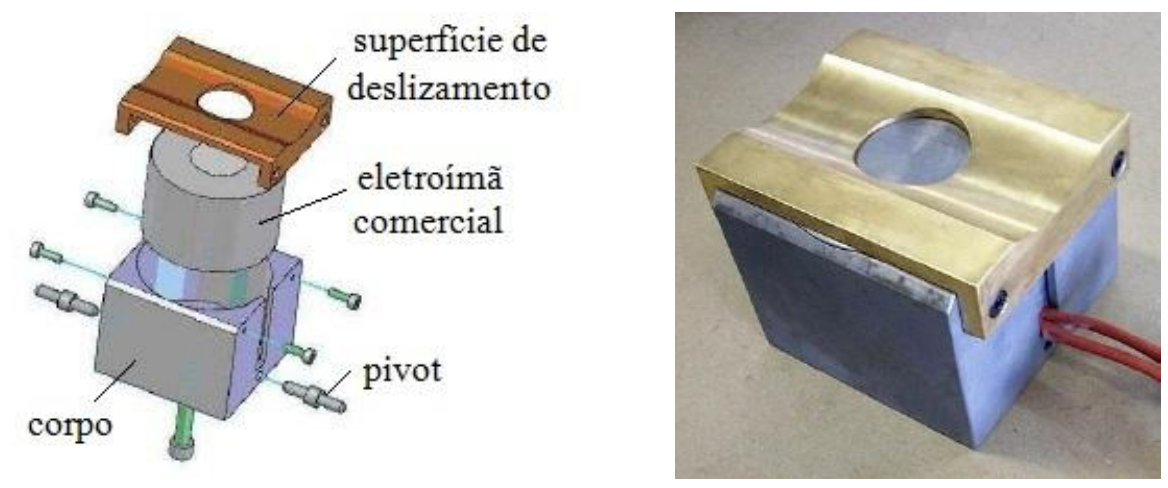

Figura 2.3: Montagem da sapata móvel magnética.
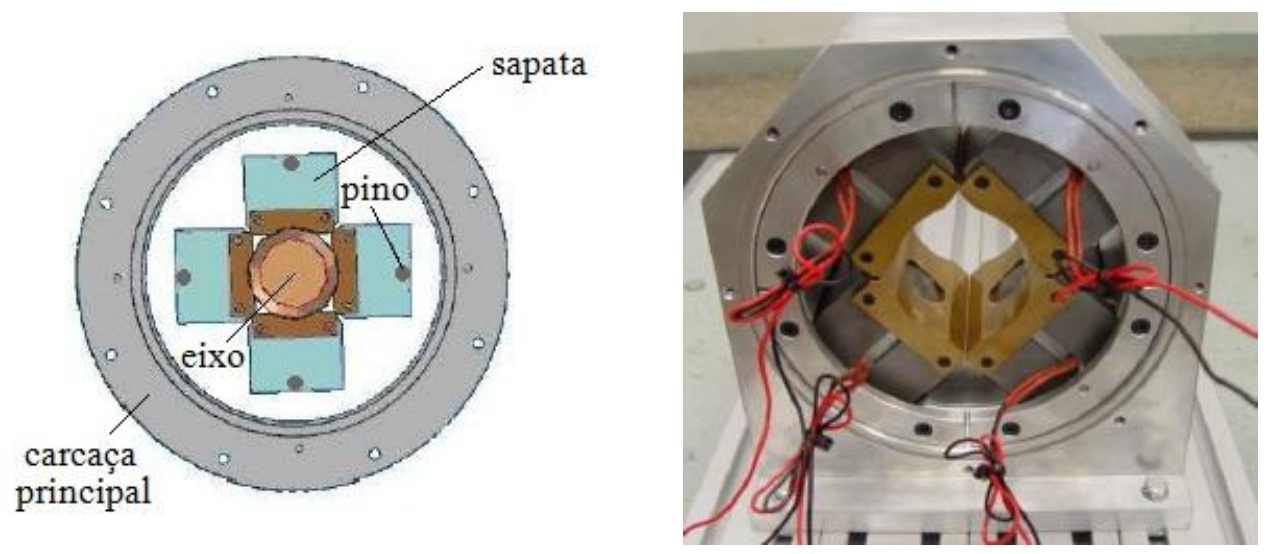

Figura 2.4: Mancal hidrodinâmico segmentado com sapatas móveis magnéticas. 
Tabela 2.1: Vantagens e desvantagens do uso de mancais hidrodinâmicos segmentados e mancais magnéticos.

\begin{tabular}{|c|c|c|}
\hline Mancal & Vantagens & Desvantagens \\
\hline $\begin{array}{c}\text { Mancal } \\
\text { hidrodinâmico } \\
\text { segmentado }\end{array}$ & $\begin{array}{l}\text { - } \\
\text { - Desacoplamento entre direções } \\
\text { ortogonais } \\
\text { - Facilidade de montagem }\end{array}$ & $\begin{array}{l}\text { - Sistema periférico volumoso } \\
\text { (suprimento de óleo) } \\
\text { - Baixa limpeza } \\
\text { - Possível instabilidade dinâmica }\end{array}$ \\
\hline $\begin{array}{c}\text { Mancal } \\
\text { magnético }\end{array}$ & $\begin{array}{l}\text { - Facilidade de alteração das } \\
\text { características dinâmicas } \\
\text { - Contato nulo com o rotor } \\
\text { - Alta limpeza } \\
\text { - Ampla faixa de operação (altas } \\
\text { freqüências de rotação) }\end{array}$ & $\begin{array}{l}\text { - } \text { Baixa capacidade de carga } \\
\text { - Complexidade construtiva } \\
\text { proporcional ao tamanho } \\
\text { - Necessidade de sistema de } \\
\text { proteção em caso de falha ou } \\
\text { excesso de carga }\end{array}$ \\
\hline
\end{tabular}

Em relação aos MMAs convencionais, o mancal em questão requer atuadores eletromagnéticos menores, pois estes passam a ser responsáveis apenas pelo controle ativo de vibrações, ficando a sustentação do eixo a cargo do princípio hidrodinâmico (fenômeno que ocorre quando há um fluido viscoso entre dois corpos com movimento relativo entre si, gerando uma distribuição de pressões), em que um sistema hidráulico de suprimento é responsável pelo bombeamento de óleo para o interior do mancal e retorno para o reservatório. Deste modo, tem-se uma montagem mais compacta e um sistema de proteção não se faz necessário.

\subsection{Identificação de sistemas rotativos}

Devido ao fato dos mancais ativos apresentarem um sistema de atuação e sensoriamento para o controle ativo de vibrações, eles têm sido utilizados também na identificação dos parâmetros modais de sistemas rotativos (tanto para o rotor parado como em movimento). O princípio básico da identificação consiste na excitação do sistema em consideração a partir de forças conhecidas (entrada) e a medição da resposta (saída) e, a partir das relações medidas de entrada/saída, é possível conhecerem-se as propriedades do sistema (Ewins, 1995; Maia e Silva, 1997). No caso de atuadores eletromagnéticos, os fatores relacionados à sua capacidade de excitar um sistema são a corrente elétrica, entreferro, superfície do polo do atuador e também frequência de excitação, cujas influências são estudadas por Furtado (2008).

Destaca-se que a identificação de sistemas utilizando o próprio mancal ativo como fonte de excitação pode ser feita on-line, i.e., durante a operação normal da máquina rotativa. Com a informação adquirida a partir desta identificação, modelos obtidos através da teoria de 
dinâmica de rotores podem ser checados, validando hipóteses simplificadoras adotadas (Schweitzer e Maslen, 2009). Como exemplos da utilização de um mancal magnético ativo para determinação dos parâmetros de sistemas rotativos citam-se Aenis et al. (2002), que utilizam os atuadores eletromagnéticos do mancal de uma bomba centrífuga como excitadores da mesma em operação, e Zutavern e Childs (2008), que, de forma semelhante, identificam os parâmetros de rigidez e amortecimento de um selo anular a gás.

Além dos exemplos citados, a identificação de sistemas rotativos utilizando mancais ativos pode ser útil na diagnose de falhas. Mani et al. (2006) definem o termo monitoramento da saúde estrutural como o processo de implantação de uma estratégia de detecção de danos. Em seu trabalho, a rigidez de um eixo trincado é monitorada ao longo do tempo e utilizada como parâmetro do estado de dano do sistema.

No presente trabalho, a identificação do sistema rotativo estudado será feita de forma automática (autoidentificação ${ }^{1}$ ) e a força não será medida, sendo o sinal enviado ao atuador considerado como sendo a entrada aplicada ao sistema, sendo levada em consideração, assim, a dinâmica dos atuadores na identificação do sistema como um todo. Desta forma, a partir da identificação das FRFs do sistema, uma técnica de projeto de sistemas de controle a partir de medições de resposta em frequência será empregada, permitindo, automaticamente, o cálculo dos ganhos do controlador.

\subsection{Projeto de sistemas de controle}

Em relação à estratégia de controle adotada nos mancais ativos, diversas técnicas são encontradas na literatura, entre elas as que se baseiam na teoria clássica de controle (controle PD e PID) e as que se baseiam em uma abordagem de espaço de estados (teoria de controle moderno), como controle ótimo e robusto. Uma abordagem teórica ampla de projeto de sistemas de controle aplicados a sistemas rotativos pode ser encontrada em Schweitzer e Maslen (2009) e como exemplos de trabalhos experimentais em que controladores são utilizados para controle de vibrações em sistemas rotativos citam-se Nicoletti e Santos (2008), Simões et al. (2007) e Horst e Wolfel (2004). Nestes trabalhos, verifica-se que inicialmente o

\footnotetext{
${ }^{1} \mathrm{O}$ conceito de identificação em questão difere do de self-sensing, amplamente estudado na literatura (Noh e Maslen, 1997; Li et al., 2004; Schammass et al., 2005). No caso de self-sensing, o sensor de proximidade é eliminado, sendo a posição do eixo estimada a partir de informações de tensão e corrente nos enrolamentos do atuador.
} 
modelo matemático do sistema rotativo é obtido, para que, então, o controlador possa ser projetado.

Entretanto, uma vez que o sucesso do controle ativo de vibrações em sistemas rotativos depende fundamentalmente da qualidade do modelo do sistema (incluindo os atuadores e sensores) e da posição dos atuadores e sensores (Ulbrich, 1998), tem-se que todas as estratégias tradicionais de controle são dependentes de modelos precisos para serem efetivas, tornando a modelagem matemática do sistema um dos desafios no controle ativo de vibrações em máquinas rotativas.

Uma vez que modelos imprecisos prejudicam a efetividade da estratégia de controle (especialmente em se tratando de sistemas que utilizam atuadores eletromagnéticos, cujos modelos matemáticos frequentemente não permitem uma descrição realística de sua dinâmica) e, além disso, podem ser de difícil obtenção, surge a motivação para buscarem-se técnicas de controle livre de modelos matemáticos (Buttini e Nicoletti, 2011).

O desenvolvimento destas técnicas é relativamente recente, tendo atraído a atenção de muitos pesquisadores nos últimos anos (Keel e Bhattacharyya, 2005; Keel e Bhattacharyya, 2008; Li et al., 2008; Emami e Watkins, 2009; Jinggong et al., 2010; Yang et al., 2011) e não se encontram na literatura exemplos de sua aplicação a sistemas rotativos, sendo que, tradicionalmente, em casos em que não se emprega o modelo de dado sistema rotativo no projeto do controlador, a estratégia adotada é a da tentativa e erro, que raramente conduz a um desempenho ótimo, e não garante a estabilidade do sistema para diferentes velocidades de rotação.

Um trabalho pioneiro no projeto de controladores sem o uso de modelos matemáticos é o apresentado por Keel e Bhattacharyya (2005), em que, para um controlador da forma da Equação (1.1), o qual se pode comportar como um compensador de avanço/atraso de fase, é possível encontrarem-se regiões no espaço de ganhos do controlador $\left(x_{1}, x_{2}, x_{3}\right)$ que garantem a estabilidade do sistema em malha fechada (regiões de estabilização) a partir de medições de resposta em frequência - Buttini e Nicoletti (2009).

Em Keel e Bhattacharyya (2008), a teoria para projeto de controladores a partir da FRF do sistema é desenvolvida para os controladores do tipo proporcional-integral-derivativo. No caso, os autores definem uma sequência de passos que permitem a obtenção das regiões de 
estabilização baseada em uma estratégia de controle livre de modelos matemáticos, os quais são formalmente representados através de equações escritas em termos da resposta em frequência por Li et al. (2008), sendo apresentada por Emami e Watkins (2009) uma metodologia que permite determinar, a partir das regiões de estabilização para o controlador PID, os ganhos que otimizam uma norma de desempenho robusto, garantido estabilidade e robustez do sistema em malha fechada.

No caso, os trabalhos citados para projeto de controladores a partir de medições de FRF do sistema são baseados em uma técnica denominada Decomposição-d (apresentada em detalhes no Capítulo 3) e são poucas as referências que a utilizam para a obtenção de regiões de estabilização em termos da resposta em frequência do sistema. Por outro lado, esta técnica é largamente utilizada por muitos trabalhos recentes para a obtenção dessas regiões com base no modelo matemático da planta para controladores lineares e controle $H_{\infty}$, como em Fujisaki et al. (2004), Saeki (2007) e Gryazina et al. (2008).

\subsection{Controle autônomo}

Devido ao efeito giroscópico, as características dinâmicas dos sistemas rotativos variam de acordo com a velocidade de rotação do eixo. Assim, melhor desempenho pode ser atingido se os ganhos do controlador utilizado para o controle de vibrações forem ajustados de acordo com a velocidade de rotação (Lallart, 2010). Neste sentido, a utilização de um sistema de controle autônomo aplicado ao controle de vibrações em máquinas rotativas é uma forma de assegurar que o desempenho da máquina será sempre otimizado, independentemente da frequência em que o rotor está girando, pois os ganhos do controlador são reajustados de forma automática de acordo com as condições de operação.

O conceito de controle autônomo pode ser definido como sendo um sistema de controle inteligente capaz de emular inteligência humana através de adaptação e/ou aprendizagem, assegurando, automaticamente, que uma planta sujeita a perturbações e/ou a alterações de suas características apresente determinado comportamento (Antsaklis, 1997; Rehtanz, 2003). Enquadram-se neste conceito técnicas de controle adaptativo, redes neurais, controle fuzzy e autotuning; sendo o controle adaptativo e o autotuning as estratégias mais simples de controle autônomo, cuja idéia consiste em ter-se um controlador cujos ganhos não são fixos, sendo capazes de se ajustarem automaticamente. 
A estratégia de controle adaptativo baseia-se em um mecanismo de adaptação responsável pela variação dos ganhos do controlador de acordo com as alterações de alguma saída monitorada (Tao, 2003). Assim, um sistema de controle adaptativo possui duas malhas de realimentação: uma delas corresponde à realimentação convencional com o processo e o controlador, e a outra a uma realimentação responsável pelo ajuste dos parâmetros do controlador (Astrom e Wittenmark, 2008) - Figura 2.5.

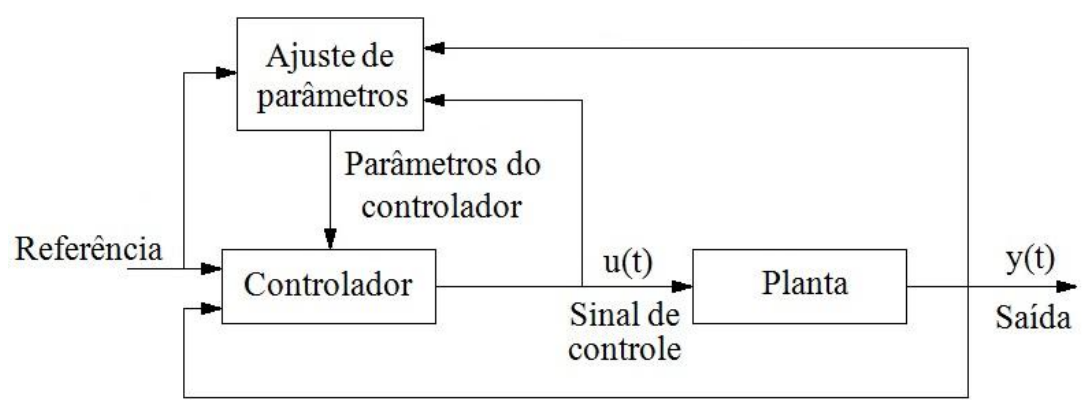

Figura 2.5: Exemplo de malha de controle adaptativo (Astrom e Wittenmark, 2008).

Já a estratégia de autotuning é frequentemente empregada no campo de controle de processos industriais em aplicações como controle de temperatura de fluidos armazenados em reservatórios e controle do nível de água em tanques (Yu, 2006; Sung et al., 2009). Com base em parâmetros do processo medidos experimentalmente, como ganho de regime estático, tempo morto e constante de tempo, um algoritmo é empregado para determinar automaticamente os ganhos de um controlador PID.

Destaca-se que as estratégias de controle autônomo mais elementares baseiam-se em modelos matemáticos ajustados (controle adaptativo), os quais podem não ser precisos, ou em regras de sintonia que não asseguram a determinação dos ganhos ótimos de um controlador (autotuning a partir de regras empíricas de sintonia). Assim, visando o controle autônomo de vibrações em sistemas rotativos, o projeto do sistema de controle a partir de medições de resposta em frequência insere-se como uma alternativa simples e eficaz capaz de contornar a imprecisão de modelos e permitir o cálculo dos ganhos ótimos de um controlador, a partir da identificação automática do sistema rotativo por meio de um algoritmo de autoidentificação, conforme proposto por este trabalho.

Schweitzer (1998) define o conceito de máquina inteligente como sendo uma máquina capaz de reconhecer sua condição de operação e otimizá-la através de um processamento interno de informações de forma autônoma. Assim, acredita-se que a integração das idéias apre- 
sentadas e os resultados obtidos neste trabalho podem viabilizar o aperfeiçoamento do mancal hidrodinâmico segmentado com sapatas móveis magnéticas de forma a torná-lo um componente inteligente de uma máquina rotativa, em que um mancal híbrido combinando as vantagens de MMAs e mancais hidrodinâmicos em uma mesma montagem seria responsável por assegurar estabilidade de máquinas que são ou podem vir a ser instáveis e aprimorar seu desempenho automaticamente. 


\section{Capítulo 3}

\section{Projeto de controladores PD}

Schweitzer e Maslen (2009) citam as técnicas de controle passivo, $H_{\infty}$ e PID como sendo as mais importantes a fim de se controlar vibrações em máquinas rotativas. A estratégia de controle passivo baseia-se na mudança de características físicas da máquina (como a modificação dos suportes dos mancais, aumentando ou reduzindo sua rigidez), de modo a melhorar seu desempenho, que é ótimo apenas para uma condição específica de operação. Desta forma, caso as condições de operação sejam alteradas, esta estratégia, ao contrário do controle $H_{\infty}$ e PID, não permite que a atenuação de vibrações seja realmente efetiva - o que não ocorre no caso destas últimas, uma vez que os ganhos do controlador podem ser facilmente reajustados.

Considerando-se que os controladores PID e suas variações são os mais utilizados em aplicações industriais (Yu, 2006; Sung et al., 2009) e também a simplicidade de sua implementação, optou-se pela utilização de um controle PD neste trabalho, sendo o ganho proporcional responsável por alterar a rigidez do sistema em malha fechada, e o derivativo por aumentar o amortecimento; de modo que o controlador proporcional-derivativo seja capaz de satisfazer o objetivo de atenuar vibrações e, por ser de dois termos, sua estrutura é mais simples que o PID.

Neste capítulo, apresenta-se a estratégia de controle proposta para o controle ativo de vibrações em rotores, a qual permite a obtenção de regiões de ganhos estáveis (regiões de estabilização) no plano $\left(K_{D}, K_{P}\right)$ para um controlador do tipo proporcional-derivativo a partir das FRFs do sistema rotativo, de modo que seja possível conhecerem-se todos os ganhos do controlador que estabilizam o sistema em malha fechada. Através de uma metodologia que 
não requer o modelo matemático do sistema, a técnica de controle apresentada tem por objetivos:

- assegurar a estabilidade de dado sistema rotativo para uma faixa de velocidades de rotação do eixo, o qual pode ser ou vir a se tornar instável;

- a partir dos valores dos ganhos que garantem a estabilidade do sistema em malha fechada, determinar aqueles que otimizem o desempenho do rotor do ponto de vista de atenuação de vibrações.

Inicialmente, expõem-se os conceitos básicos de uma técnica denominada Decomposição-d (D-decomposition), que é a base para o entendimento e formulação da teoria para cálculo das regiões de estabilização a partir de medições de resposta em frequência. Em seguida, o teorema para o cálculo de tais regiões - proposto originalmente por Li et al. (2008) - é apresentado. Finalmente, é proposta uma metodologia para a seleção dos ganhos mais apropriados em termos de atenuação de vibrações considerando a redução da amplitude do pico de ressonância como critério de desempenho.

\subsection{A Decomposição-d}

A idéia básica da técnica denominada Decomposição-d consiste em dividir o domínio formado pelos parâmetros do controlador em regiões com um número fixo de polos estáveis e instáveis em malha fechada (Gryazina e Polyak, 2006). Esta divisão é obtida calculando-se fronteiras que mapeiam a condição de estabilidade no plano complexo (eixo imaginário) em termos dos ganhos do controlador. Desta forma, uma vez que cada região delimitada por estas fronteiras corresponde a uma região com um número fixo de polos, se um conjunto de ganhos dentro de uma delas torna o sistema estável (ou seja, não possui nenhum polo instável), então todos os ganhos dentro desta mesma região também o farão.

As primeiras idéias sobre a Decomposição-d são atribuídas a Vishnegradsky (1876), que representou graficamente a condição de estabilidade no plano complexo de um sistema cuja equação característica em malha fechada no domínio da frequência é dada pela Equação (3.1) em termos dos parâmetros $K_{1}$ e $K_{2}$ do controlador utilizado (Figura 3.1).

$$
\pi\left(j \omega, K_{1}, K_{2}\right)=-j \omega^{3}-K_{1} \omega^{2}+K_{2} j \omega+1
$$




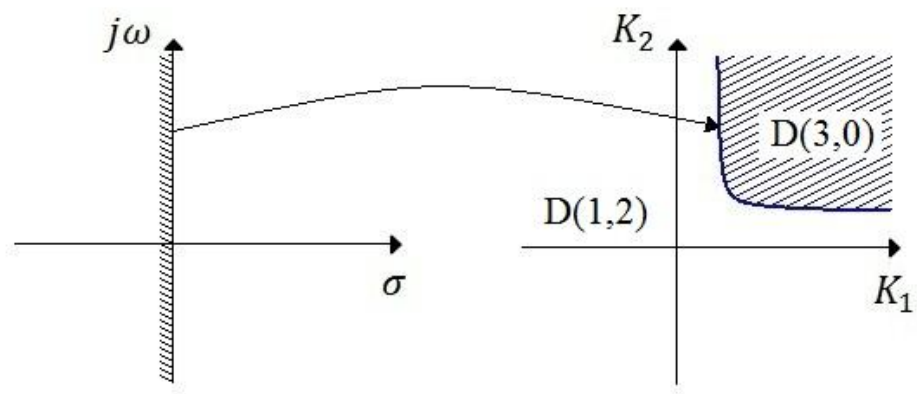

Figura 3.1: Regiões cujos números de polos em malha fechada é invariável para o sistema da Equação (3.1) (a área hachurada corresponde à região de estabilização).

De acordo com Gryazina e Polyak (2006), as mesmas idéias foram exploradas por Frazer e Duncan (1929) e Sokolov (1946), mas foi Neimark (1948) quem desenvolveu rigorosamente o algoritmo e cunhou o nome Decomposição-d. Embora seu desenvolvimento não seja recente, ela tem despertado o interesse de vários pesquisadores nos últimos anos, uma vez que sua formulação é a base para o desenvolvimento de técnicas de controle que permitem a obtenção de regiões de estabilização no espaço de ganhos do controlador, tanto para sistemas cujo modelo matemático é conhecido, como nos casos em que a modelagem não é requerida (sendo utilizadas medições de resposta em frequência para o projeto do controlador) - Keel e Bhattacharyya, 2005; Saeki, 2007; Li et al., 2008; Jinggong et al., 2010; Buttini et al., 2011.

A técnica consiste em três condições que permitem decompor o espaço formado pelos ganhos do controlador em regiões com um número fixo de polos estáveis e instáveis. Assim, considere $\pi(j \omega, \lambda)$ como sendo o polinômio característico, escrito no domínio da freqüência, de um sistema linear e invariante no tempo de grau $n$, com coeficientes reais $a_{k}(\lambda)$, em que $\lambda \in \mathfrak{R}^{m}$ é o parâmetro do controlador, $j$ é a unidade imaginária e $\omega \in[0,+\infty)$

$$
\pi(j \omega, \lambda)=a_{n}(\lambda) \times(j \omega)^{n}+a_{n-1}(\lambda) \times(j \omega)^{n-1}+\ldots+a_{0}(\lambda)
$$

Tem-se que o espaço formado pelos ganhos do controlador pode ser dividido em regiões denotadas por $D(m, n-m)$, as quais correspondem ao polinômio dado pela Equação (3.2) com $m$ raízes com parte real negativa (polos estáveis) e $n-m$ com parte real positiva (polos instáveis). Esta decomposição no espaço de parâmetros do controlador nestas regiões $D(m, n-m)$ é denominada Decomposição-d. As fronteiras de cada região são definidas por 


$$
\begin{gathered}
\pi(\omega=0, \lambda)=0 \\
\pi(j \omega, \lambda)=0 \\
a_{n}(\lambda)=0
\end{gathered}
$$

As Equações (3.3) a (3.5) são conhecidas, respectivamente, como fronteira da raiz real (real root boundary - RRB), fronteira da raiz complexa (complex root boundary - CRB) e fronteira da raiz infinita (infinity root boundary - IRB). Tomando-se um ponto (conjunto de ganhos) sobre a fronteira da raiz real, ter-se-á que o sistema em malha fechada apresentará um polo na origem. Para um ponto sobre a fronteira da raiz complexa, o sistema apresentará um par de polos complexos sobre o eixo imaginário. Por fim, para um ponto sobre a fronteira da raiz infinita, o sistema apresentará uma redução do seu grau, $n$, o que também implica em mudança no número de polos.

Enfatiza-se que a Decomposição-d é válida somente para sistemas lineares e invariantes no tempo e que, quando suas três condições são aplicadas (Equações (3.3) a (3.5)), não há garantia da existência de uma região $D(n, 0)$, i.e., uma região de estabilização - este conjunto pode ser vazio e todas as regiões obtidas podem resultar em instabilidade (Siljak, 1969).

\subsection{Teorema para cálculo das regiões de estabilização}

Considere o sistema de controle mostrado na Figura 3.2, em que o controlador, $C(j \omega)$, é do tipo PD, e a planta, $P(j \omega)$, é linear e invariante no tempo. Eles são definidos, respectivamente, pelas Equações (3.6) e (3.7) (a planta é descrita em termos de suas partes real e imaginária).

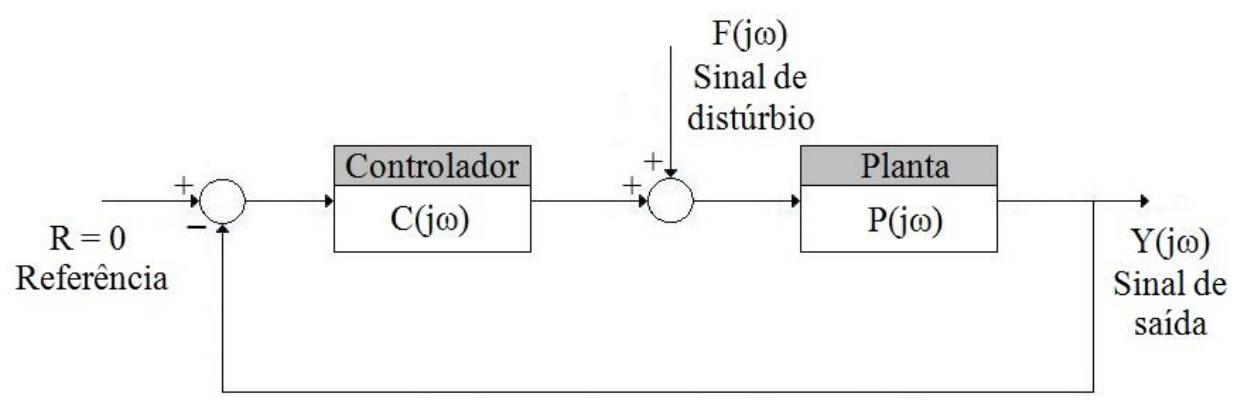

Figura 3.2: Configuração do sistema de controle realimentado.

$$
\begin{gathered}
C(j \omega)=K_{P}+K_{D} j \omega \\
P(j \omega)=P_{r}(\omega)+P_{i}(\omega) j
\end{gathered}
$$


A função de transferência em malha fechada para o sistema da Figura 3.2 é dada por

$$
\frac{Y}{F}(j \omega)=G(j \omega)=\frac{P(j \omega)}{1+C(j \omega) P(j \omega)}=\frac{P_{r}(\omega)+P_{i}(\omega) j}{1+\left(K_{P}+K_{D} j \omega\right)\left(P_{r}(\omega)+P_{i}(\omega) j\right)}
$$

Pela Equação (3.8), tem-se que o polinômio característico é

$$
\pi(j \omega)=1+\left(K_{P}+K_{D} j \omega\right)\left(P_{r}(\omega)+P_{i}(\omega) j\right)=\pi_{r}(\omega)+\pi_{i}(\omega) j
$$

em que

$$
\begin{gathered}
\pi_{r}(\omega)=1+K_{P} P_{r}(\omega)-K_{D} P_{i}(\omega) \omega \\
\pi_{i}(\omega)=K_{P} P_{i}(\omega)+K_{D} P_{r}(\omega) \omega
\end{gathered}
$$

Assim, a partir da FRF da planta (Equação (3.7)), a qual pode ser obtida experimentalmente, podem-se determinar, sem se conhecer o modelo matemático do sistema, as regiões em que o número de raízes do sistema em malha fechada é invariável no plano de ganhos do controlador $\left(K_{D}, K_{P}\right)$ utilizando-se o Teorema 3.1 .

Teorema 3.1 (Cálculo das regiões com número invariável de polos - Li et al., 2008)

Dada a resposta no domínio da frequiência de uma planta linear e invariante no tempo, $P(j \omega)$, pode-se determinar duas linhas retas e uma curva, tais que estas são fronteiras que decompõem o plano $\left(K_{D}, K_{P}\right)$ em regiões com um número fixo de polos estáveis e instáveis para o sistema em malha fechada, dadas por

$$
\begin{gathered}
K_{P}=-\frac{1}{P(0)} \\
\left\{\begin{aligned}
K_{D}(\omega) & =\frac{P_{i}(\omega)}{\omega|P(j \omega)|^{2}} \\
K_{P}(\omega) & =-\frac{P_{r}(\omega)}{|P(j \omega)|^{2}} \\
K_{D} & =\frac{-1}{P(\infty)}
\end{aligned}\right.
\end{gathered}
$$

\section{Demonstração}

A partir das três condições da Decomposição-d, as regiões com número fixo de polos podem ser escritas em termos da FRF da planta como se segue: 
(A) Fronteira da raiz real (Equação (3.3))

$$
\pi\left(\omega=0, K_{P}\right)=1+K_{P} P(0)=0
$$

Considerando-se que o valor da resposta em freqüência para $\omega=0, P(0)$, é diferente de zero (caso contrário a condição não será aplicável)

$$
K_{P}=-\frac{1}{P(0)}
$$

(B) Fronteira da raiz complexa (Equação (3.4))

$$
\pi\left(j \omega, K_{P}, K_{D}\right)=0
$$

Igualando-se $\pi_{r}(\omega)$ e $\pi_{i}(\omega)$ (Equações (3.10) e (3.11)) a zero

$$
\begin{gathered}
1+K_{P} P_{r}(\omega)-K_{D} P_{i}(\omega) \omega=0 \\
K_{P} P_{i}(\omega)+K_{D} P_{r}(\omega) \omega=0
\end{gathered}
$$

Isolando-se $K_{P}$ na Equação (3.18)

$$
K_{P}=\frac{-1+K_{D} P_{i}(\omega) \omega}{P_{r}(\omega)}
$$

Então, substituindo-se $K_{P}$ na Equação (3.19), o ganho derivativo pode ser encontrado como função da FRF da planta

$$
K_{D}(\omega)=\frac{P_{i}(\omega)}{\omega|P(j \omega)|^{2}}
$$

Finalmente, substituindo-se a Equação (3.21) em (3.20), o ganho proporcional pode ser obtido

$$
K_{P}(\omega)=-\frac{P_{r}(\omega)}{|P(j \omega)|^{2}}
$$

(C) Fronteira da raiz infinita (Equação (3.5))

Denotando-se os coeficientes dos termos de maior ordem do denominador e numerador de $P(j \omega)$ como $d_{n}$ e $n_{n}$, respectivamente, e considerando-se que o grau do denominador 
é $n$ e o do numerador $n-1$, tem-se que o coeficiente dominante do polinômio característico do sistema em malha fechada, $a_{n}$, pode ser escrito como

$$
a_{n}\left(K_{D}\right)=d_{n}+K_{D} n_{n}=0
$$

Assim

$$
K_{D}=-\frac{d_{n}}{n_{n}}=-\frac{1}{P(\infty)}
$$

Em que $\lim _{\omega \rightarrow \infty} P(j \omega)=P(\infty)$ e $P(\infty) \neq 0$ (caso contrário, a condição não é aplicável). Para dados experimentais, o valor de $P(\infty)$ muitas vezes não é conhecido (medições de FRF são restritas a uma faixa de frequência limitada), de modo que esta condição não seja utilizada.

Assim, aplicando-se o Teorema 3.1, o plano formado pelos ganhos do controlador proporcional-derivativo pode ser dividido em regiões com um número fixo de polos estáveis, $m$, e instáveis, $n-m$, (regiões $D(m, n-m)$ ) e a única informação requerida é a FRF da planta. De modo a se determinar qual região corresponde a uma região $D(n, 0)$, i.e., que não resulta em nenhum polo instável em malha fechada, é necessário selecionar um ponto (conjunto de ganhos) dentro de cada uma das regiões obtidas e testar sua estabilidade, o que pode ser feito através do critério de estabilidade de Nyquist (neste caso, faz-se necessário conhecer o número de polos instáveis em malha aberta da planta considerada). Para sistemas intrinsecamente estáveis (nenhum polo em malha aberta com parte real positiva), como a maioria dos sistemas rotativos, basta verificar se o contorno de Nyquist envolve o ponto $(-1,0)$, de maneira que o sistema em malha fechada será estável se não houver nenhum envolvimento.

No presente trabalho, utiliza-se o controlador PD em sua forma clássica (Equação (3.6)), mas, frequentemente, a fim de se reduzir erros introduzidos pela ação derivativa (amplificação de ruídos), utiliza-se uma forma modificada do controlador proporcional-derivativo (Yu, 2006), como apresentado na Equação (3.25).

$$
C(j \omega)=\frac{K_{P}+K_{D} j \omega}{\alpha j \omega+1}
$$


Em que $0<\alpha<<1$, sendo que, tipicamente, $\alpha$ assume valores da ordem de grandeza de $10^{-3}$. Deste modo, ao se utilizar esta forma modificada do controlador PD, está se adicionando em malha aberta um polo real estável e distante da origem (Moudgalya, 2007). Ela é frequentemente utilizada em casos em que a ação derivativa pura é indesejável, pois a diferenciação de uma entrada ruidosa pode resultar em grandes erros (Fadali, 2009), de modo que o uso do controlador PD da Equação (3.25), diferentemente do da Equação (3.6), é capaz de minimizar os efeitos de amplificação de ruídos devido à ação derivativa.

Neste caso, o teorema para o cálculo das regiões com número invariável de polos pode ser facilmente deduzido considerando o controlador PD em sua forma modificada (Equação (3.25)). Sua formulação é dada pelo Teorema 3.2, cuja demonstração é omitida por ser análoga à do Teorema 3.1 .

Teorema 3.2 (Cálculo das regiões com número invariável de polos)

Dada a resposta no domínio da frequiência de uma planta linear e invariante no tempo, $P(j \omega)$, e $\alpha$ um polo introduzido no controlador PD, pode-se determinar duas linhas retas e uma curva, tais que estas são fronteiras que decompõem o plano $\left(K_{D}, K_{P}\right)$ em regiões com um número fixo de polos estáveis e instáveis para o sistema em malha fechada, dadas por

$$
\begin{gathered}
K_{P}=-\frac{1}{P(0)} \\
\left\{\begin{array}{c}
K_{D}(\omega)=\frac{P_{i}(\omega)-P_{r} \alpha \omega}{\omega|P(j \omega)|^{2}} \\
K_{P}(\omega)=-\frac{P_{r}(\omega)+P_{i}(\omega) \alpha \omega}{|P(j \omega)|^{2}} \\
K_{D}=\frac{-1}{P(\infty)}
\end{array}\right.
\end{gathered}
$$

\subsection{Amplitude do pico de ressonância}

O Teorema 3.1 permite a determinação das regiões de estabilização para uma planta linear e invariante no tempo uma vez conhecida sua respectiva resposta em frequência. Determinando-se tais regiões, resta encontrar quais os ganhos mais apropriados visando atenuação de vibrações. Neste trabalho, a fim de se atingir este objetivo, considera-se a minimização da amplitude do pico de ressonância como critério de desempenho. 
De modo a se determinar a amplitude do pico de ressonância, $M_{r}$, considere a função de transferência do sistema em malha fechada (Equação (3.8)). Calculando-se seu módulo, dado pela Equação (3.29), é possível determinar-se $M_{r}$, em que $M_{r}=\max (|G(j \omega)|)$.

$$
|G(j \omega)|=\frac{\sqrt{P_{r}(\omega)^{2}+P_{i}(\omega)^{2}}}{\sqrt{\left(1+K_{P} P_{r}(\omega)-K_{D} P_{i}(\omega) \omega\right)^{2}+\left(K_{P} P_{i}(\omega)+K_{D} P_{r}(\omega) \omega\right)^{2}}}
$$

Varrendo-se uma faixa de ganhos $\left(K_{D}, K_{P}\right)$, a Equação (3.29) permite traçar uma superfície em termos de $K_{D} \times K_{P} \times M_{r}$. Assim, é possível conhecer-se como diferentes valores dos ganhos do controlador influenciam na amplitude do pico de ressonância do sistema em malha fechada.

No caso de o sistema ter mais de um modo preponderante de vibrar (e, portanto, mais de um pico de ressonância), cada um dos máximos locais da função $|G(j \omega)|$ pode ser traçado em função dos ganhos, sendo obtidas várias superfícies, as quais permitem a seleção dos ganhos mais apropriados visando redução do pico de amplitude para um modo de vibrar em particular ou daqueles que otimizem o comportamento global do sistema, considerando-se todos os seus modos. No caso de se desejar minimizar um pico de ressonância específico, ao utilizar-se a Equação (3.29), deve-se varrer uma faixa de frequências $\omega_{1}<\omega<\omega_{2}$, tal que o pico considerado esteja situado entre $\omega_{1}$ e $\omega_{2}$ (Figura 3.3).

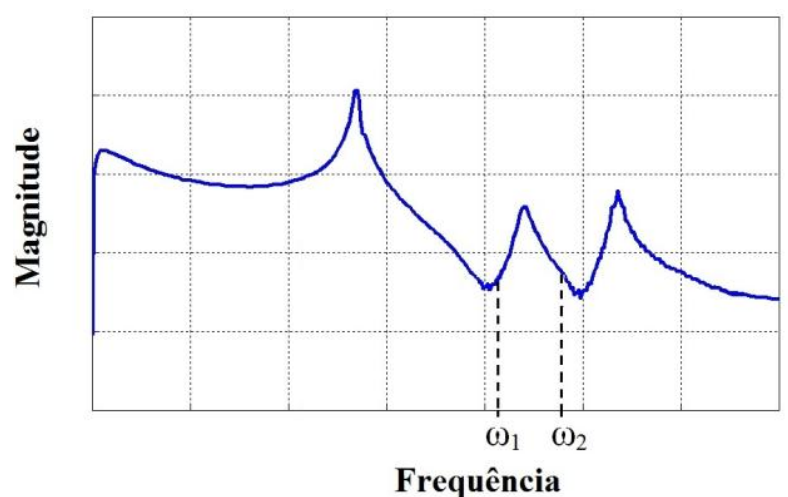

Figura 3.3: Faixa de frequências a ser varrida a fim de minimizar o segundo pico de ressonância.

Por fim, destaca-se que o critério de otimização proposto, o qual visa minimizar a amplitude do pico de ressonância, $M_{r}=\max (|G(j \omega)|)$, em que a função de transferência do 
sistema em malha fechada é dada em termos de sua resposta em frequência (Equação (3.29)), corresponde à norma de desempenho $\mathrm{H}_{\infty}$, a qual é definida pela Equação (3.30). Ela pode ser interpretada como sendo a máxima distância do contorno de Nyquist de $G(j \omega)$ em relação à origem ou como a amplitude do maior pico do diagrama de Bode de um sistema (Gu et al., 2005). Neste sentido, esta norma pode ser utilizada como especificação de desempenho no domínio da frequência e, no caso do presente trabalho, a sua minimização é desejada visando atenuação de vibrações em um sistema rotativo.

$$
\|G(j \omega)\|_{\infty}=\sup _{\omega}|G(j \omega)|
$$




\section{Capítulo 4}

\section{Identificação dinâmica experimental do sistema rotativo}

Uma vez formulada a teoria para o projeto de sistemas de controle utilizando um controlador do tipo PD a partir de medições das funções de resposta em frequência do sistema, a mesma será testada e validada em uma bancada de testes. Neste capítulo, a bancada é apresentada e suas FRFs são identificadas experimentalmente.

\subsection{Montagem da bancada de testes}

A fim de se estudar a técnica de controle apresentada e implementar-se o algoritmo de autoidentificação, adota-se uma bancada de testes constituída por um eixo com discos rígidos em duas configurações diferentes: na primeira, os discos rígidos estão em uma posição centrada em relação aos mancais (Figura 4.1), e, na segunda, os discos rígidos estão dispostos a 1/6 e 5/6 em relação ao comprimento do eixo situado entre os mancais (Figura 4.2). Ao longo deste trabalho, a primeira configuração será denominada "sistema com um disco", e a segunda como "sistema com dois discos".

No caso do sistema com um disco, esta configuração é conhecida como rotor de Laval $^{2}$ (Figura 4.3). Trata-se de um disco rígido com desbalanço residual montado em um eixo flexível e posicionado ao centro do suportes dos mancais, os quais apresentam a mesma rigidez (isotrópicos). Uma vez que não é possível construir-se um rotor perfeitamente

\footnotetext{
${ }^{2}$ Em algumas referências, como Childs (1993), esta configuração também é conhecida como rotor de Jeffcott em homenagem a Henry Homan Jeffcott (1877-1937) que modelou matematicamente, pela primeira vez, um rotor semelhante ao do modelo da Figura 4.3.
} 
balanceado e a força de desbalanço excita os tipos de vibração mais comumente observados em máquinas rotativas, este tipo de rotor, apesar da simplicidade, é de grande utilidade na análise da dinâmica de rotores (Vance et al., 2010).

Entretanto, para o rotor de Laval o sistema apresenta apenas um grau-de-liberdade, não havendo acoplamento entre as direções vertical e horizontal, de modo que, quando o eixo está em rotação, não se observa o efeito giroscópico. Por isso, também se adota um sistema com 2 gdl (sistema com dois discos) a fim de se verificarem as influências deste efeito na resposta do sistema e, por conseguinte, nas regiões de estabilização quando da implantação da técnica de controle (Figura 4.2).

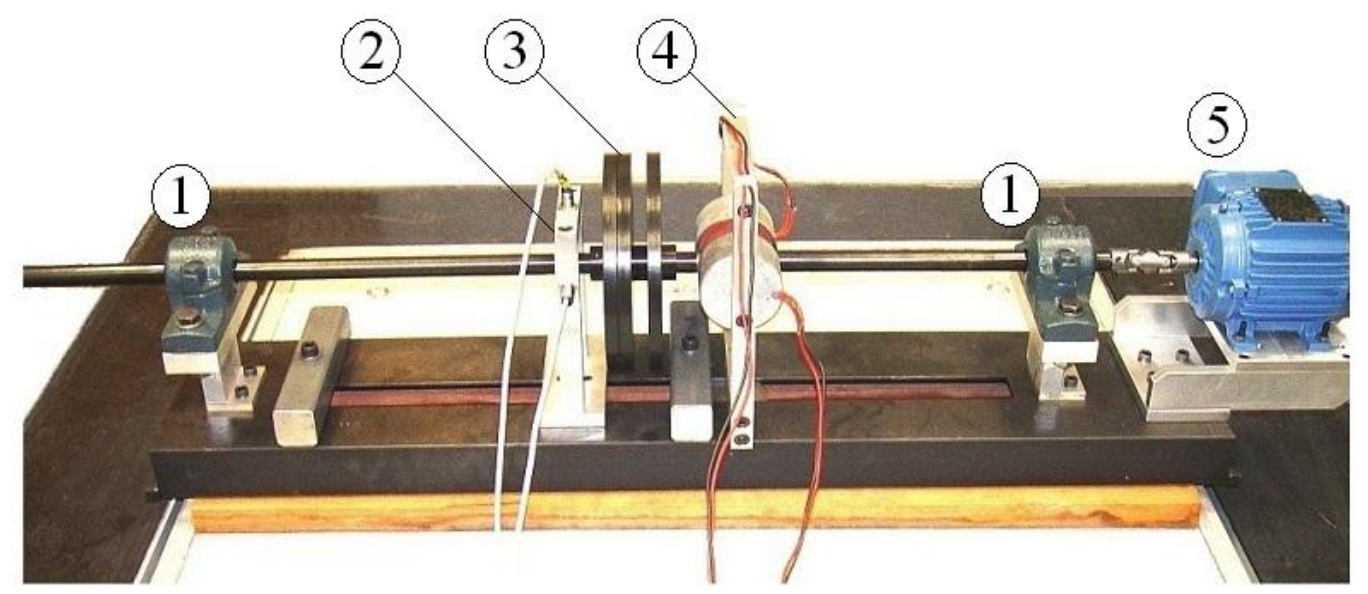

Figura 4.1: Sistema com um disco: 1. mancais de rolamento, 2. sensores de posição, 3. discos rígidos, 4. atuadores eletromagnéticos e 5. motor elétrico.

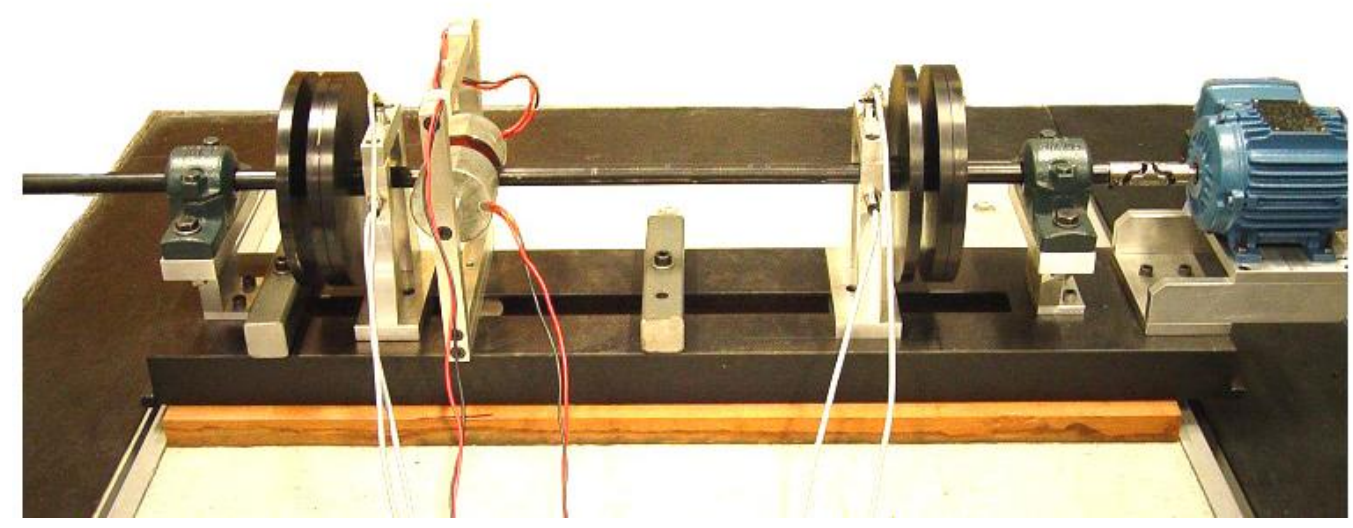

Figura 4.2: Sistema com dois discos.

A bancada de testes utilizada encontra-se aparafusada em uma plataforma inercial, cuja frequência de ressonância é de aproximadamente $2 \mathrm{~Hz}$. O eixo é suportado por mancais de rolamentos autocompensadores de esferas e está acoplado por meio de uma junta universal 
a um motor elétrico trifásico de $0,5 \mathrm{cv}$, cuja frequência de rotação é controlada através de um inversor de frequência. O eixo e os discos rígidos foram usinados em aço, e os suportes dos mancais, sensores, atuadores e do motor em alumínio.

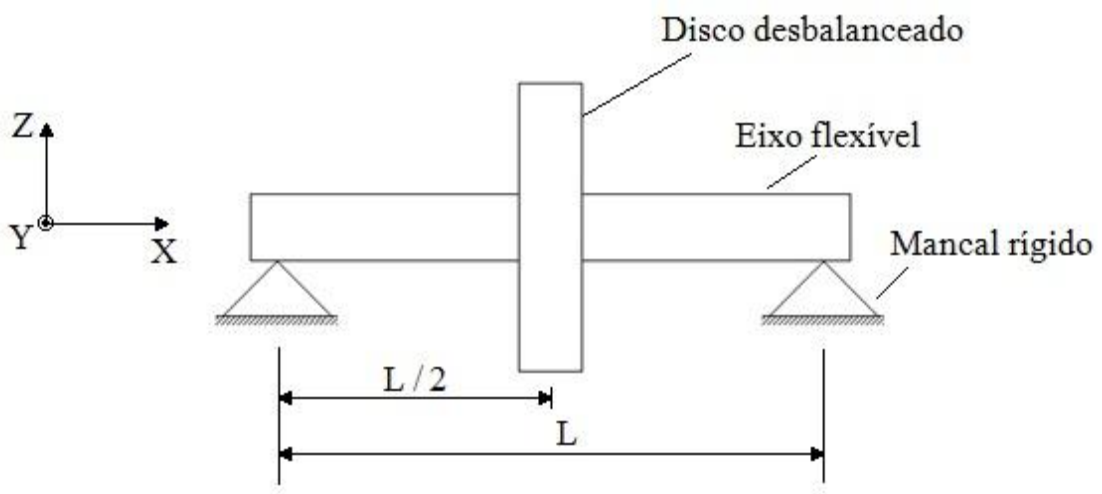

Figura 4.3: Rotor de Laval (Vance et al., 2010).

Observando-se a Figura 4.1, tem-se um suporte com dois sensores de proximidade indutivos (item \#2), responsáveis por medir o deslocamento do eixo nas direções horizontal e vertical; três discos rígidos (item \#3), de massa $3 \mathrm{~kg}$ cada; e um suporte com um par de atuadores eletromagnéticos (item \#4). Para o sistema com dois discos, foram acrescentados mais três discos e mais um par de sensores. Uma vista ampliada dos sensores e dos atuadores utilizados na bancada de testes é apresentada na Figura 4.4.
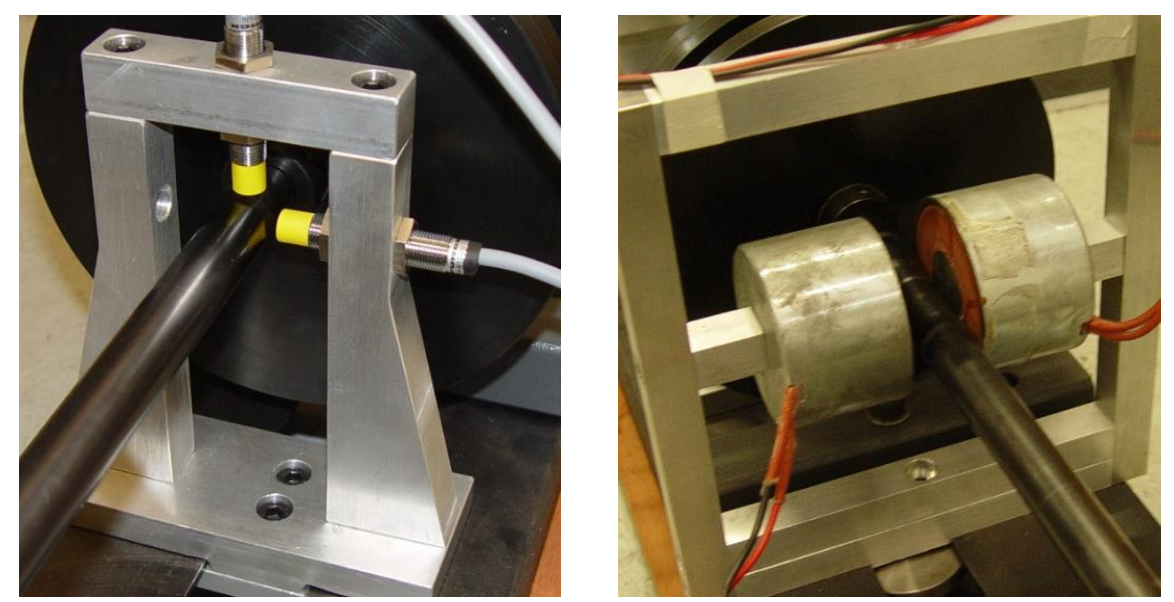

Figura 4.4: Vistas ampliadas dos sensores e atuadores (itens \#2 e \#4, respectivamente, da Figura 4.1).

As dimensões e as distâncias relativas entre os componentes da bancada de testes das Figuras 4.1 e 4.2 são apresentadas, respectivamente, nas Figuras 4.5 e 4.6. Em ambos os casos, os atuadores eletromagnéticos foram posicionados de forma que a sua capacidade de atu- 
ação fosse maximizada. Este posicionamento levou em consideração a análise modal do sistema com dois discos (Figura 4.7) para as posições indicadas na Figura 4.6. No caso, para esta configuração do sistema, verificou-se a existência de ressonâncias paras as frequências $\mathrm{f}$ $=27 \mathrm{~Hz}$, a qual, pelo seu modo de vibrar, corresponde ao $1^{\circ}$ modo do rotor; $\mathrm{f}=44,2 \mathrm{~Hz}$, a qual se acredita corresponder a um modo de vibrar de algum componente da bancada, como o motor; e $\mathrm{f}=53,6 \mathrm{~Hz}$, a qual corresponde ao $2^{\circ}$ modo do rotor.

Assim, para o sistema com um disco, os atuadores foram colocados na posição central do eixo em relação aos mancais, pois é de se esperar que o modo de vibrar do sistema para esta configuração seja similar ao $1^{\circ}$ modo do sistema com dois discos (o deslocamento máximo ocorre na porção central, sendo maximizada a capacidade de atuação - Figura 4.7 (a)). Para o sistema com dois discos, os atuadores foram deslocados desta posição, pois ela corresponde a um nó para o $2^{\circ}$ modo (Figura 4.7 (c)).

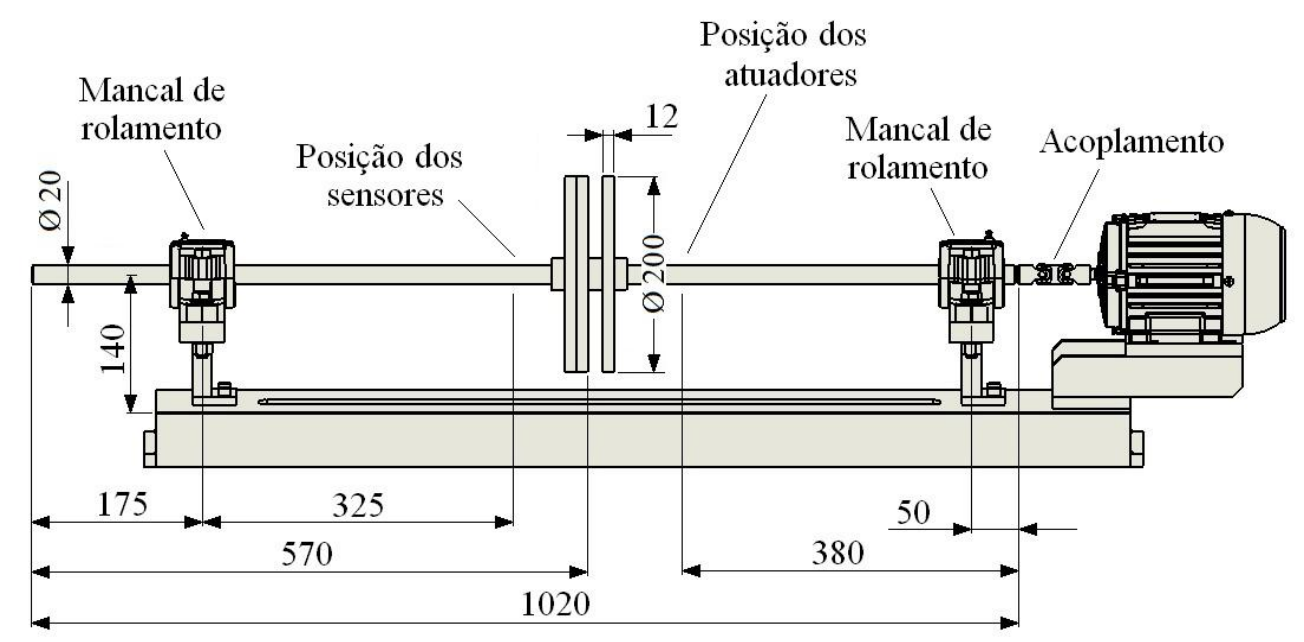

Figura 4.5: Sistema com um disco: dimensões e distâncias relativas entre os componentes.

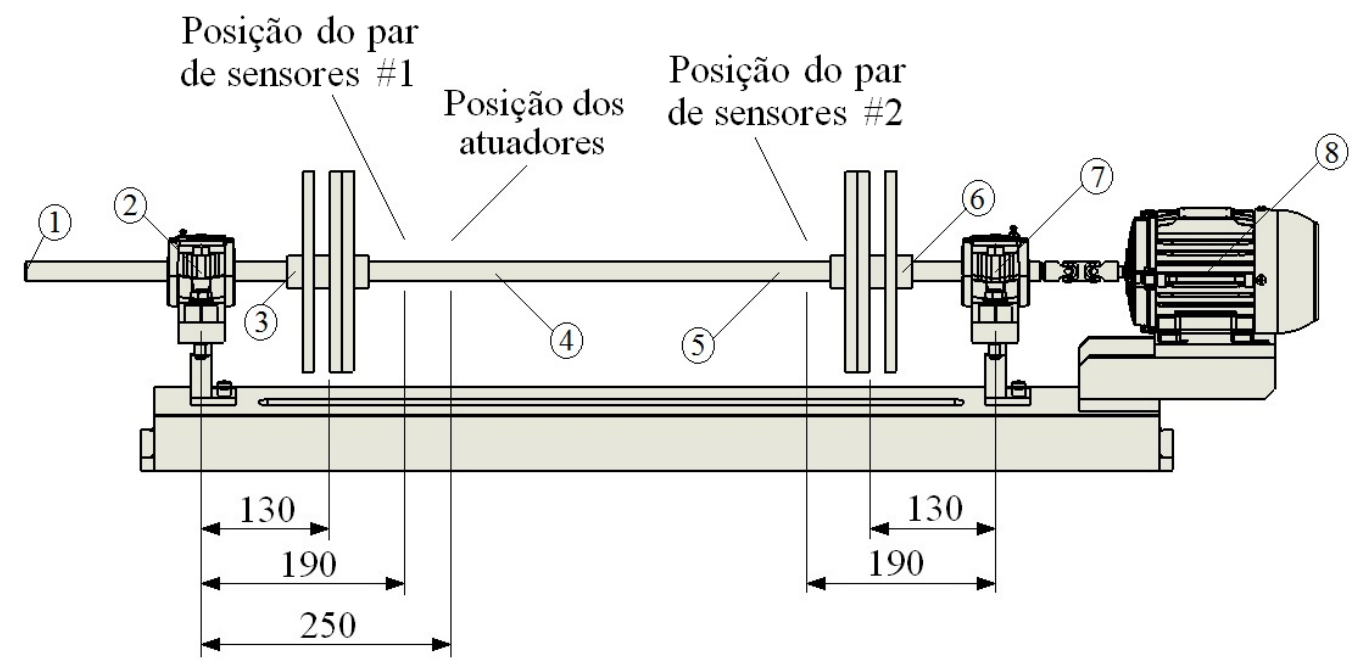

Figura 4.6: Sistema com dois discos: distâncias e pontos considerados para a análise modal. 


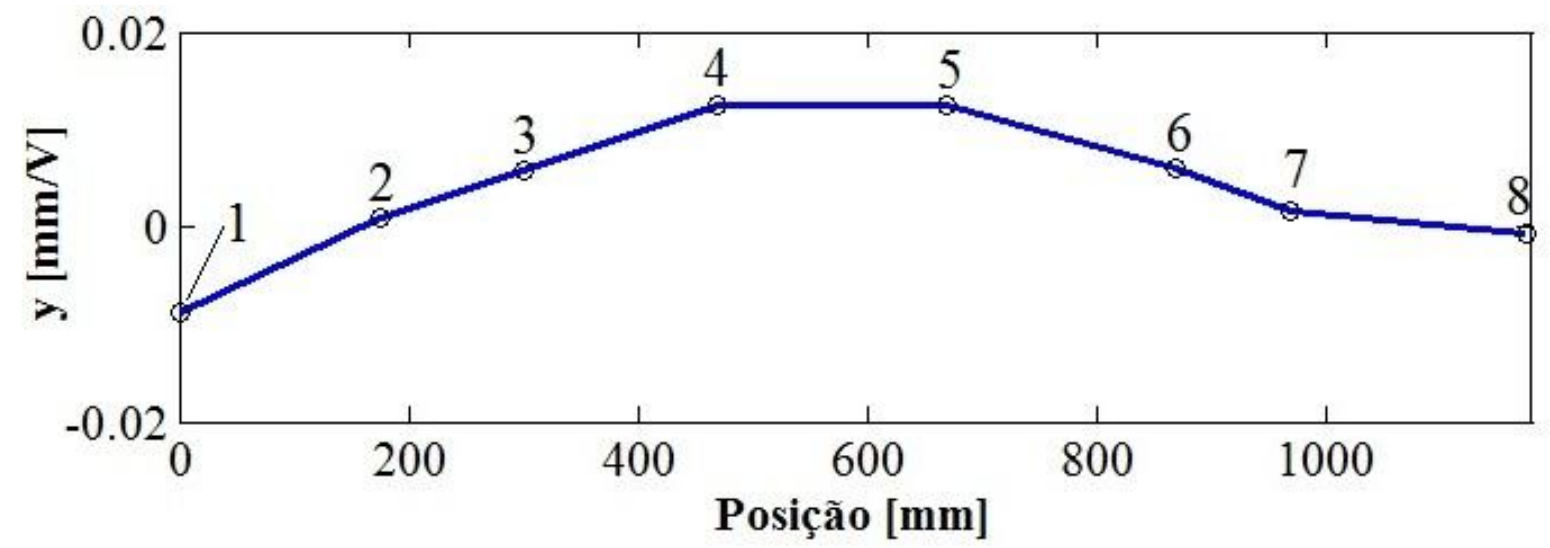

(a) $\mathrm{f}=27 \mathrm{~Hz}\left(1^{\circ}\right.$ modo do rotor $)$

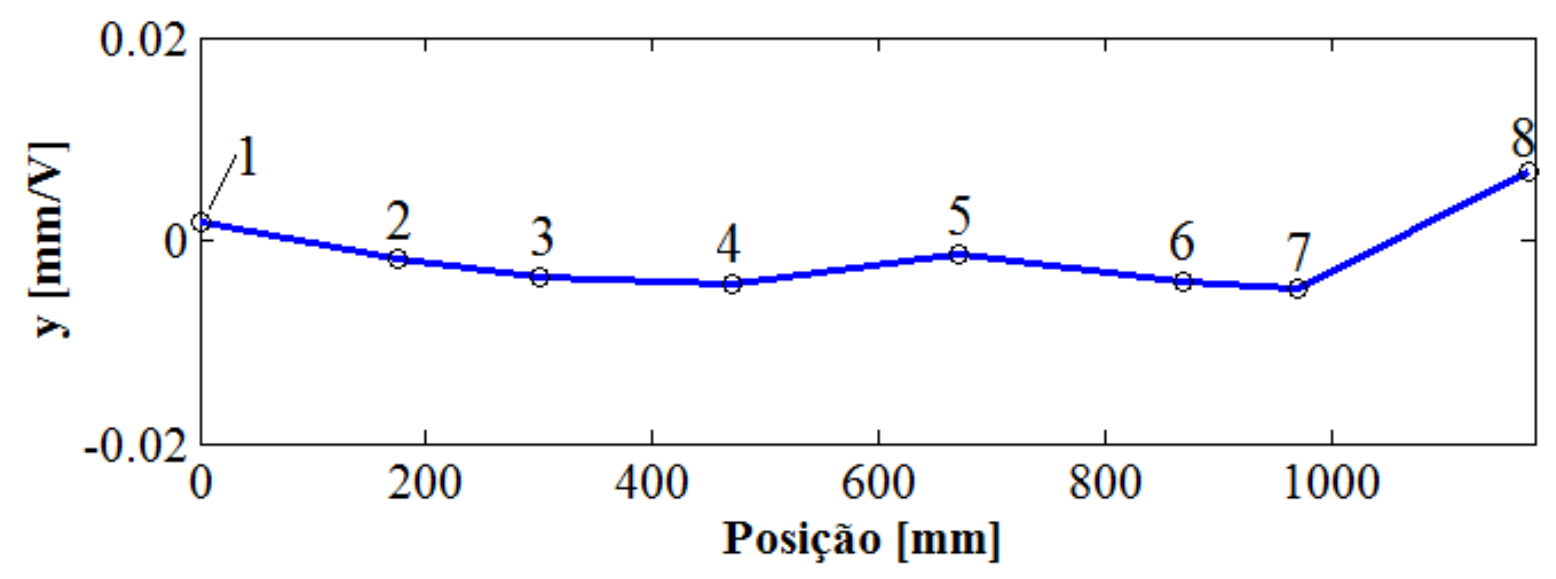

(b) $\mathrm{f}=44,2 \mathrm{~Hz}$ (modo do motor)

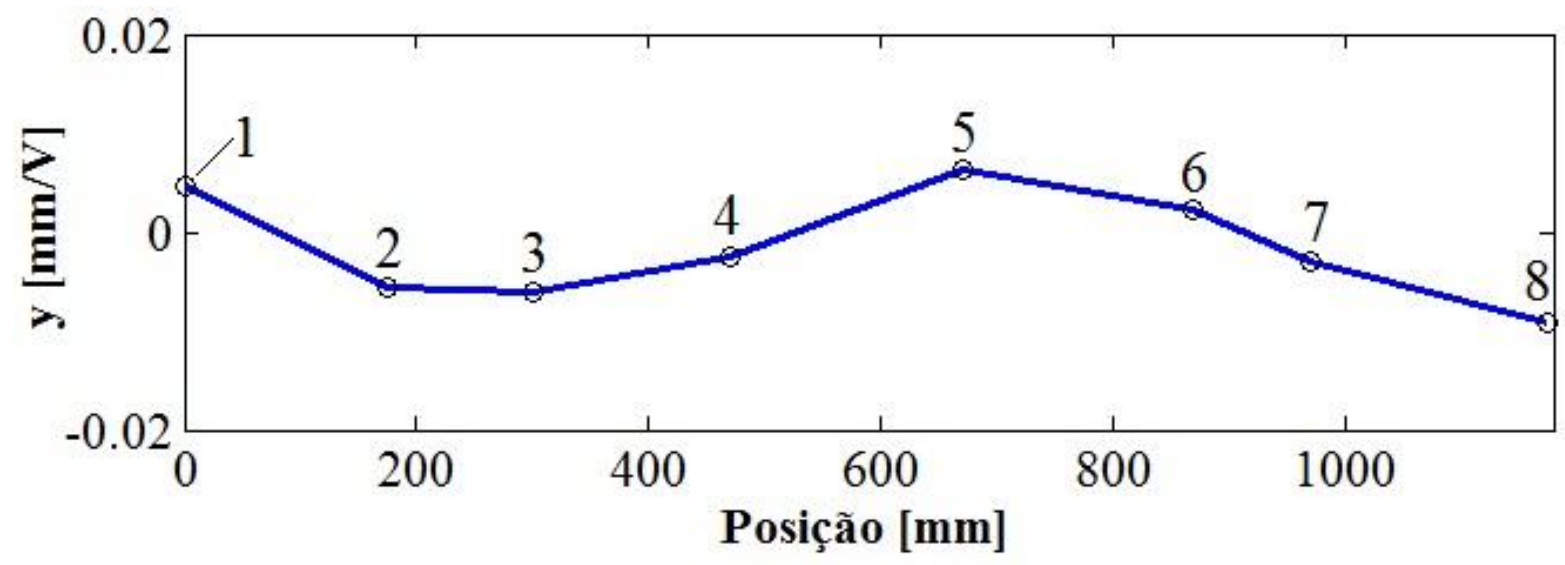

(c) $\mathrm{f}=53,6 \mathrm{~Hz}\left(2^{\circ}\right.$ modo do rotor)

Figura 4.7: Modos de vibrar do sistema com dois discos (a ressonância verificada em $\mathrm{f}=44,2$ $\mathrm{Hz}$, pela forma do seu modo de vibrar associado, não corresponde a um modo do rotor; acredita-se que ela seja devida a um modo de vibrar do motor). 


\subsection{Procedimento de identificação experimental das FRFs}

As funções de resposta em frequência são obtidas utilizando-se o estimador de FRF $H_{1}(\omega)$ (Maia e Silva, 1997) e, para isso, o sistema será excitado utilizando-se os próprios atuadores eletromagnéticos e sua resposta será medida através dos sensores de posição. Uma das vantagens da abordagem empregada neste trabalho é que não se considera apenas a dinâmica do rotor no projeto e análise do sistema de controle, mas sim a do sistema como um todo, incluindo os atuadores e sensores (Figura 4.8).

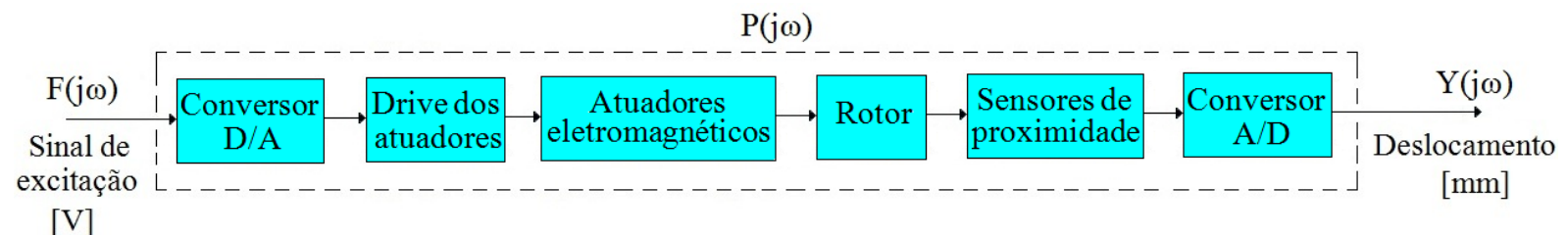

$[\mathrm{V}]$

Figura 4.8: Diagrama de blocos da planta: a FRF contém informações do sistema como um todo, incluindo os sensores e atuadores.

Destaca-se que, quando da implementação do sistema de controle, os eletroímãs serão responsáveis por excitar e, simultaneamente, controlar o sistema, i.e., o sinal de excitação (utilizado para obtenção da resposta em freqüência), $F(j \omega)$, e o de controle serão somados (vide diagrama de blocos da Figura 3.2) e enviados para os atuadores eletromagnéticos (Figura 4.9). Além disso, uma vez que se tem por objetivo controlarem-se somente as vibrações na direção horizontal, o deslocamento medido pelo sensor posicionado na vertical não realimentará a malha de controle.

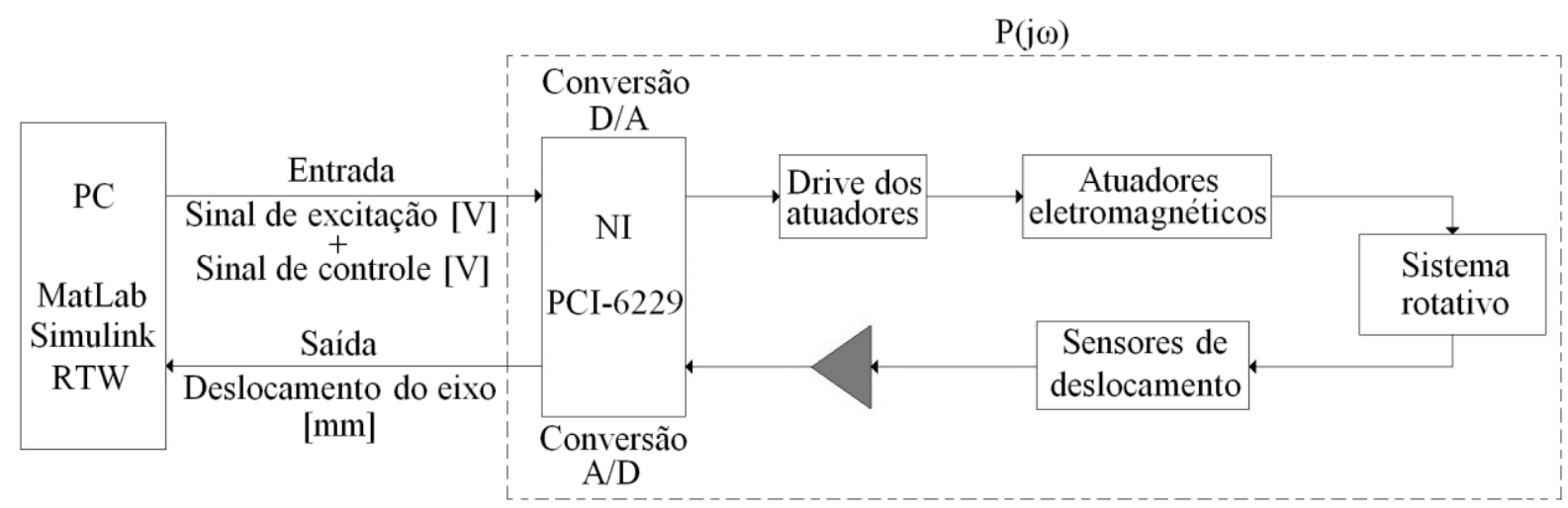

Figura 4.9: Esquematização do procedimento para excitação e aquisição dos dados de saída do sistema (inicialmente, o sinal de controle é zero, sendo somado ao de excitação quando da implantação da estratégia de controle). 
Para o sistema com um disco, o sinal de excitação enviado para os atuadores é um sinal harmônico do tipo chirp de amplitude $2 \mathrm{~V}$ que varia sua frequência de 1 a $40 \mathrm{~Hz}$ e volta a $1 \mathrm{~Hz}$, em um período de $10 \mathrm{~s}$, sendo repetido por 4 vezes, perfazendo um tempo total de excitação de $40 \mathrm{~s}$ (Figura 4.10). No caso do sistema com dois discos, uma vez que o sistema está mais pesado (possui três discos a mais, totalizando um ganho adicional de massa de $9 \mathrm{~kg}$ ), utiliza-se um sinal chirp de amplitude $4 \mathrm{~V}$ e, por este sistema ter mais de um modo de vibrar, o sinal varia sua frequência de 1 a $70 \mathrm{~Hz}$ (Figura 4.11).

O sinal de excitação é enviado a uma freqüência de amostragem de $1 \mathrm{kHz}$ ao conversor D/A de uma placa de aquisição de dados (placa National Instruments PCI-6229) e, em seguida, é enviado para um drive de potência, que balanceia a tensão de trabalho a ser enviada para cada atuador (faixa de $-24 \mathrm{a}+24 \mathrm{~V}$ ), de maneira que o sinal é enviado proporcionalmente aos atuadores: mais voltagem para um dos magnetos quando a tensão de controle for negativa e mais voltagem para o outro magneto quando a tensão de controle for positiva (Figura 4.12).

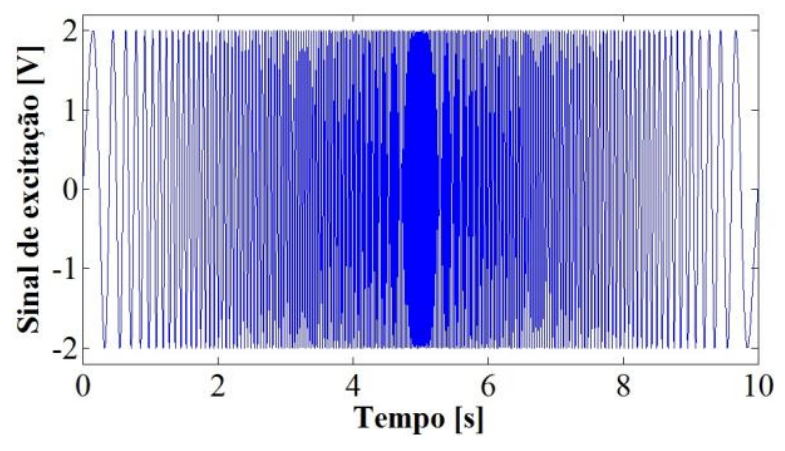

(a) um período

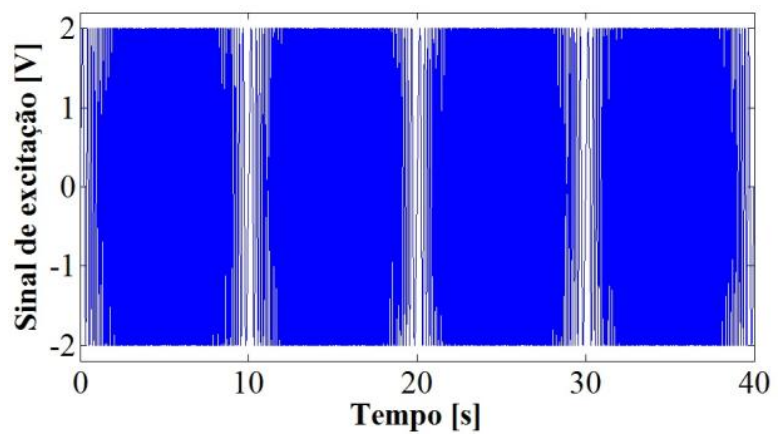

(b) sinal replicado 4 vezes

Figura 4.10: Sinal de excitação do tipo chirp utilizado para excitar o sistema com um disco.

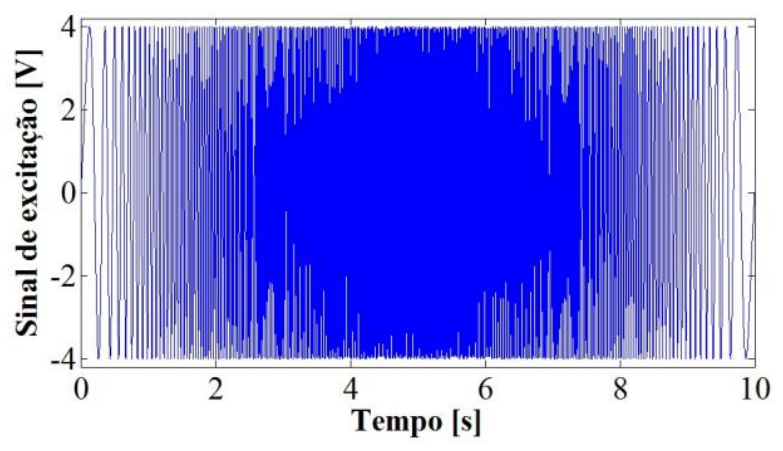

(a) um período

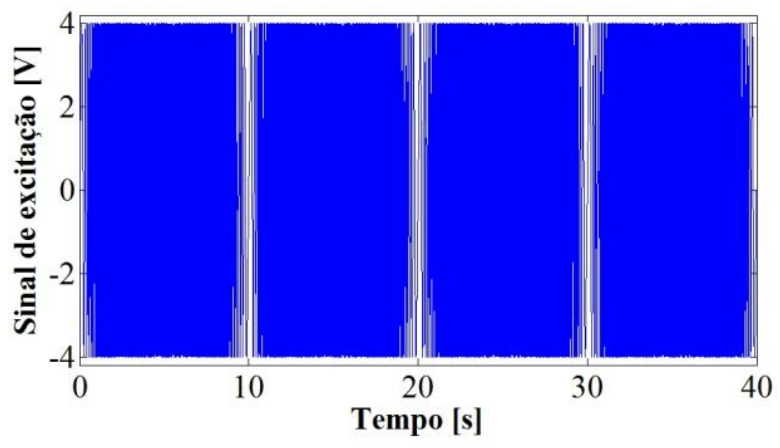

(b) sinal replicado 4 vezes

Figura 4.11: Sinal de excitação do tipo chirp utilizado para excitar o sistema com dois discos. 
Os deslocamentos laterais são medidos por sensores de proximidade analógicos, cujos sinais são adquiridos pelo sistema de aquisição de dados (placa NI PCI-6229), responsável pela conversão A/D e envio ao microcomputador (Figura 4.9). Todo o procedimento para a identificação da resposta do sistema é implementado em tempo real no ambiente MatLab Simulink (Figura 4.13) através da ferramenta Real Time Workshop (RTW).

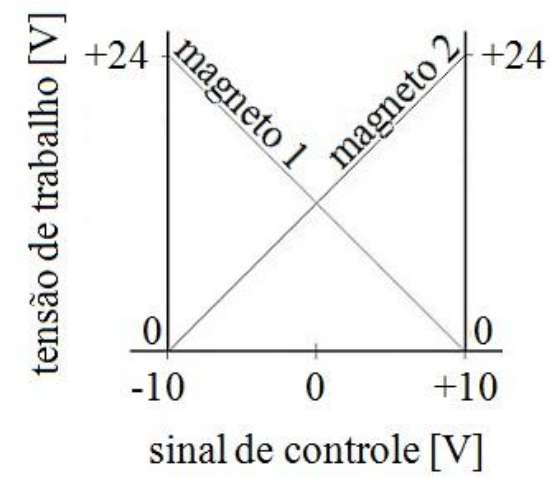

Figura 4.12: Balanceamento da tensão de trabalho nos atuadores.
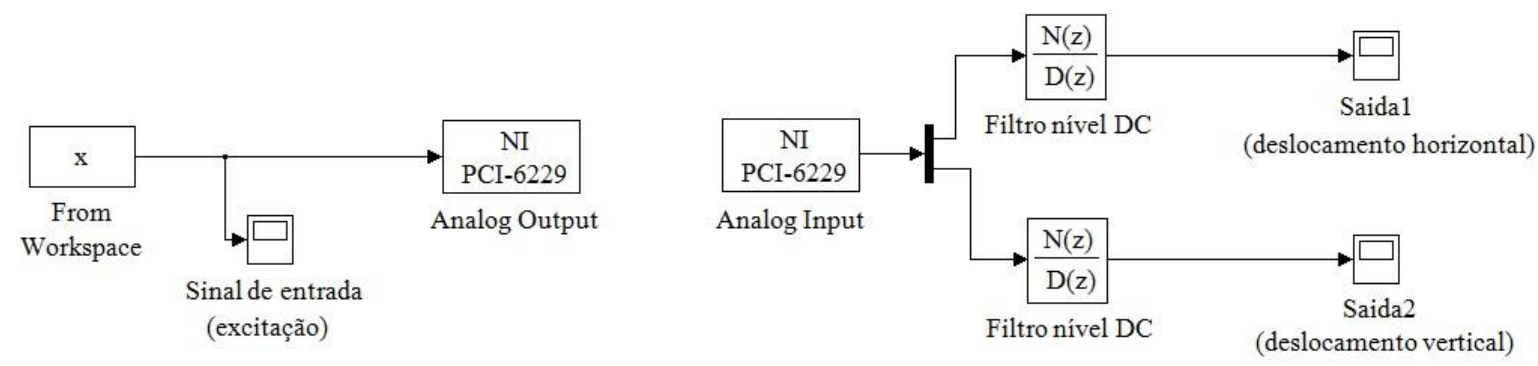

Figura 4.13: Programa em MatLab Simulink para excitação e aquisição da resposta.
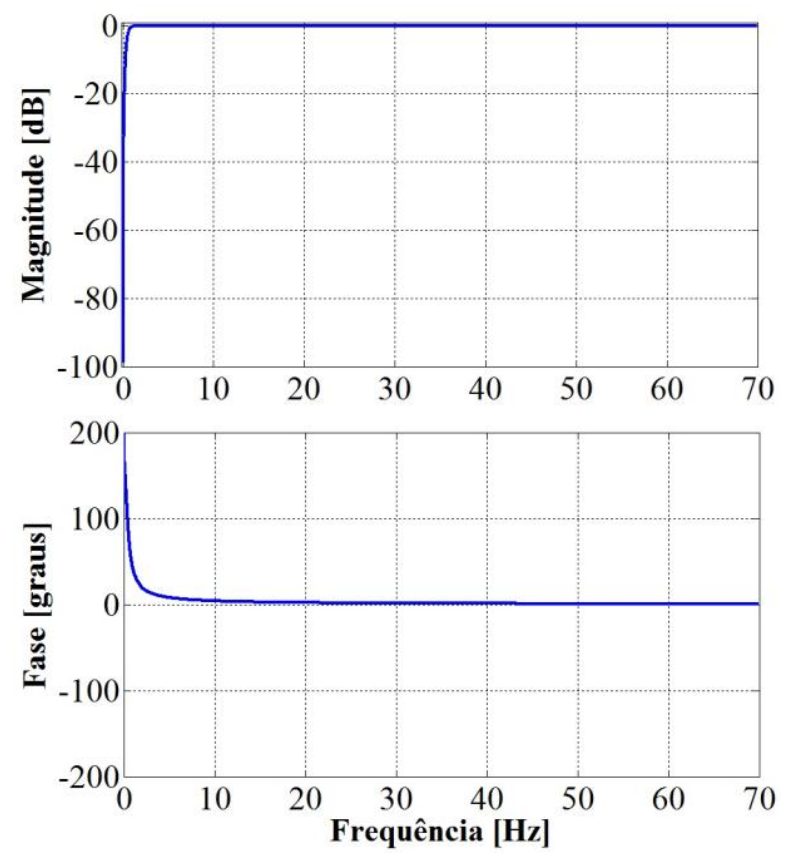

Figura 4.14: Filtro Butterworth de segunda ordem passa alta (frequência de corte de 0,5 Hz). 
Como se pode observar na Figura 4.13, utilizou-se um filtro para remover o nível DC do sinal medido pelos sensores, a fim de tornar o seu valor médio como sendo igual a zero. $\mathrm{O}$ filtro empregado é do tipo Butterworth de segunda ordem passa-alta (Equação (4.1)) e a sua resposta em frequência é apresentada na Figura 4.14. A importância de sua aplicação consiste em reduzir a tensão de controle enviada aos atuadores, uma vez que a voltagem medida pelos sensores será menor, permitindo a adoção de ganhos mais elevados para o controlador PD sem saturar as portas de saída D/A da placa de aquisição de dados (faixa de -10 a $10 \mathrm{~V}$ ).

$$
F(j \omega)=\frac{-0,998 \omega^{2}-0,00493 j \omega+0}{-\omega^{2}+4,443 j \omega+9,870}
$$

\subsection{Obtenção experimental das FRFs}

Através do procedimento ilustrado na Figura 4.9 e do sinal de excitação do tipo chirp (Figuras 4.10 e 4.11), obtêm-se as FRFs do sistema rotativo para as duas configurações consideradas.

\subsubsection{Sistema rotativo com um disco}

A Figura 4.15 apresenta a amplitude da resposta em frequência do sistema rotativo para uma faixa de velocidades do eixo de 0 a $2100 \mathrm{rpm}(0$ a $35 \mathrm{~Hz})$. Este diagrama, conhecido como diagrama de cascata, permite verificar a influência da rotação na resposta do sistema. A componente A corresponde aos picos de ressonância (ocorrem em torno de $22 \mathrm{~Hz}$ ), e a $\mathbf{B}$ aos picos de harmônicas, ocasionados devido à velocidade de rotação.

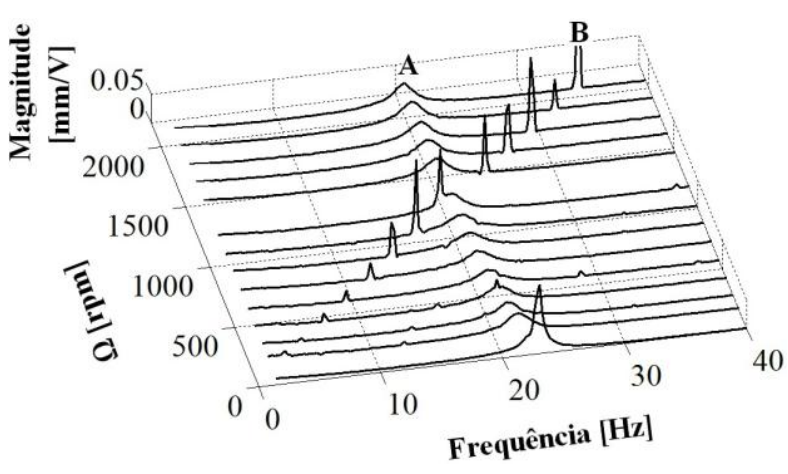

(a) deslocamento na horizontal

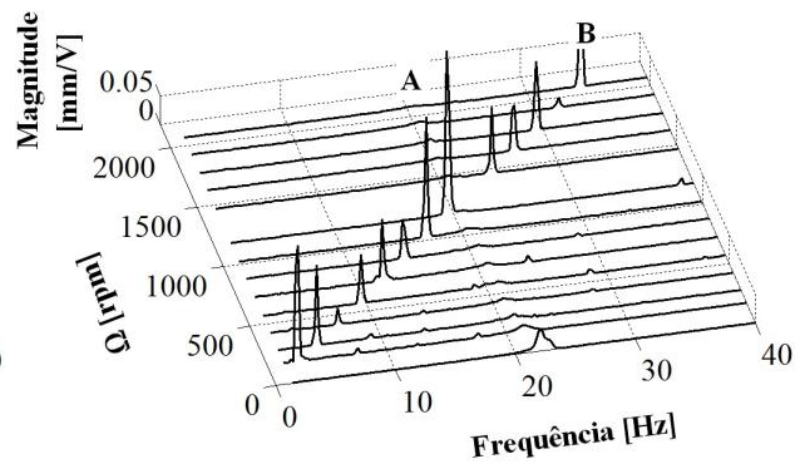

(b) deslocamento na vertical

Figura 4.15: Diagrama de cascata experimental do sistema com um disco em malha aberta. 
Nota-se que a rotação modifica a forma do pico de ressonância (componente A), tornando-o mais amortecido: ao se comparar a amplitude do pico para o sistema parado e em movimento, esta diminui quando o eixo está girando (Figura 4.16). Não se sabe ao certo qual a causa de tal fenômeno. Uma hipótese para explicá-lo é o efeito conhecido como correntes de Foucault (ou correntes parasitas): o eixo move-se em um campo magnético, induzindo uma corrente, a qual cria campos magnéticos que se opõem ao campo magnético original devido à lei de Lenz, resultando em forças que atenuam a excitação aplicada ao sistema.
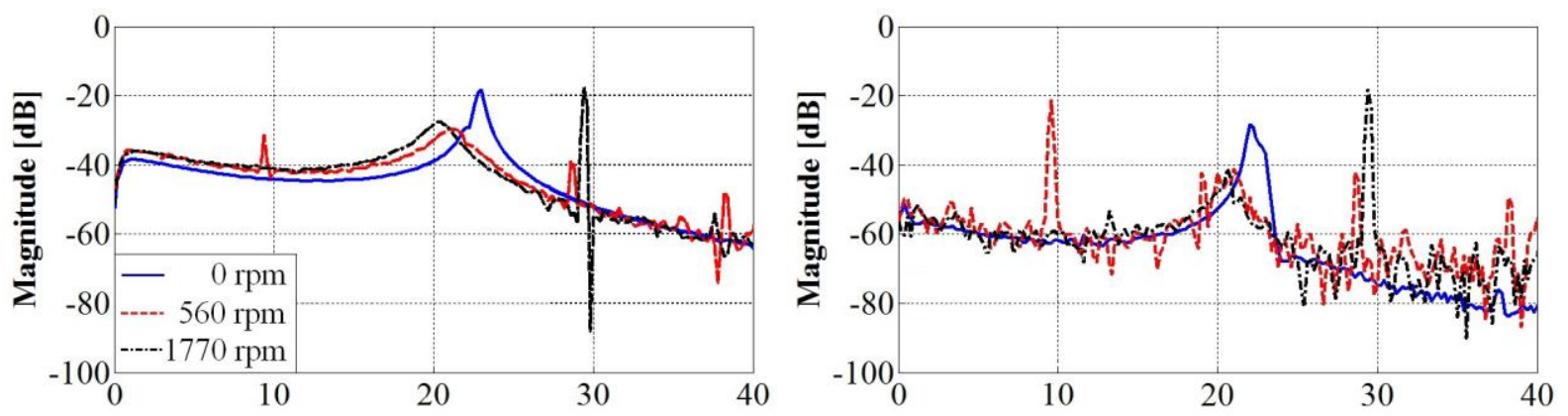

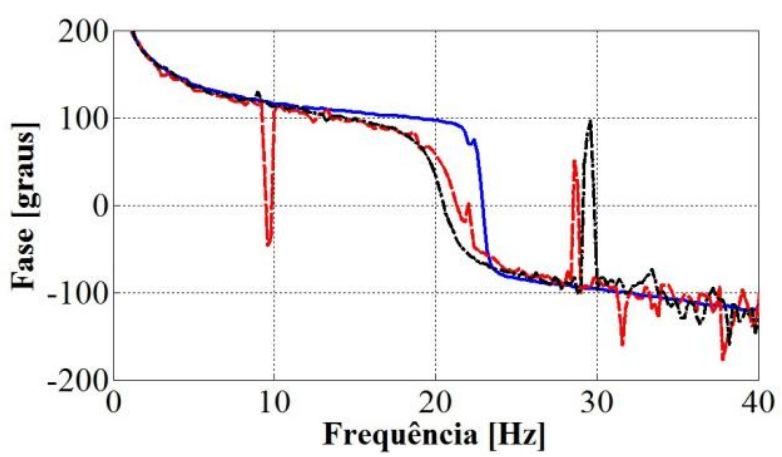

(a) deslocamento na horizontal

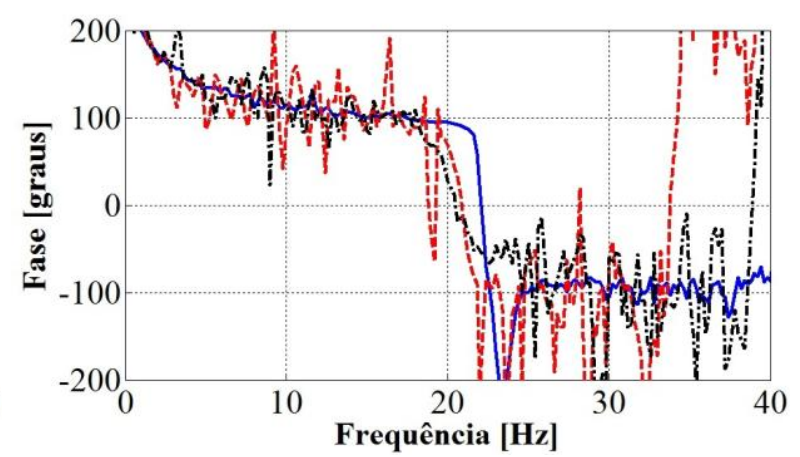

(b) deslocamento na vertical

Figura 4.16: $\mathrm{FRF}^{3}$ do sistema com um disco parado e girando a duas velocidades diferentes.

Conforme mencionado no início deste capítulo, as funções de resposta em frequência foram calculadas utilizando-se o estimador $H_{1}(\omega)$. Outro estimador também bastante utilizado é o conhecido como $H_{2}(\omega)$, o qual, em comparação com $H_{1}(\omega)$, pondera mais o sinal de saída que o de entrada no cálculo da FRF. Como no presente caso o sinal de entrada aplicado (sinal de excitação) é perfeitamente conhecido, justifica-se a adoção do primeiro estimador, uma vez que ele conduzirá a resultados mais precisos. Uma comparação entre os resultados obtidos por ambos os estimadores pode ser feita através da razão $H_{1}(\omega) / H_{2}(\omega)$,

\footnotetext{
${ }^{3}$ A unidade decibel é definida como $[d B]=20 \times \log _{10}[\mathrm{~mm} / \mathrm{V}]$.
} 
conhecida como função coerência ordinária (Figura 4.17), cujo valor máximo é 1 (quanto mais próxima a coerência estiver deste valor, maior será a semelhança entre os resultados obtidos por ambos os estimadores).

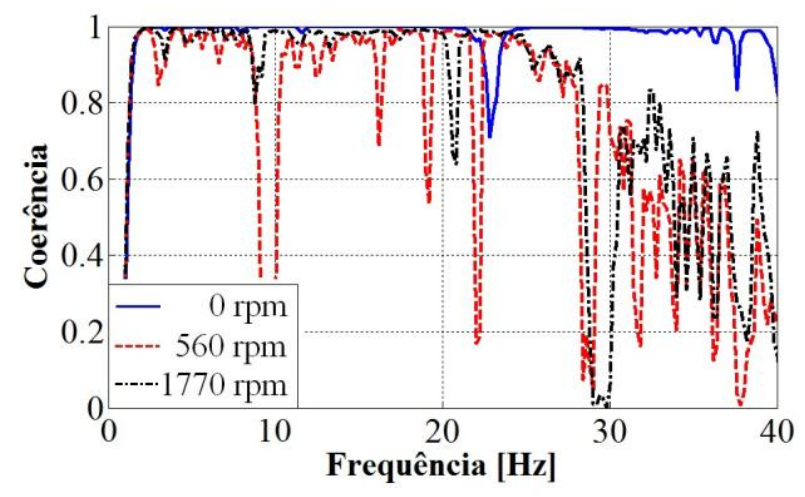

(a) coerência na horizontal

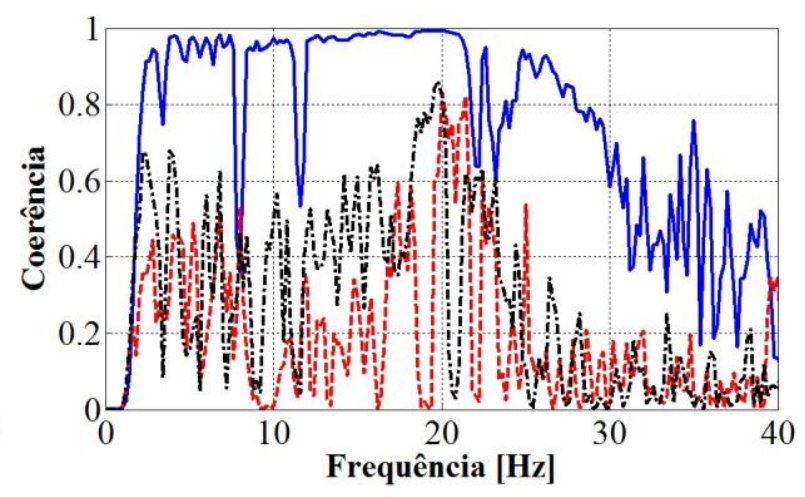

(b) coerência na vertical

Figura 4.17: Função coerência ordinária para as FRFs da Figura 4.16.

No caso da Figura 4.16b, as FRFs obtidas para as medições de deslocamento na direção vertical apresentam grande influência de erros de medição (ruído) e coerência relativamente baixa (Figura 4.17b). Isso se deve ao pouco efeito que uma excitação na direção horizontal exerce naquela direção, de modo que a relação ruído/excitação seja alta, comprometendo a qualidade das medições.

\subsubsection{Sistema rotativo com dois discos}

Para o sistema com dois discos, o seu diagrama de cascata é apresentado na Figura 4.18, em que a componente $\mathbf{A}$ corresponde aos picos de ressonância (ocorrem em torno de 25 $\mathrm{Hz}$ ), e a $\mathbf{B}$ aos picos de harmônicas, ocasionados devido à velocidade de rotação. No caso, verifica-se que os picos de ressonância se dividem em dois e este fenômeno de bipartição do pico ocorre devido à presença do efeito giroscópico, sendo mais pronunciado à medida que a velocidade de rotação aumenta. Além disso, assim como para o sistema com um disco, verifica-se que o pico de ressonância diminui quando se compara sua amplitude para o sistema parado e em movimento (Figura 4.19).

Observando-se a Figura 4.19, verifica-se que a resposta do sistema apresenta maiores níveis de ruído para valores de frequência acima de $40 \mathrm{~Hz}$, o que se deve à menor capacidade de atuação dos eletromagnetos em alta frequência (maior relação ruído/excitação). Além disso, assim como para o sistema com um disco, os resultados obtidos para o deslocamento na 
direção horizontal (Figuras 4.19 (a) e (c)) são melhores que aqueles para o deslocamento na vertical (Figuras 4.19 (b) e (d)), pois a excitação (força eletromagnética) é na direção horizontal.

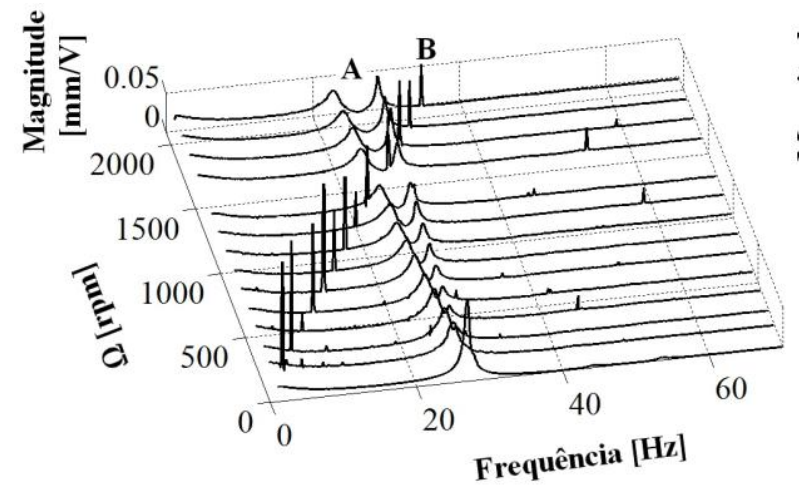

(a) deslocamento na horizontal (sensor \#1)

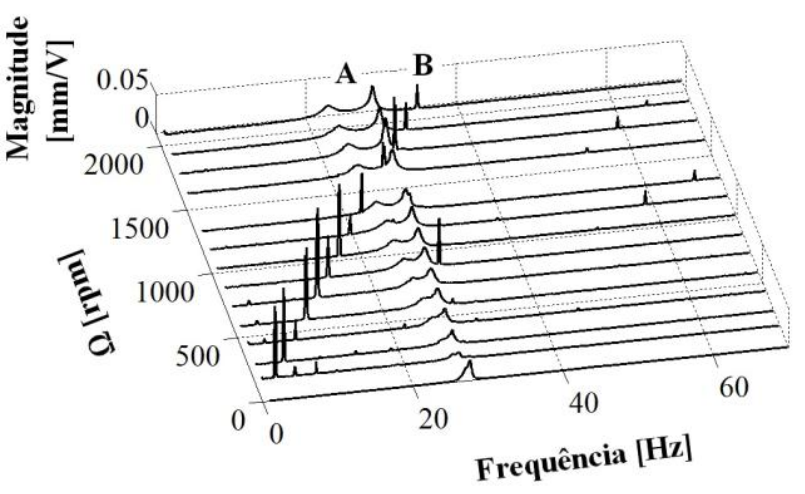

(b) deslocamento na vertical (sensor \#1)

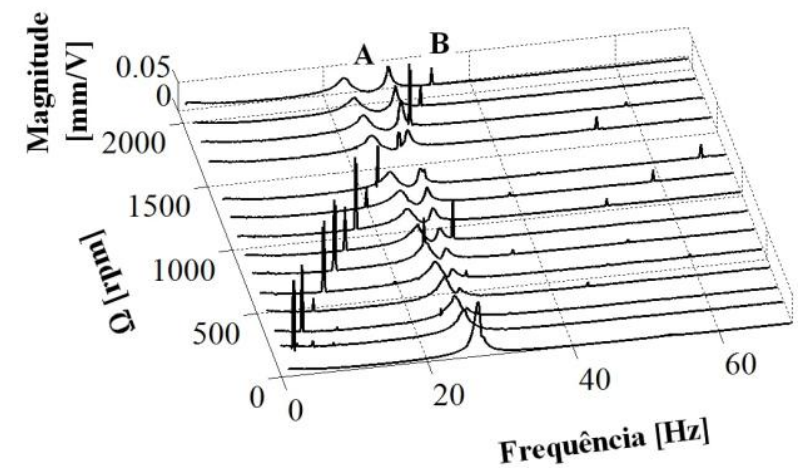

(c) deslocamento na horizontal (sensor \#2)

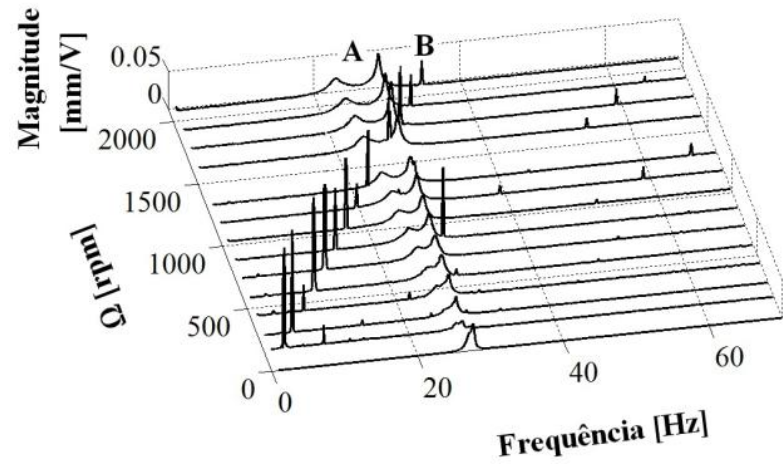

(d) deslocamento na vertical (sensor \#2)

Figura 4.18: Diagrama de cascata experimental do sistema com dois discos em malha aberta.

Verificam-se três picos de ressonância na Figura 4.19 (a), sendo que, a partir da análise modal da bancada (Figura 4.7), tem-se que o $1^{\circ}$ modo de vibrar do rotor corresponde ao primeiro pico, e o $2^{\circ}$ modo ao terceiro pico. As Figuras 4.19 (b) e (c) sugerem a existência de um quarto pico em $67 \mathrm{~Hz}$, o qual pode ser devido a um modo de vibrar de algum componente da bancada, como o suporte do mancal.

Destaca-se que para o sistema com um disco os picos de ressonância na direção vertical são pouco evidentes para o eixo em rotação (Figuras 4.15 (b) e 4.16 (b)) quando comparados com os do sistema com dois discos nesta mesma direção (Figuras 4.18 (b), (d) e 4.19 (b), (d)). Neste último caso, os picos de ressonância para o $1^{\circ}$ modo de vibrar são visualizados com clareza, o que se deve ao fato de que, para esta configuração, uma excitação na 
direção horizontal influencia significativamente no movimento do sistema na direção vertical devido ao acoplamento entre as direções, decorrente do efeito giroscópico.
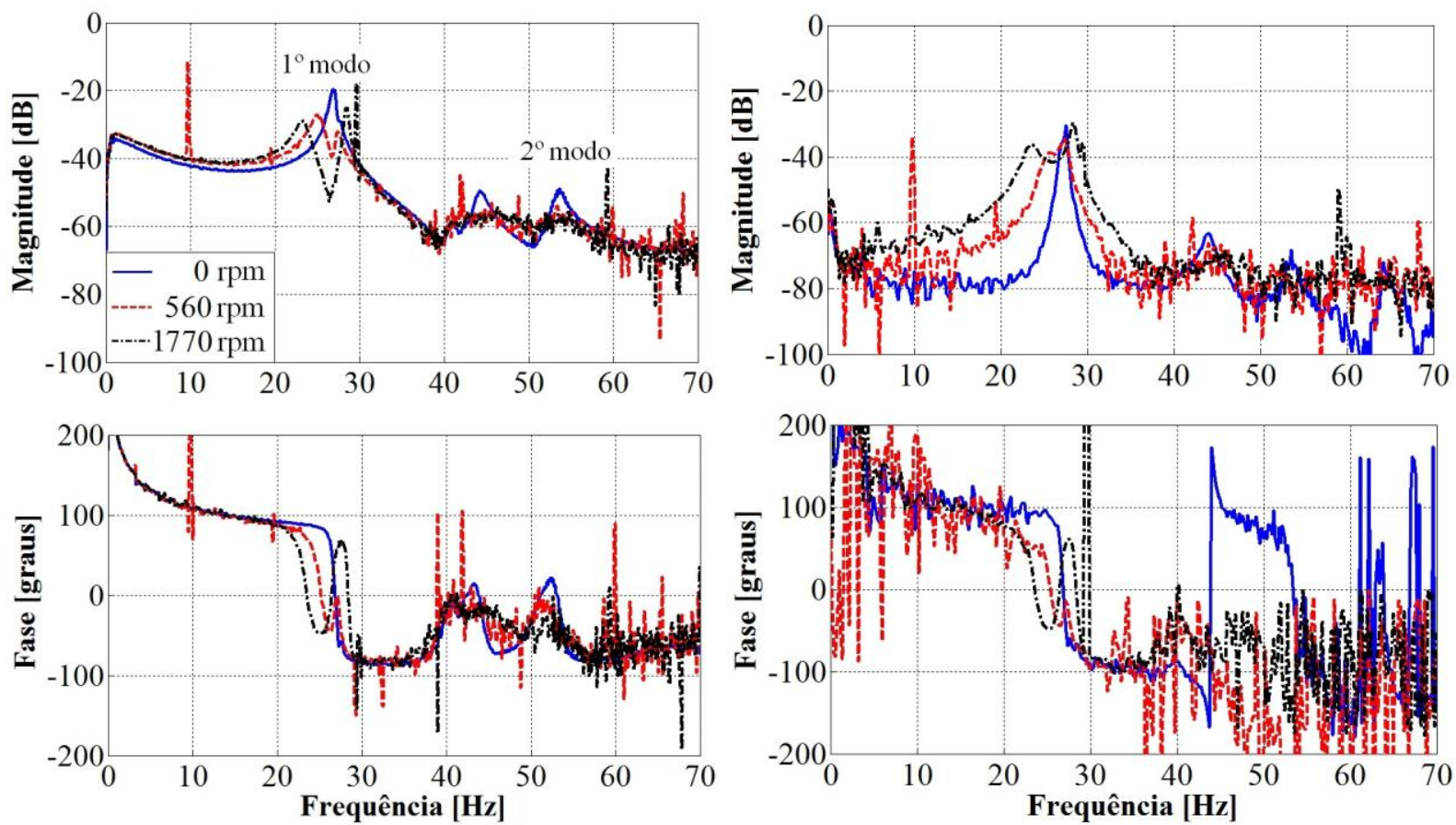

(a) deslocamento na horizontal (sensor \#1)

(b) deslocamento na vertical (sensor \#1)
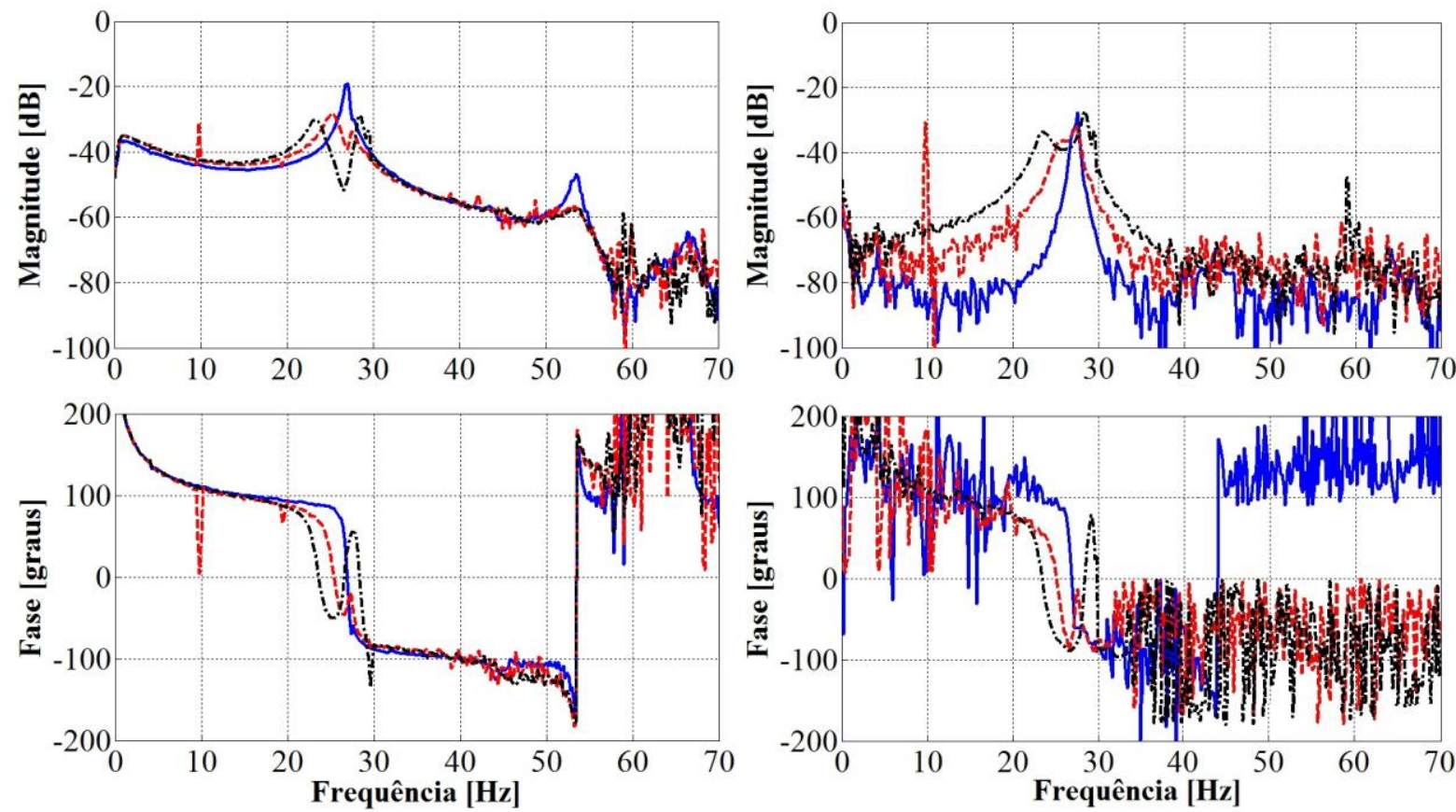

(c) deslocamento na horizontal (sensor \#2)

(d) deslocamento na vertical (sensor \#2)

Figura 4.19: FRF do sistema com dois discos parado e girando a duas velocidades diferentes. 
A função de coerência ordinária para as FRFs da Figura 4.19 é apresentada na Figura 4.20. De forma geral, tem-se que a coerência é consideravelmente menor para faixas de frequência acima de $40 \mathrm{~Hz}$ (menor capacidade de atuação dos atuadores em alta frequência). Além disso, os resultados para o sistema parado tendem a ser melhores do que quando o mesmo está em rotação, uma vez que, quando girando, a força de desbalanço excita o rotor (vibração auto-excitada) e esta excitação não é considerada no cálculo da FRF. No caso do sistema a $30 \mathrm{~Hz}$, os resultados são ligeiramente melhores que a $10 \mathrm{~Hz}$ pelo nível de vibração ser menor (autocentragem do eixo ao superar a $1^{\text {a }}$ velocidade crítica).

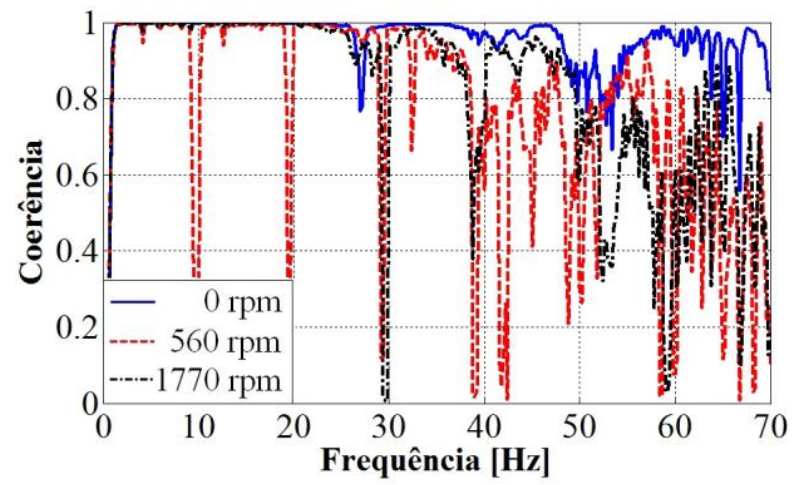

(a) coerência na horizontal (sensor \#1)

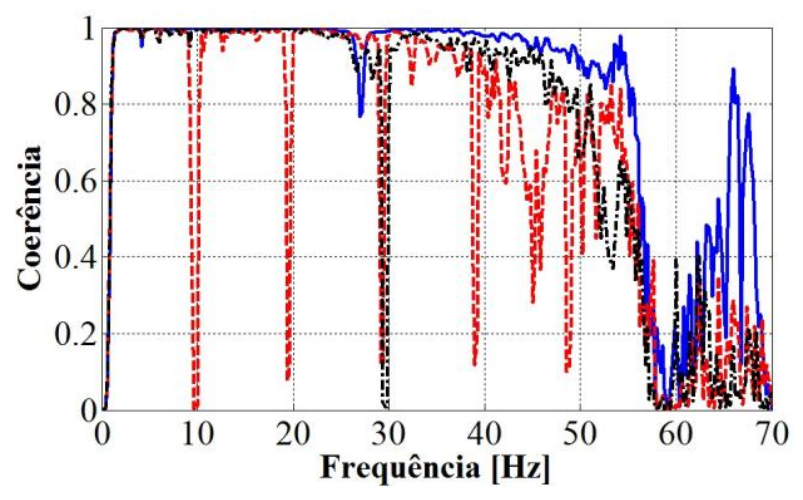

(c) coerência na horizontal (sensor \#2)

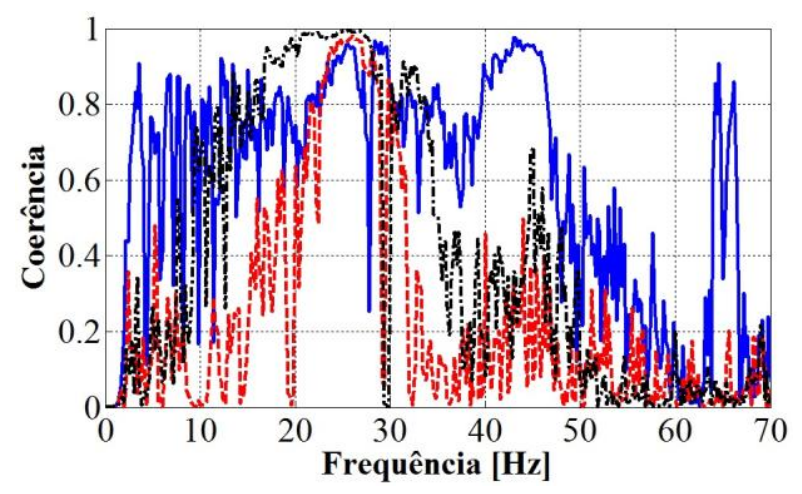

(b) coerência na vertical (sensor \#1)

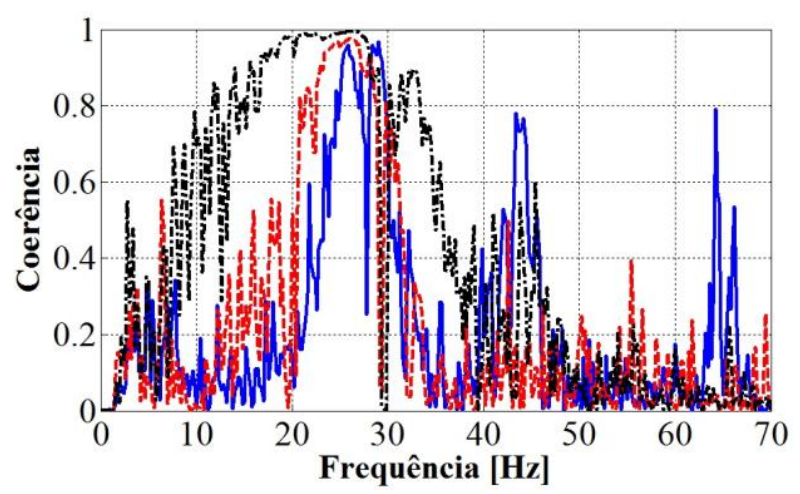

(d) coerência na vertical (sensor \#2)

Figura 4.20: Função coerência ordinária para as FRFs da Figura 4.19. 


\section{Capítulo 5}

\section{Implantação experimental da técnica de controle}

Neste capítulo, a técnica de controle apresentada no Capítulo 3 é implementada experimentalmente para a bancada de testes em estudo nas configurações com um disco (Figura 4.5) e com dois discos (Figura 4.6). Tem-se por objetivo atenuar as vibrações na direção horizontal e, no caso do sistema com dois discos, a malha de controle é realimentada com o deslocamento na horizontal medido pelo sensor \#1. Neste sentido, as FRFs consideradas para o projeto do sistema de controle são as apresentadas na Figura 4.15 (a) (sistema com um disco) e na Figura 4.18 (a) (sistema com dois discos).

A partir das Equações (3.12) a (3.14), as quais correspondem às três condições da Decomposição-d (Equações (3.3) a (3.5)) escritas em função da reposta em frequência da planta para um controlador do tipo PD em sua forma clássica (Teorema 3.1), decompõe-se o plano $\left(K_{D}, K_{P}\right)$ em regiões tais que, para cada uma delas, todos os ganhos resultam em um mesmo número de polos estáveis e instáveis para o sistema em malha fechada (regiões de ganhos invariáveis). O critério de estabilidade de Nyquist é então utilizado a fim de se determinar quais destas regiões são do tipo $D(n, 0)$, isto é, implicam em $n$ polos estáveis e zero polos instáveis para o sistema em malha fechada (regiões de estabilização).

Uma vez determinados os ganhos do controlador proporcional-derivativo que garantem a estabilidade do sistema para uma faixa de velocidades do eixo considerada, a Equação (3.29) é aplicada a fim de se conhecerem os valores dos ganhos que minimizam a amplitude do pico de ressonância, com o objetivo de atenuar as vibrações laterais do eixo. Por fim, o sistema de controle é implantado experimentalmente, e as FRFs do sistema rotativo contro- 
lado são levantadas e comparadas com as originais. Os resultados obtidos permitem verificar a eficiência da técnica de controle estudada, sendo, no próximo capítulo, o procedimento para obtenção da resposta do sistema e projeto do controlador executado de forma automática a partir de um algoritmo de autoidentificação, visando o controle autônomo de vibrações do sistema rotativo.

\subsection{Sistema rotativo com um disco}

Nesta seção, os ganhos do controlador PD que estabilizam o sistema com um disco e atenuam o seu nível de vibrações laterais são calculados, e a estratégia de controle é implantada experimentalmente.

\subsubsection{Análise de estabilidade}

Aplicando-se o Teorema 3.1 para o sistema com um disco girando a velocidade de 880 rpm, obtêm-se as regiões de ganhos invariáveis apresentadas na Figura 5.1. Deste modo, temse o espaço formado pelos ganhos do controlador divido em regiões (I, II e III) que resultam em um número fixo de pólos estáveis e instáveis para o sistema em malha fechada girando a esta velocidade.

A linha reta foi obtida através da aplicação da Equação (3.12) e a curva através da Equação (3.13), as quais correspondem, respectivamente, a fronteira da raiz real (real root boundary - RRB) e a fronteira da raiz complexa (complex root boundary - CRB). No caso, a fim de se aplicar a Equação (3.12), considerou-se $|P(\omega=1)| \cong P(0)$ (pois o sistema foi excitado em um faixa de frequências de $1 \mathrm{a} 40 \mathrm{~Hz})$ e, como $\lim _{\omega \rightarrow \infty} P(j \omega)=0$, a Equação (3.14) não é aplicável (fronteira da raiz infinita).

Para as velocidades do eixo de 0, 560 e 2080 rpm, têm-se as regiões de ganhos invariáveis apresentadas na Figura 5.2. Uma vez que a FRF do sistema não se altera significativamente com a velocidade de rotação (apenas quando se compara o sistema parado e em movimento) (Figura 4.16 (a)), as regiões obtidas para o rotor girando a 560 e $2080 \mathrm{rpm}$ são semelhantes. De modo a se testar a estabilidade do sistema em malha fechada, cinco conjuntos de ganhos foram tomados na Figura 5.2 - pontos A, B, C, D e E (Tabela 5.1). 


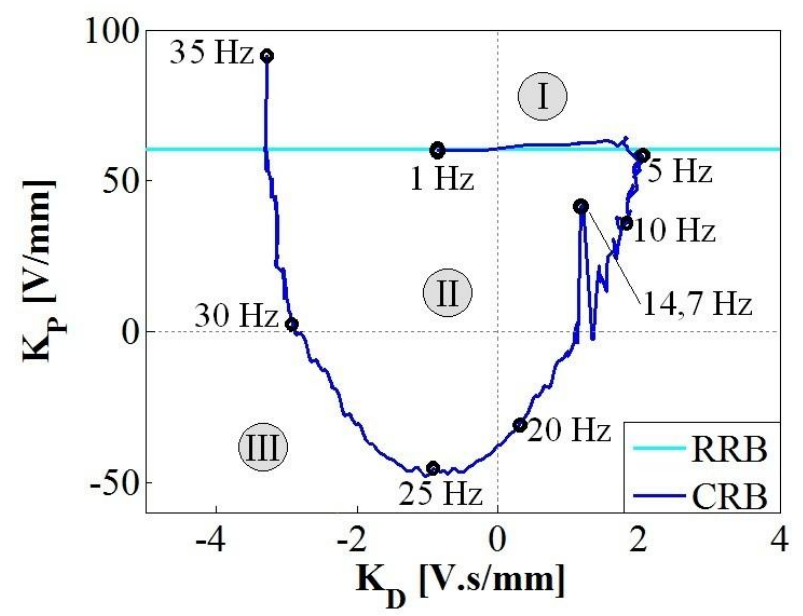

Figura 5.1: Regiões de ganhos invariáveis para $\Omega=880 \mathrm{rpm}$ (o pico observado para a frequência de 14,7 Hz é devido à harmônica da FRF - componente B na Figura 4.15 (a)).

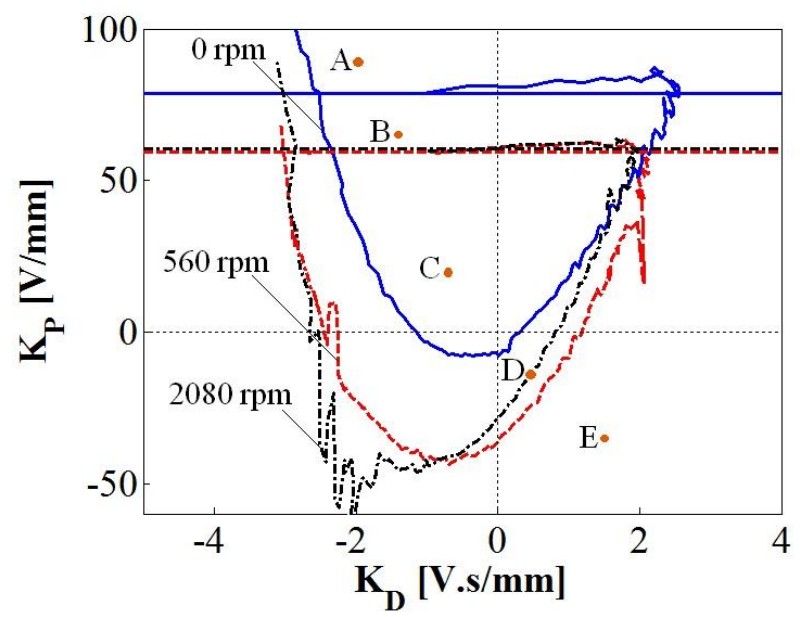

Figura 5.2: Regiões de ganhos invariáveis para $\Omega=0,560$ e $2080 \mathrm{rpm}$.

Tabela 5.1: Conjuntos de ganhos selecionados na Figura 5.2 para testar a estabilidade do sistema em malha fechada.

\begin{tabular}{|c|c|c|c|c|c|}
\hline \hline Ponto & A & B & C & D & E \\
\hline \hline$K_{D}[\mathrm{~V} . \mathrm{s} / \mathrm{mm}]$ & -2 & $-1,4$ & $-0,7$ & 0.39 & 1.5 \\
\hline$K_{P}[\mathrm{~V} / \mathrm{mm}]$ & 90 & 65 & 20 & $-16,32$ & -35 \\
\hline
\end{tabular}

Escrevendo-se o polinômio característico do sistema (Equação (3.9)) como

$$
\pi(j \omega)=1+C(j \omega) P(j \omega)=1+L(j \omega)
$$


tem-se que o gráfico de $L(j \omega)$ traçado em termos de sua parte real e imaginária (conhecido como contorno de Nyquist) permite determinar se o sistema em malha fechada é estável ou não a partir do critério de estabilidade de Nyquist, que pode ser enunciado como (Dorf e Bishop, 2009):

"Um sistema realimentado será estável se, e somente se, o número de envolvimentos realizados pelo contorno de Nyquist no sentido anti-horário em torno do ponto $(-1,0)$ for igual ao número de polos da planta com parte real positiva."

Assim, para cada um dos pontos selecionados na Figura 5.2, tem-se os diagramas de Nyquist apresentados na Figura 5.3. Como o sistema rotativo em malha aberta é estável, os ganhos que estabilizam o sistema em malha fechada são aqueles cujo respectivo contorno de Nyquist não envolve o ponto $(-1,0)$.

Para o ponto A, o sistema em malha fechada é instável para as três velocidades consideradas (Figura 5.3 (a)), pois os seus respectivos contornos envolvem o ponto $(-1,0)$. Para o ponto B, o sistema em malha fechada é estável apenas para o sistema parado (neste caso, o ponto testado está abaixo da RRB e acima da CRB) - Figura 5.3 (b). Para o ponto C, o qual está abaixo da RRB e acima da CRB para as três velocidades consideradas, o sistema em malha fechada é estável nos três casos (Figura 5.3 (c)). Para o ponto D (Figura 5.4 (d)), o sistema em malha fechada para a velocidade de $0 \mathrm{~Hz}$ é instável e estável para a velocidade de 560 rpm. No caso da velocidade de 2080 rpm, o sistema em malha fechada é criticamente estável, pois o contorno de Nyquist passa sobre o ponto $(-1,0)$, o que é coerente com o esperado, uma vez que, para esta velocidade, tem-se que o Ponto D está situado sobre a fronteira da raiz complexa (o que implica que o sistema em malha fechada tem um par de pólos complexos conjugados situados sobre o eixo imaginário). Finalmente, para o ponto E o sistema em malha fechada é instável para as três velocidades consideradas (Figura 5.4 (e)).

Deste modo, tendo-se em vista os resultados obtidos através do Critério de Nyquist e sabendo-se que, se um ponto dentro de uma região de ganhos estabiliza o sistema, então todos os outros pontos situados dentro desta mesma região também possuem essa propriedade (pois o plano formado pelos ganhos do controlador é dividido em regiões que correspondem a um número fixo de pólos para o sistema em malha fechada), tem-se que os pontos situados nas regiões acima da $\mathrm{CRB}$ e abaixo da RRB, i.e., na área correspondente à região II (Figura 5.1), estabilizam o sistema (regiões de estabilização). 


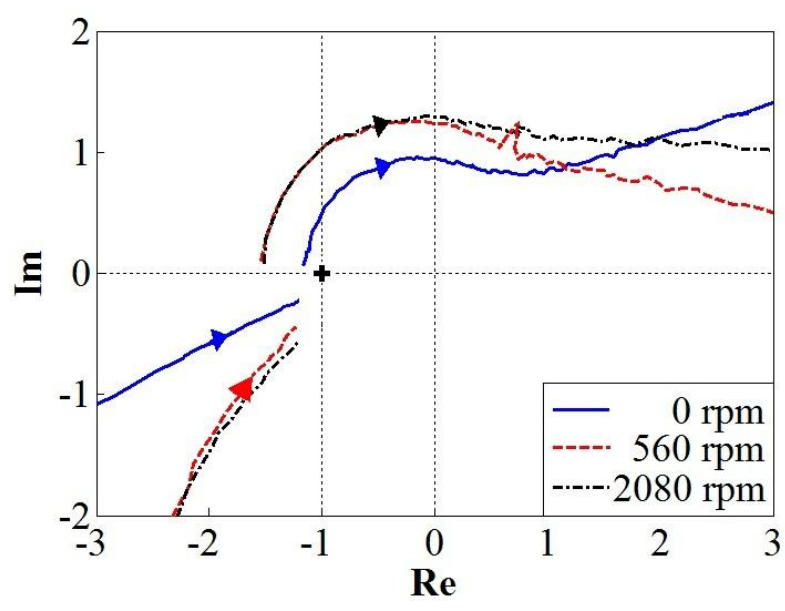

(a) ponto $\mathrm{A}$

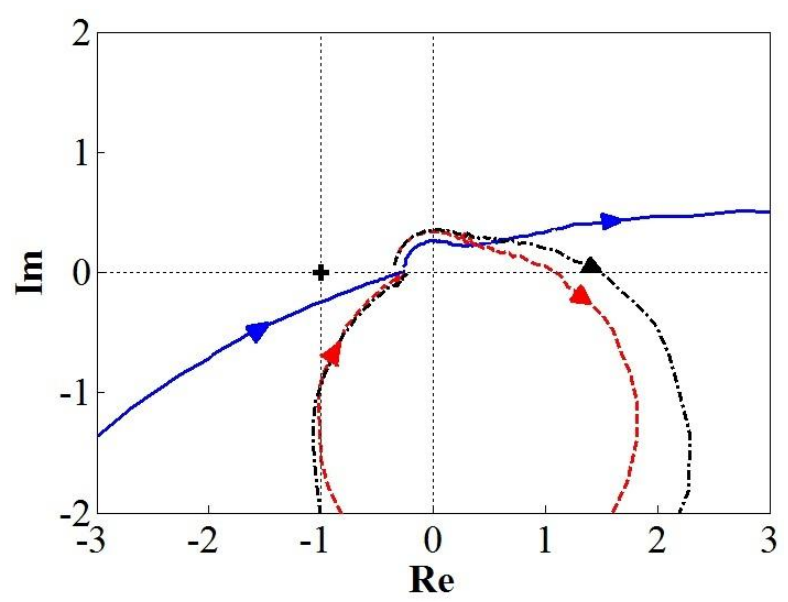

(c) ponto $\mathrm{C}$

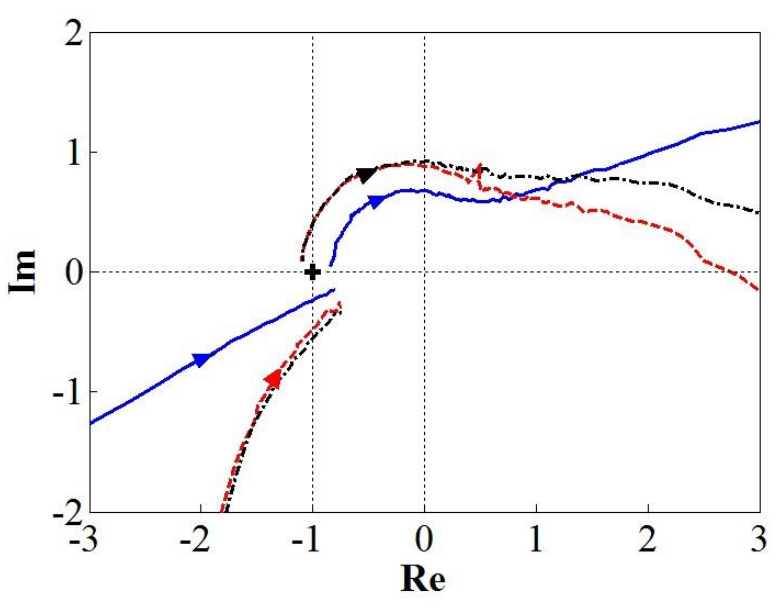

(b) ponto B

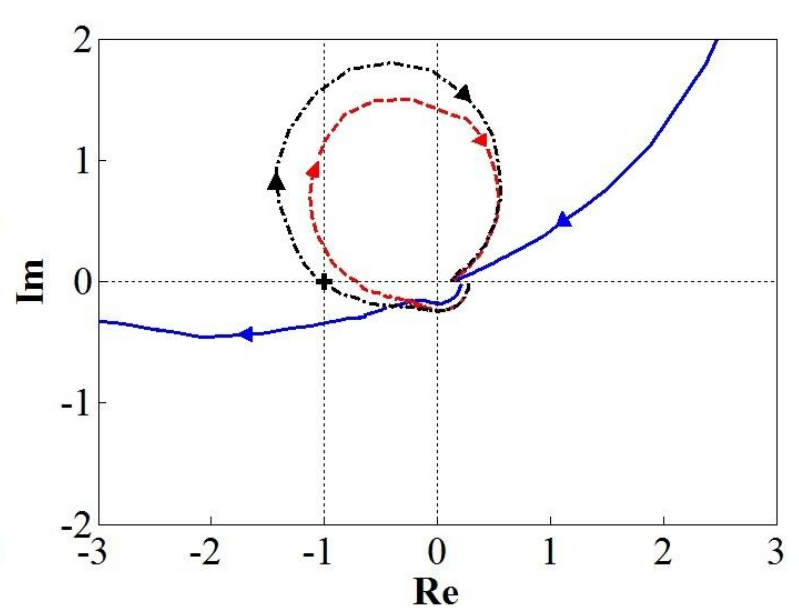

(d) ponto $\mathrm{D}$

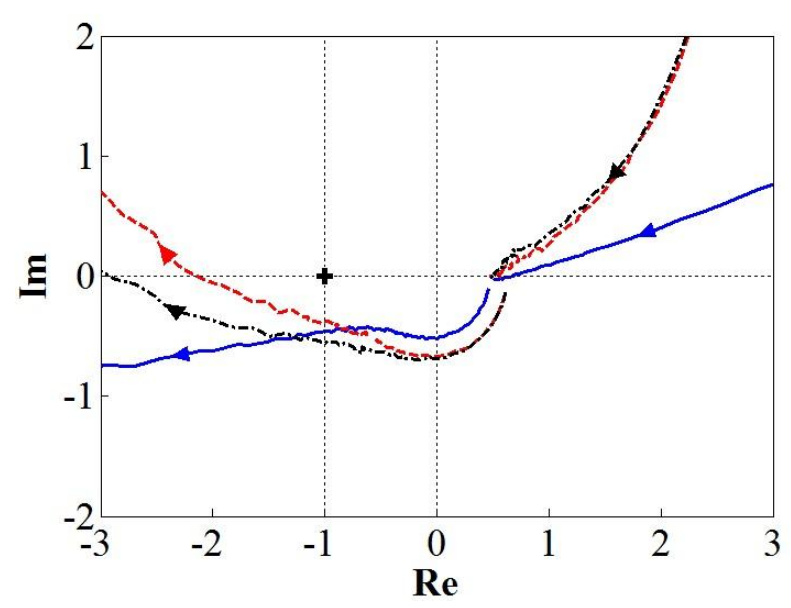

(e) ponto $\mathrm{E}$

Figura 5.3: Contornos de Nyquist para os conjuntos de ganhos selecionados na Figura 5.2. 
Assim, sabendo-se que a região II é a que estabiliza o sistema o sistema em malha fechada, calculam-se as regiões de ganhos invariáveis para cada uma das FRFs apresentadas na Figura 4.15 (a). Determinando-se a intersecção entre a área situada acima da CRB e abaixo da RRB para cada uma destas regiões, tem-se uma região que garante a estabilidade do sistema com um disco em malha fechada para a faixa de velocidades de rotação do eixo considerada, 0 a 2080 rpm, denominada região de estabilização (Figura 5.4 (a)).

Selecionam-se pontos nesta região (Figura 5.4 (b)) a fim de se determinar quais destes ganhos estáveis minimizam a amplitude do pico de ressonância, de forma a se assegurar estabilidade e desempenho do sistema em malha fechada. Os ganhos selecionados assumem valores tais que $-0,7<K_{D}<0,1$ e $-3<K_{P}<3$, e a adoção de valores mais elevados resulta na saturação das portas de saída D/A da placa de aquisição de dados $( \pm 10 \mathrm{~V})$, sendo, por isso, considerados apenas estes intervalos de valores para os ganhos proporcional e derivativo na análise de desempenho.

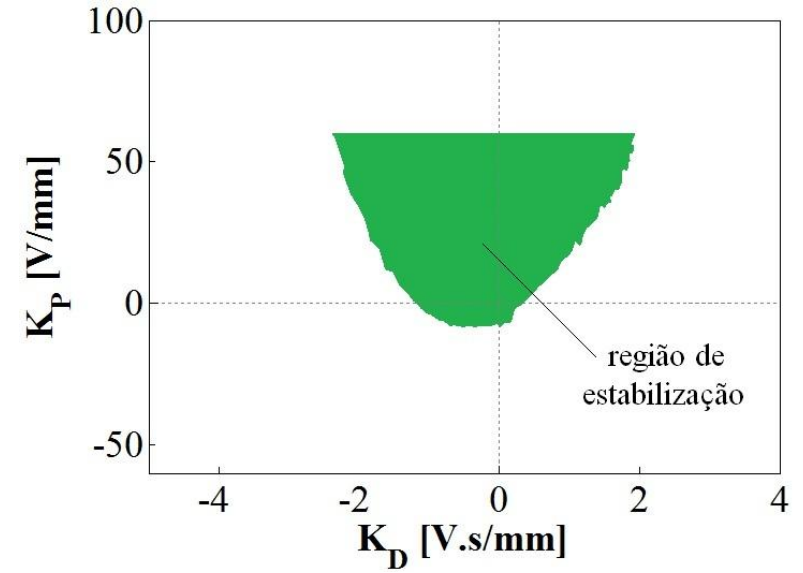

(a) região de estabilização

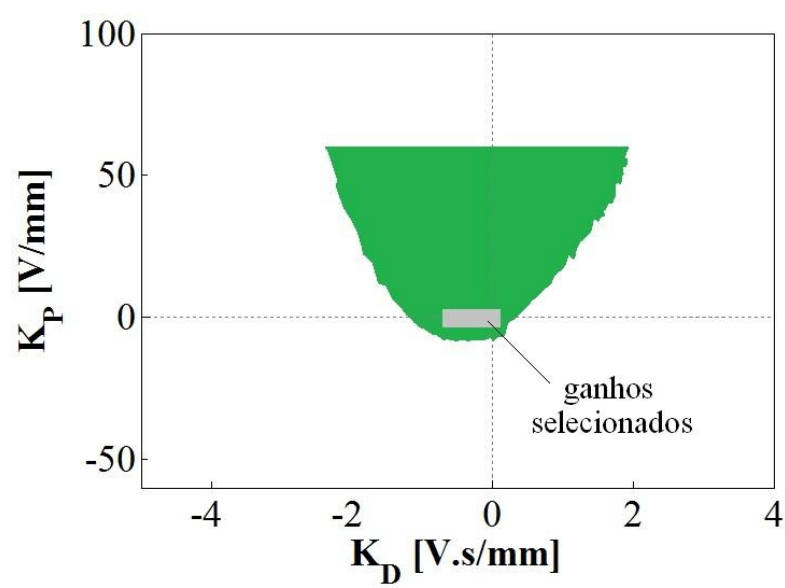

(b) ganhos estáveis selecionados

Figura 5.4: Valores dos ganhos do controlador PD que garantem a estabilidade do sistema com um disco em malha fechada para uma faixa de velocidades de rotação de 0 a $2080 \mathrm{rpm}$.

\subsubsection{Critério de desempenho}

Para os ganhos selecionados dentro da região de estabilização (Figura 5.4 (b)), varia-se o valor de $K_{D}$ e $K_{P}$ na Equação (3.29). Para cada valor destes ganhos, determina-se o valor máximo do módulo da função de transferência do sistema em malha fechada, i.e., a amplitude do pico de ressonância, $M_{r}$ (a análise é limitada à faixa de frequências que contém o pico de ressonância, de modo que o pico de harmônica não seja considerado). A Figura 5.5 ilustra 
como os ganhos proporcional e derivativo influenciam na amplitude do pico para as velocidades de rotação do eixo de 560, 1020, 1620 e 2080 (os valores de amplitude são traçados na forma de curvas de nível em função dos ganhos).

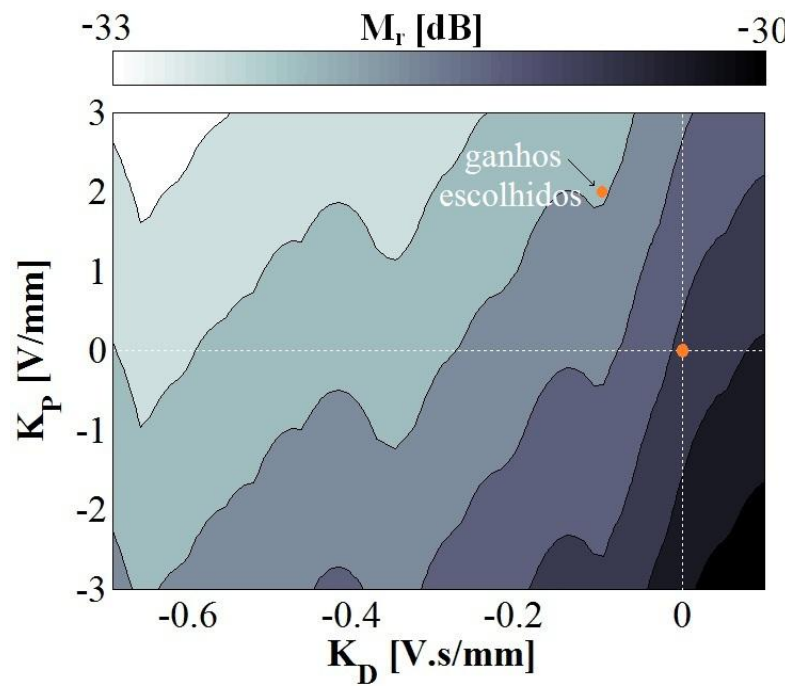

(a) $\Omega=560 \mathrm{rpm}$

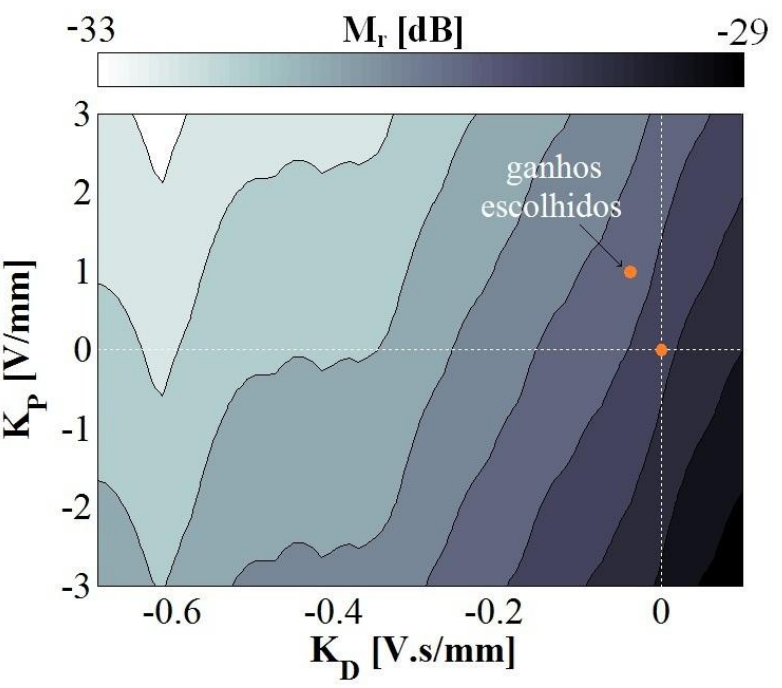

(b) $\Omega=1180 \mathrm{rpm}$

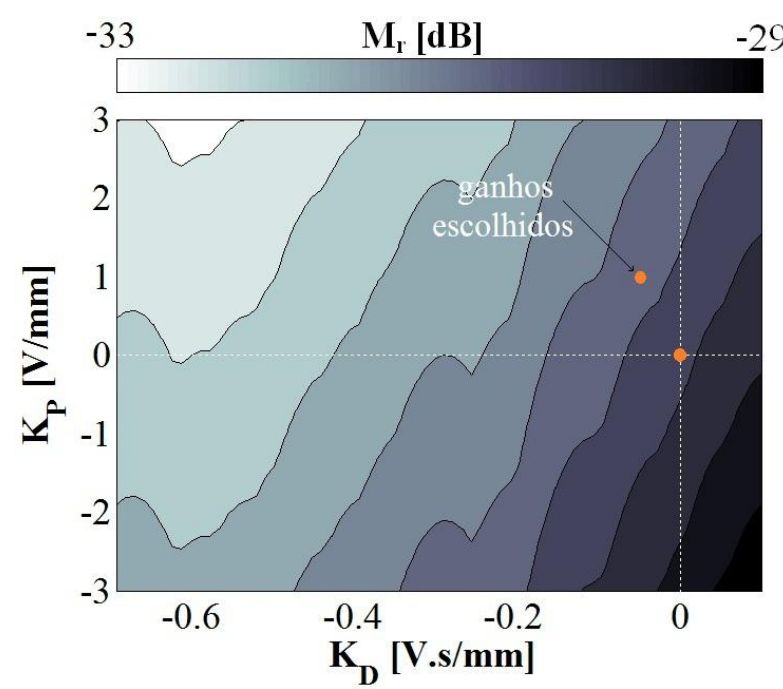

(c) $\Omega=1460 \mathrm{rpm}$

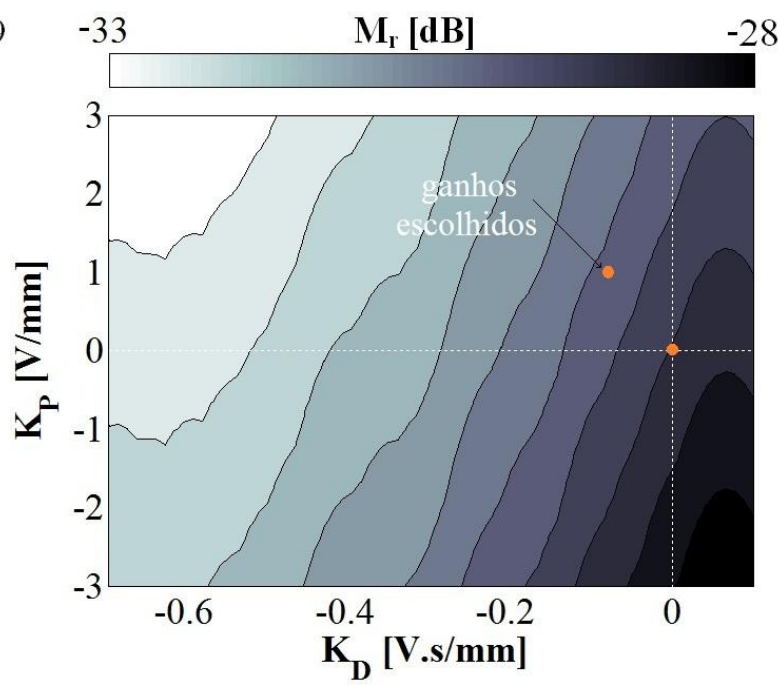

(d) $\Omega=2080 \mathrm{rpm}$

Figura 5.5: Valor esperado da amplitude do pico de ressonância em função dos valores dos ganhos do controlador.

O ponto $(0,0)$ na Figura 5.5 corresponde ao valor original da amplitude do pico de ressonância (sistema não controlado) e o valor dos ganhos escolhidos para a implantação do sistema de controle são os maiores possíveis de modo a não ocorrer saturação da porta de 
saída D/A da placa de aquisição para cada caso. Observa-se, em todos os casos analisados, a mesma tendência de minimização do pico: $K_{D}<0$ e $K_{P}>0$.

A fim de se implementar o sistema de controle, realimenta-se o programa em MatLab Simulink desenvolvido para excitação e aquisição da resposta do sistema (Figura 4.13) com as informações de deslocamento medido na direção horizontal (Figura 5.6). O sinal de controle é então somado ao de excitação (sinal chirp), conforme a configuração do sistema de controle realimentado apresentada na Figura 3.2. Assim como o filtro, o elemento derivativo também está no domínio discreto (tempo de amostragem é de $10^{-3} \mathrm{~s}$ ).

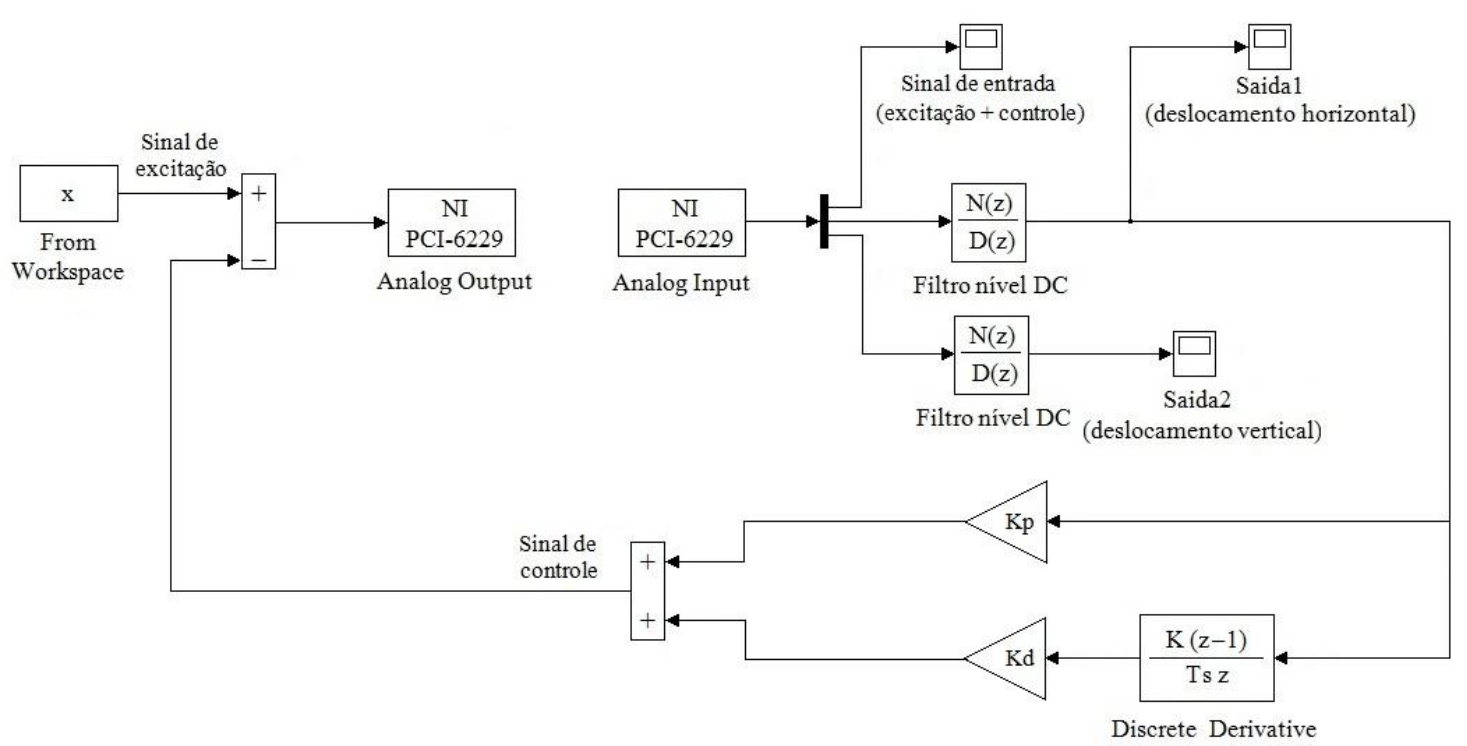

Figura 5.6: Programa em MatLab Simulink para excitação, controle e aquisição da resposta do sistema em malha fechada.

Os ganhos escolhidos para cada velocidade de rotação do eixo (Figura 5.5) são então implementados, e as FRFs do sistema (não controlado e controlado), bem como o valor estimado da amplitude do pico ressonância e o medido, são comparados (Figura 5.7). Os valores dos ganhos e a amplitude do pico são sumarizados na Tabela 5.2.

Embora seja teoricamente possível reduzir a amplitude do pico a patamares em torno de -33 dB com a implantação do sistema de controle (Figura 5.5), na prática isto não ocorre devido a limitações físicas (tensão enviada ao drive dos atuadores não pode exceder $\pm 10 \mathrm{~V}$ ). Neste sentido, a utilização de eletromagnetos com maior capacidade de atuação permitiria maior atenuação do nível de vibrações. 


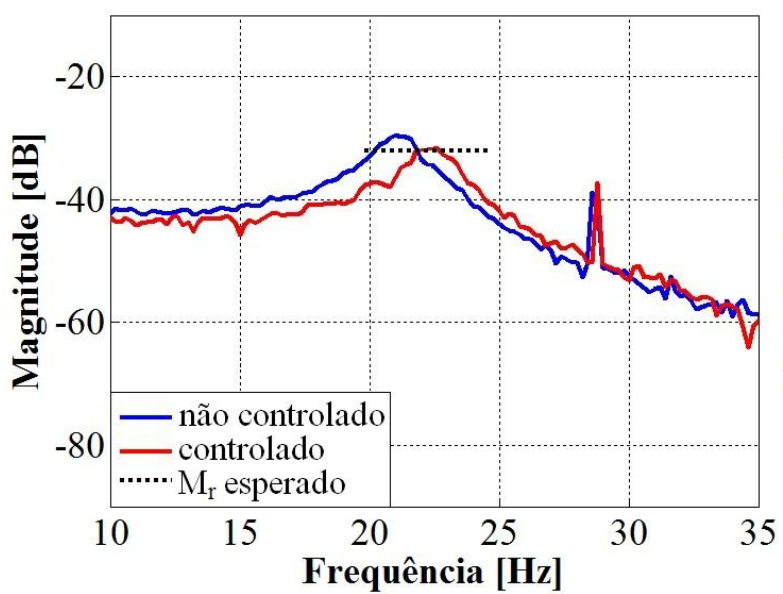

(a) $\Omega=560 \mathrm{rpm}$

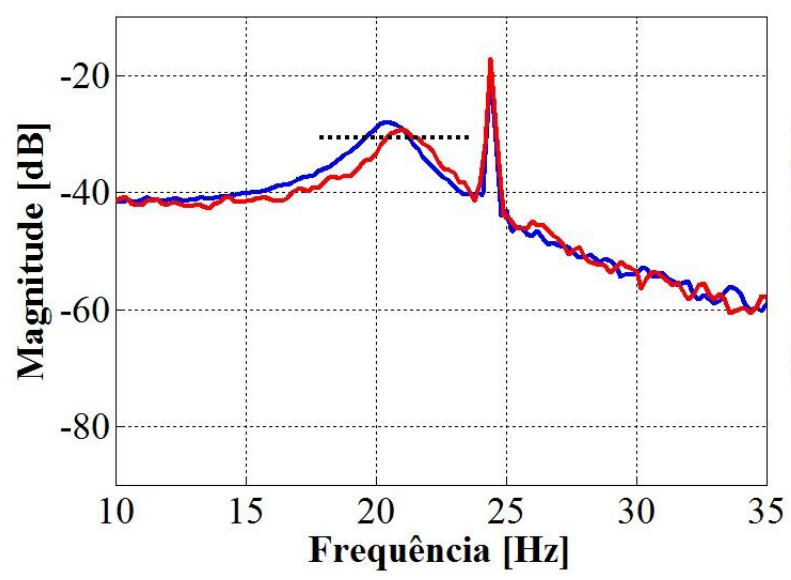

(c) $\Omega=1460 \mathrm{rpm}$

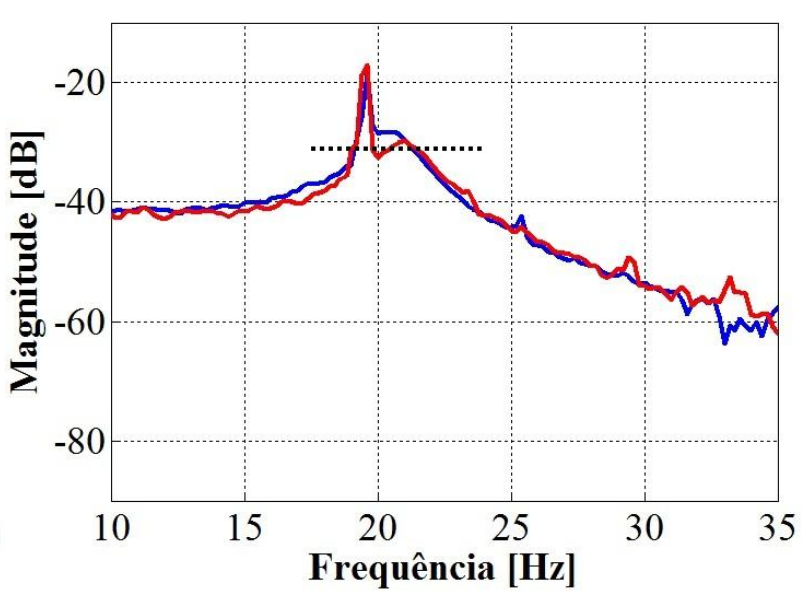

(b) $\Omega=1180 \mathrm{rpm}$

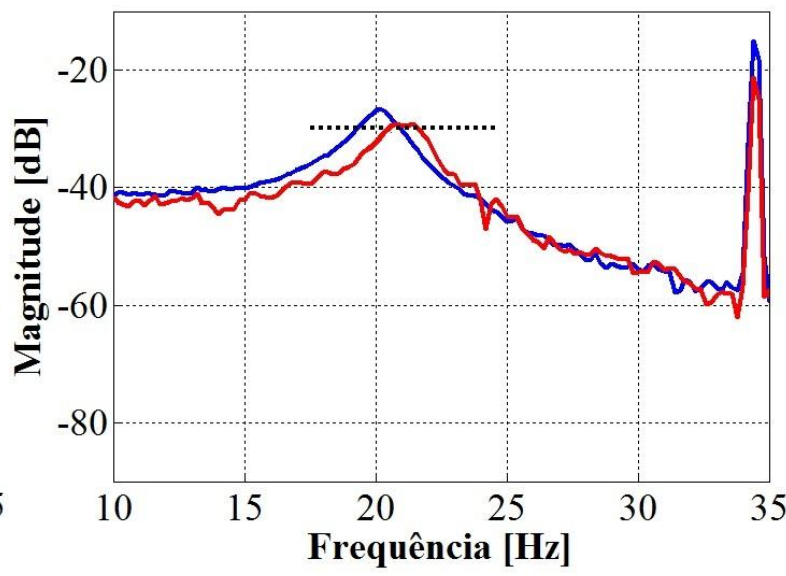

(d) $\Omega=2080 \mathrm{rpm}$

Figura 5.7: Comparação entre a amplitude do pico de ressonância na direção horizontal (sistema não controlado, controlado e valor esperado).

Tabela 5.2: Valores dos ganhos do controlador e amplitude do pico de ressonância.

\begin{tabular}{|c|c|c|c|c|c|}
\hline \hline $\begin{array}{c}\mathbf{\Omega} \\
{[\mathbf{r p m}]}\end{array}$ & $\begin{array}{c}\mathbf{K}_{\mathbf{D}} \\
{[\mathbf{V . s} / \mathbf{m m}]}\end{array}$ & $\begin{array}{c}\mathbf{K}_{\mathbf{P}} \\
{[\mathbf{V} / \mathbf{m m}]}\end{array}$ & $\begin{array}{c}\mathbf{M}_{\mathbf{r}} \mathbf{n a ̃ o} \text { controlado } \\
{[\mathbf{d B}]}\end{array}$ & $\begin{array}{c}\mathbf{M}_{\mathbf{r}} \text { esperado } \\
{[\mathbf{d B}]}\end{array}$ & $\begin{array}{c}\mathbf{M}_{\mathbf{r}} \text { controlado } \\
{[\mathbf{d B}]}\end{array}$ \\
\hline 560 & $-0,10$ & 2 & $-29,55$ & $-32,05$ & $-31,56$ \\
\hline 1180 & $-0,04$ & 1 & $-28,21$ & $-31,23$ & $-29,76$ \\
\hline 1460 & $-0,05$ & 1 & $-27,84$ & $-30,65$ & $-29,12$ \\
\hline 2080 & $-0,08$ & 1 & $-26,66$ & $-29,87$ & $-29,09$ \\
\hline
\end{tabular}

Observando-se a Figura 5.7, verifica-se maior atenuação do pico de ressonância para as velocidades de 560 e $2080 \mathrm{rpm}$ (o que pode ser explicado pela adoção de valores mais elevados dos ganhos do controlador) e, além disso, para estas velocidades, a diferença 
percentual $^{4}$ entre o valor medido do pico ( $M_{r}$ controlado) em relação ao seu valor estimado ( $M_{r}$ esperado) foi menor (Tabela 5.3).

Tabela 5.3: Redução percentual estimada e medida para o pico de ressonância e erro entre o valor medido em relação ao estimado.

\begin{tabular}{|c|c|c|c|}
\hline \hline $\boldsymbol{\Omega}$ [rpm] & Redução estimada [\%] & Redução real [\%] & Erro [\%] \\
\hline \hline 560 & 25,0 & 20,7 & 5,8 \\
\hline 1180 & 29,4 & 16,3 & 18,4 \\
\hline 1460 & 27,6 & 13,7 & 19,3 \\
\hline 2080 & 30,9 & 24,4 & 9,4 \\
\hline
\end{tabular}

Uma hipótese para explicar o fato de o erro ser maior para $\Omega=1180$ e $1460 \mathrm{rpm}(19,7$ e 24,3 Hz respectivamente) é que, para estas velocidades, o nível de vibração lateral do rotor é maior, pois o sistema opera em uma frequência de rotação mais próxima da que ocorre a ressonância (em torno de $22 \mathrm{~Hz}$ ). Assim, por acreditar-se que a ação derivativa do MatLab Simulink não é capaz de derivar o sinal medido com precisão, tem-se maior erro entre o valor estimado de $M_{r}$ e o medido quando o eixo gira à velocidades próximas da ressonância, pois a imprecisão gerada por esta ação torna-se mais expressiva (o valor do deslocamento medido é maior - Figura 5.6).

No caso do deslocamento medido na direção vertical, as FRFs do sistema (não controlado e controlado) são ilustradas na Figura 5.8, e os valores do pico de ressonância são apresentados na Tabela 5.4. Para as velocidades de 1460 e 2080 rpm não se verificam variações significativas na amplitude do pico, o que não ocorre para as velocidades de 560 e 1180 rpm (em torno de 50\%). Entretanto, dada a alta relação ruído/sinal, não é possível determinar o valor de $M_{r}$ de forma precisa para esta direção, pois os picos de ressonância se apresentam distorcidos, e, uma vez que, para esta configuração do sistema, a qual possui 1 gdl, não há

\footnotetext{
${ }^{4}$ Neste trabalho, esta diferença é definida como "erro", pois reflete quanto o valor medido do pico de ressonância difere em relação ao seu valor estimado. A convenção de sinais adotada para este parâmetro é erro $>0$ se o valor real (medido) for maior que o esperado (calculado) e erro $<0$ se o valor real for menor que o esperado.
} 
acoplamento entre as direções e é de se esperar que a atenuação das vibrações na direção horizontal não interfira no comportamento do sistema na direção vertical.

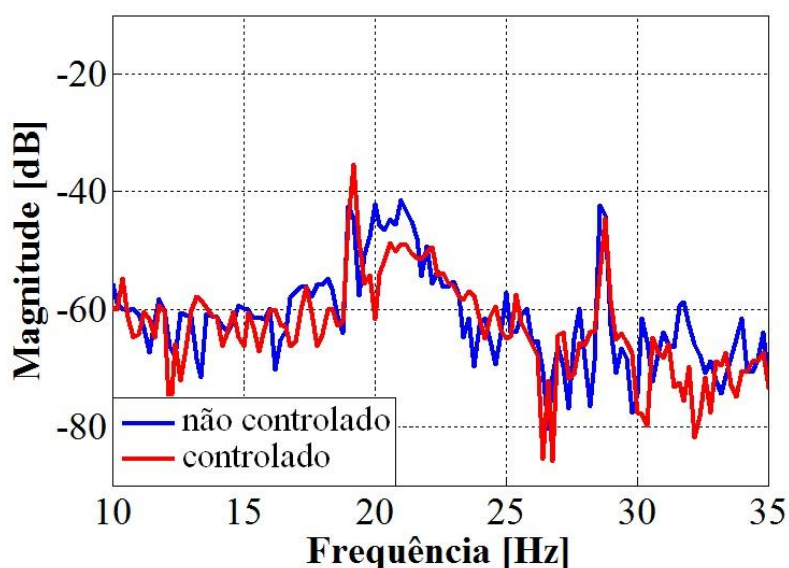

(a) $\Omega=560 \mathrm{rpm}$

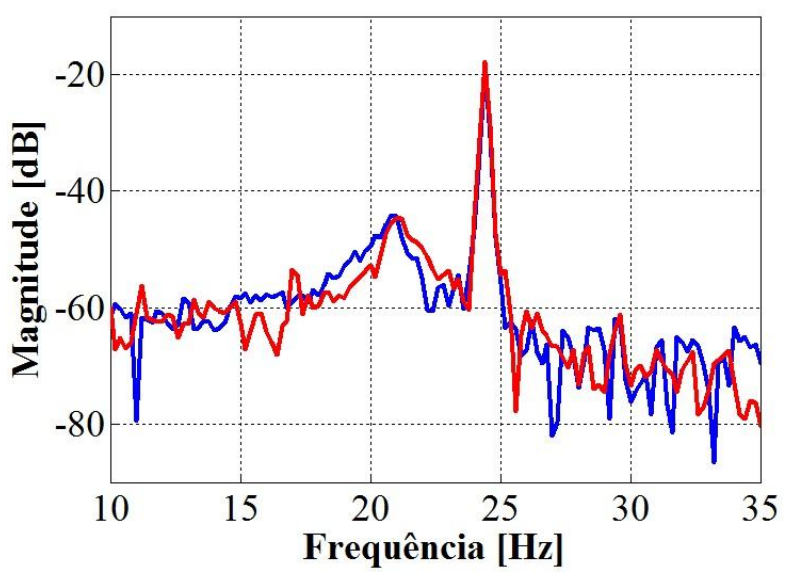

(c) $\Omega=1460 \mathrm{rpm}$

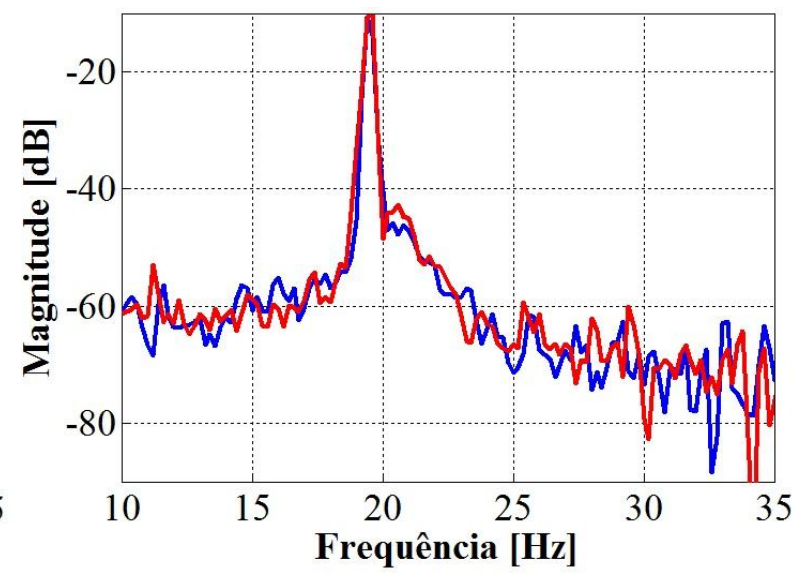

(b) $\Omega=1180 \mathrm{rpm}$

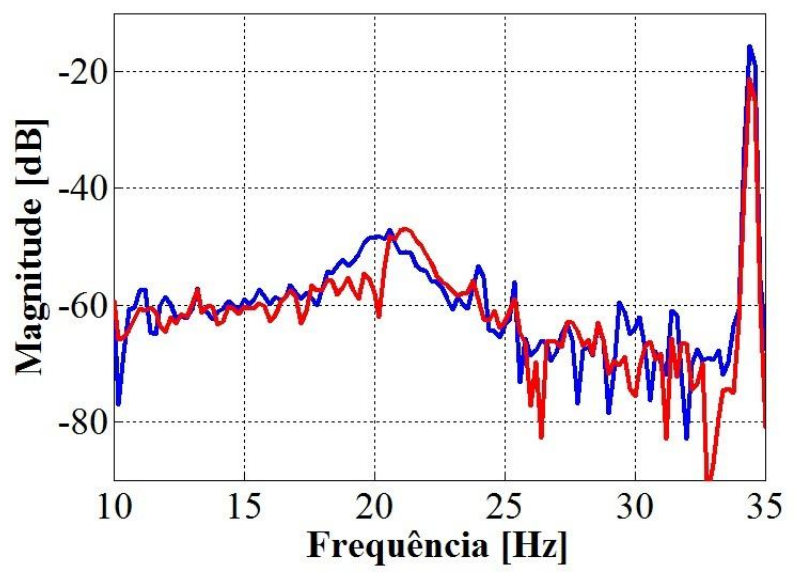

(d) $\Omega=2080 \mathrm{rpm}$

Figura 5.8: Comparação entre a amplitude do pico de ressonância na direção vertical (sistema não controlado e controlado).

Tabela 5.4: Amplitude do pico de ressonância (deslocamento na direção vertical).

\begin{tabular}{|c|c|c|c|}
\hline \hline$\Omega$ [rpm] & $M_{\mathbf{r}}$ não controlado [dB] & $M_{\mathbf{r}}$ controlado [dB] & Redução [\%] \\
\hline 560 & $-41,31$ & $-48,63$ & 56,9 \\
\hline 1180 & $-45,81$ & $-42,76$ & $-42,1$ \\
\hline 1460 & $-44,22$ & $-44,65$ & 4,8 \\
\hline 2080 & $-46,99$ & $-46,94$ & $-0,6$ \\
\hline
\end{tabular}




\subsection{Sistema rotativo com dois discos}

Nesta seção, os ganhos do controlador proporcional-derivativo que estabilizam o sistema com dois discos e atenuam o seu nível de vibrações laterais são calculados, e a estratégia de controle é implantada experimentalmente. Ao final, testa-se uma estratégia de controle do tipo $\mathrm{P}$ (proporcional) e os resultados obtidos para este controlador são comparados com os resultados para o controlador PD.

\subsubsection{Análise de estabilidade}

Aplicando-se o Teorema 3.1 para o sistema com dois discos girando a velocidade de 1770 rpm, obtêm-se as regiões de ganhos invariáveis apresentadas na Figura 5.9. Deste modo, tem-se o espaço formado pelos ganhos do controlador divido em regiões (I, II, III e IV) que resultam em um número fixo de pólos estáveis e instáveis para o sistema em malha fechada girando a esta velocidade.

A linha reta foi obtida através da aplicação da Equação (3.12) e a curva através da Equação (3.13), as quais correspondem, respectivamente, a fronteira da raiz real (real root boundary - RRB) e a fronteira da raiz complexa (complex root boundary - CRB). No caso, a fim de se aplicar a Equação (3.12), considerou-se $|P(\omega=1)| \cong P(0)$ (pois o sistema foi excitado em um faixa de frequências de 1 a $70 \mathrm{~Hz})$ e, como $\lim _{\omega \rightarrow \infty} P(j \omega)=0$, a Equação (3.14) não é aplicável (fronteira da raiz infinita).

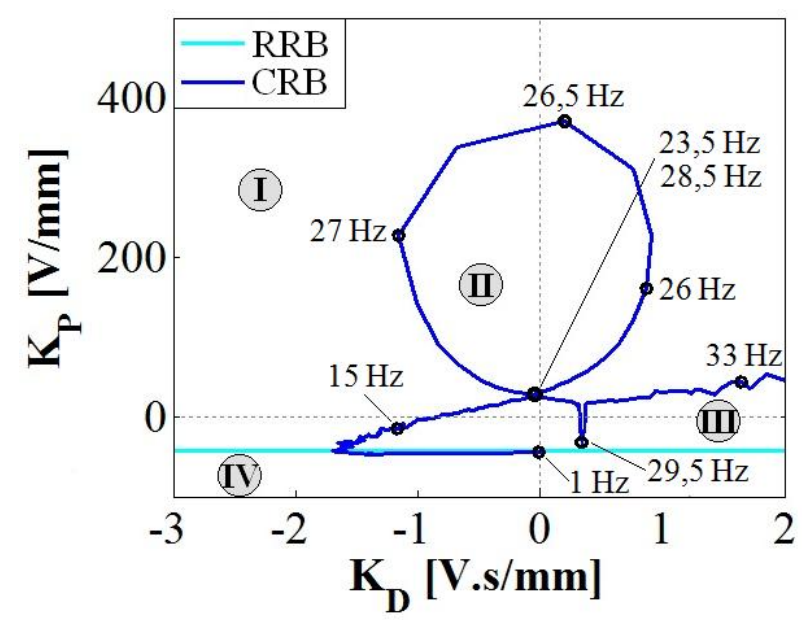

Figura 5.9: Regiões de ganhos invariáveis para $\Omega=1770 \mathrm{rpm}$ (o pico observado para a frequência de 29,5 Hz é devido à harmônica da FRF - componente $\mathbf{B}$ na Figura 4.18 (a)). 
Observando-se a Figura 5.9, verifica-se que, ao contrário do sistema com um disco, em que fronteira da raiz complexa está abaixo da fronteira real (Figura 5.1), a curva correspondente à $\mathrm{CRB}$ encontra-se acima da linha da RRB. Além disso, nota-se que a curva da CRB forma um loop, iniciando-se na frequência de $23,5 \mathrm{~Hz}$ e completando o envolvimento na frequência de $28,5 \mathrm{~Hz}$.

Estes valores de frequência equivalem, respectivamente, ao valor da frequência em que ocorrem o primeiro e segundo picos de ressonância decorrentes da bipartição do pico correspondente ao primeiro modo de vibrar do sistema (Figura 4.19 (a)), a qual ocorre quando o sistema está girando e é consequência do efeito giroscópico. Assim, tem-se que o loop formado pela CRB é decorrente deste fenômeno, pois os pontos que o constituem são os correspondentes à faixa de frequências situada entre o primeiro e o segundo picos associados ao primeiro modo de vibrar do sistema.

Para as velocidades do eixo de 0, 740, 1620 e $2080 \mathrm{rpm}$, têm-se as regiões de ganhos invariáveis apresentadas na Figura 5.10. No caso, nota-se que, para o rotor a 0 rpm, a sua respectiva região de ganhos invariáveis não apresenta loop, o que se deve ao fato de que, para o sistema parado, não ocorre bipartição do pico de ressonância (Figura 4.18). Além disso, verifica-se que o tamanho do loop aumenta conforme a velocidade de rotação. De modo a se testar a estabilidade do sistema em malha fechada, seis conjuntos de ganhos foram tomados na Figura 5.10 - pontos A, B, C, D, E e F (Tabela 5.5).

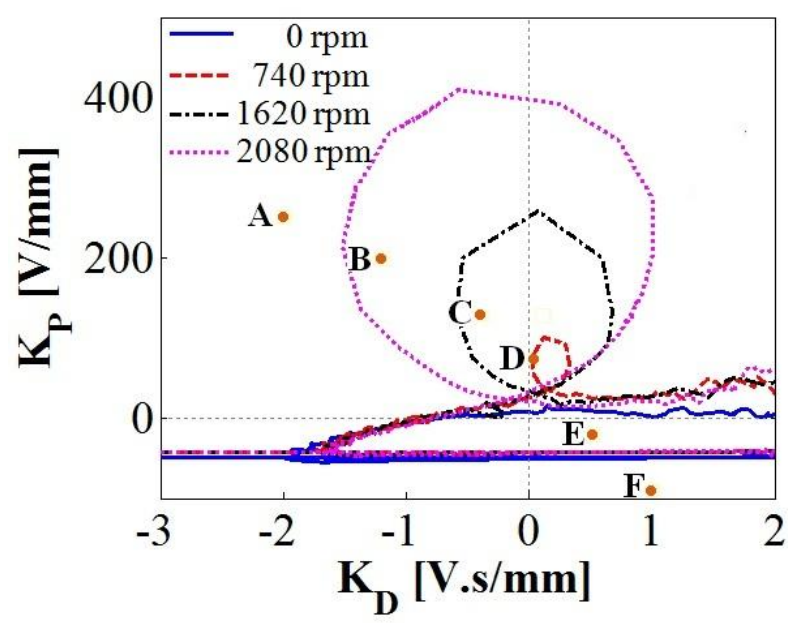

Figura 5.10: Regiões de ganhos invariáveis para $\Omega=0,740,1620$ e $2080 \mathrm{rpm}$. 
Tabela 5.5: Conjuntos de ganhos selecionados na Figura 5.10.

\begin{tabular}{|c|c|c|c|c|c|c|}
\hline \hline Ponto & A & B & C & D & E & F \\
\hline \hline$K_{D}[\mathrm{~V} . \mathrm{s} / \mathrm{mm}]$ & -2 & -1.2 & -0.4 & 0.019 & 0.5 & 1 \\
\hline$K_{P}[\mathrm{~V} / \mathrm{mm}]$ & 250 & 200 & 130 & 75,18 & -20 & -90 \\
\hline
\end{tabular}

Para cada conjunto de ganhos da Figura 5.10, tem-se os seus respectivos contornos de Nyquist apresentados na Figura 5.11. Para os pontos A, B, C e D, verifica-se que o sistema em malha fechada é instável para todas as velocidades de rotação consideradas, pois o contorno de Nyquist envolve o ponto $(-1,0)$ em todos os casos.

Nota-se que, quando o conjunto de ganhos testados encontra-se dentro de um loop para certa velocidade, o contorno de Nyquist apresenta um envolvimento adicional, sendo que para o ponto D, o qual está sobre o loop formado pela fronteira da raiz complexa do sistema a $740 \mathrm{rpm}$, este envolvimento adicional intercepta o ponto $(-1,0)$ para o sistema nesta velocidade (Figura $5.11(\mathrm{~d})$ ).

Para o caso do ponto E, o qual está situado acima da RRB e abaixo da CRB para todas as velocidades consideradas, tem-se que o sistema em malha fechada é estável (Figura 5.11 (e)). Para o ponto, F, o qual está abaixo da RRB, o sistema em malha fechada é instável (Figura $5.11(\mathrm{f})$ ).

Deste modo, tendo-se em vista os resultados obtidos através do Critério de Nyquist e sabendo-se que, se um ponto dentro de uma região de ganhos estabiliza o sistema, então todos os outros pontos situados dentro desta mesma região também possuem essa propriedade; temse que a região III da Figura 5.9, i.e., aquela situada acima da RRB e abaixo da RRB (excluindo-se o loop) corresponde à região de estabilização.

Assim, sabendo-se que a região III é a que estabiliza o sistema o sistema em malha fechada, calculam-se as regiões de ganhos invariáveis para cada uma das FRFs apresentadas na Figura 4.18 (a). Determinando-se a intersecção entre a área situada acima da RRB e abaixo da CRB para cada uma destas regiões (excluindo-se o loop), tem-se uma região que garante a estabilidade do sistema com dois discos em malha fechada para a faixa de velocidades de rotação do eixo considerada, 0 a 2080 rpm, apresentada na Figura 5.12 (a). 
Conhecidos os ganhos estáveis, selecionam-se ganhos na região de estabilização (Figura 5.12 (b)), os quais assumem valores tais que $-0,25<K_{D}<0,25$ e $-3<K_{P}<3$. A adoção de valores mais elevados resulta na saturação da porta de saída D/A da placa de aquisição, sendo, por isso, considerados apenas estes intervalos de valores para os ganhos proporcional e derivativo na análise de desempenho.

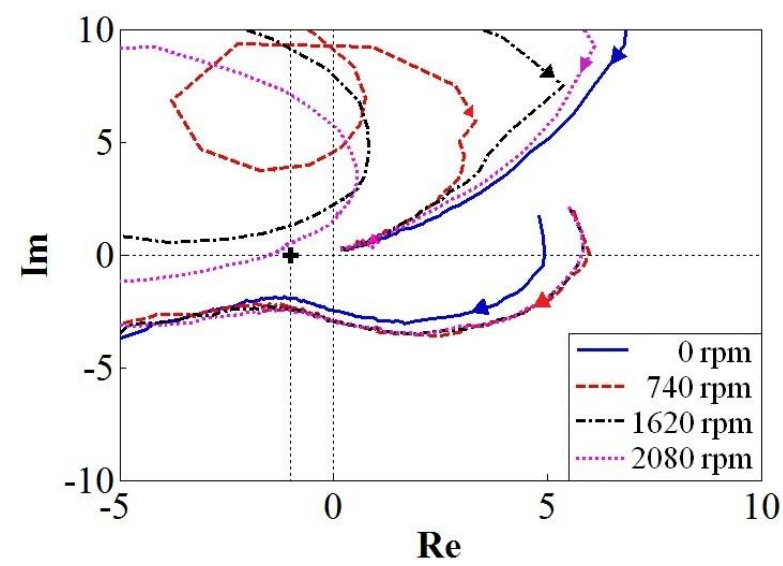

(a) ponto $\mathrm{A}$

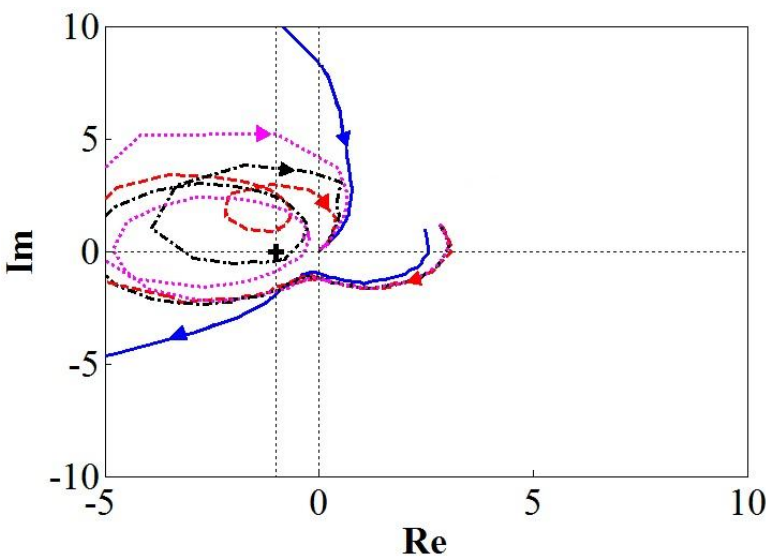

(c) ponto $\mathrm{C}$

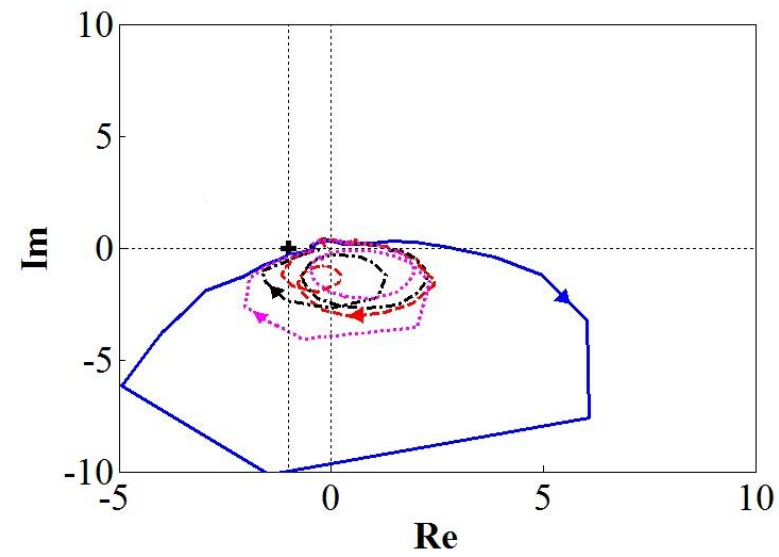

(e) ponto $\mathrm{E}$

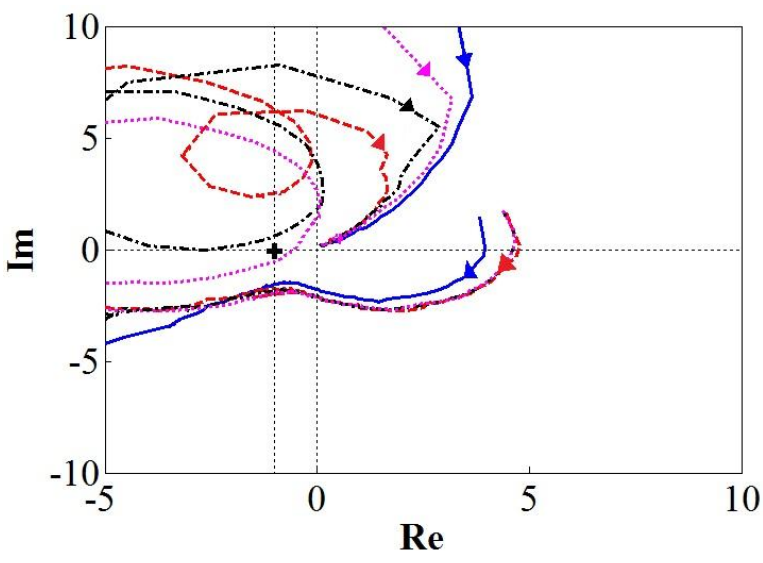

(b) ponto $\mathrm{B}$

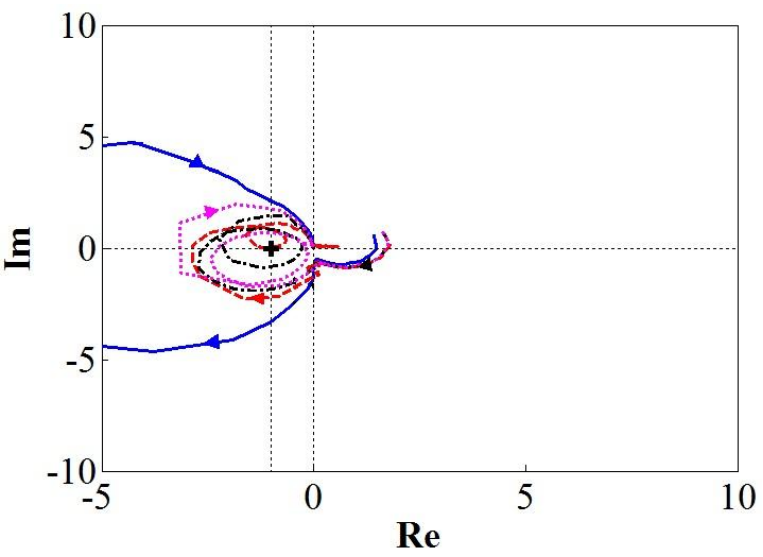

(d) ponto $\mathrm{D}$

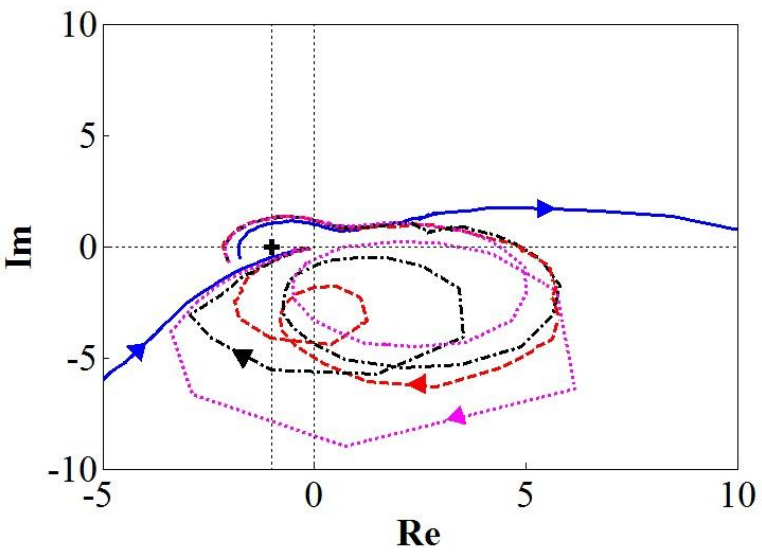

(f) ponto $\mathrm{F}$

Figura 5.11: Contornos de Nyquist para os conjuntos de ganhos selecionados na Figura 5.10. 


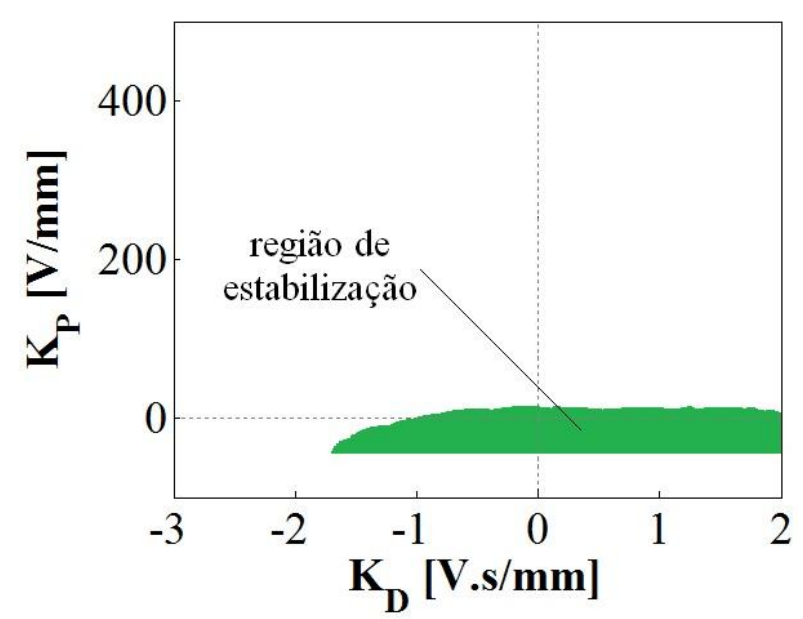

(a) região de estabilização

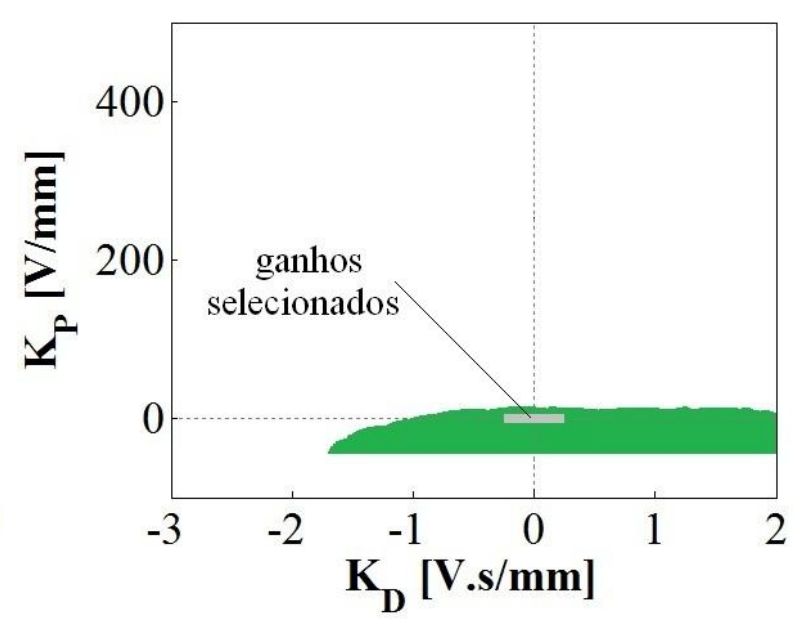

(b) ganhos estáveis selecionados

Figura 5.12: Valores dos ganhos do controlador PD que garantem a estabilidade do sistema com dois discos em malha fechada para uma faixa de velocidades de rotação de 0 a 2080 rpm.

\subsubsection{Critério de desempenho}

Para os ganhos selecionados dentro da região de estabilização (Figura 5.12 (b)), variase o valor de $K_{D}$ e $K_{P}$ na Equação (3.29). Para cada valor destes ganhos, determina-se o valor máximo do módulo da função de transferência do sistema em malha fechada (esta análise é limitada a faixa de frequências que contém os dois picos correspondentes ao $1^{\circ}$ modo de vibrar do sistema, sendo a variável $M_{r}$ correspondente a amplitude do maior dos dois picos). Assim, têm-se os valores esperados de $M_{r}$ obtidos através de simulação em computador (Figura 5.13).

Observando-se a Figura 5.13, verifica-se que para as velocidades abaixo da primeira velocidade crítica $(\Omega=280$ e $740 \mathrm{rpm})$, i.e., abaixo da velocidade correspondente ao primeiro pico de ressonância, a amplitude do maior dos dois picos tende a reduzir quando $K_{D}>0$ e $K_{P}<0$. Para $\Omega=1620 \mathrm{rpm}(27 \mathrm{~Hz})$, a qual é uma velocidade intercrítica (para este valor de frequência, a o valor da amplitude correspondente da FRF está situado entre os dois picos de ressonância), tem-se uma tendência de redução aproximadamente simétrica em relação à reta $K_{D}=-0,03$ para o ganho derivativo e, para o ganho proporcional, o valor de $M_{r}$ diminui para $K_{P}<0$. Finalmente, para $\Omega=2080 \mathrm{rpm}$ (velocidade supercrítica) tem-se uma inversão na tendência de redução do maior dos dois picos de ressonância para o ganho derivativo quando comparada à tendência para as velocidades subcríticas. Para esta velocidade, o pico 
diminui quando $K_{D}<0$ e, no caso do ganho proporcional, a tendência é a mesma que a verificada para as demais rotações $\left(K_{P}<0\right)$.

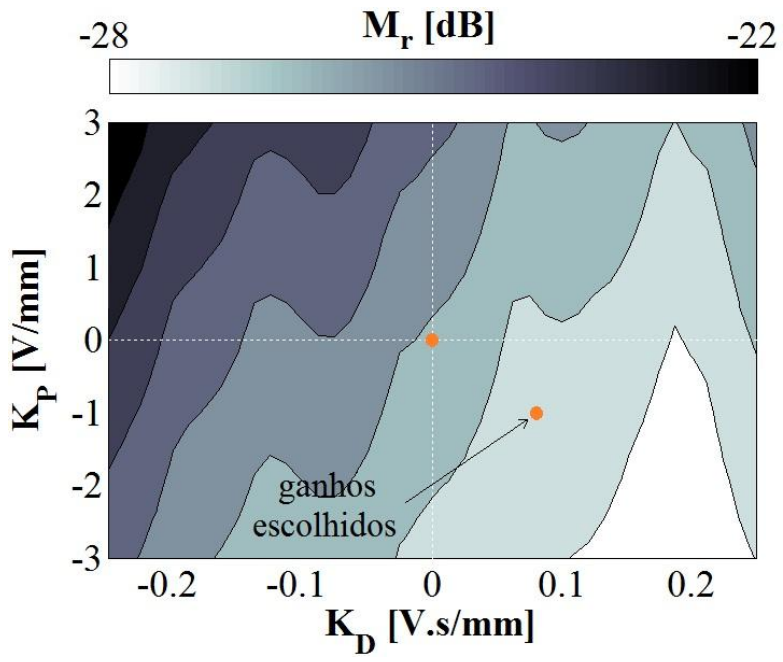

(a) $\Omega=280 \mathrm{rpm}$

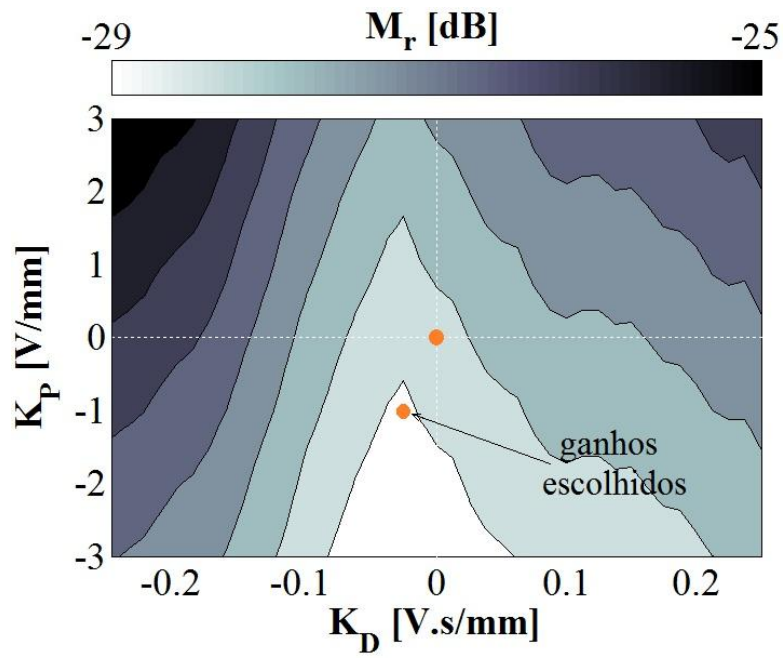

(c) $\Omega=1620 \mathrm{rpm}$

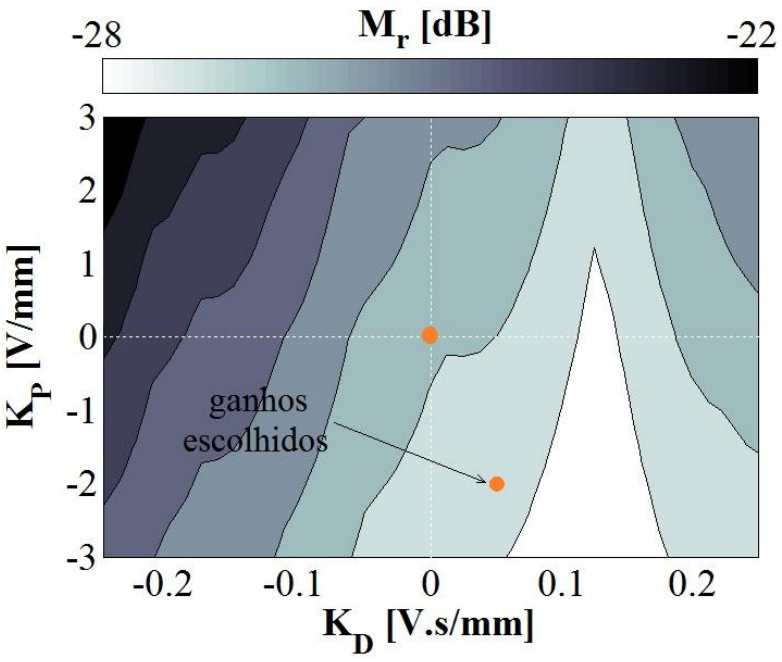

(b) $\Omega=740 \mathrm{rpm}$

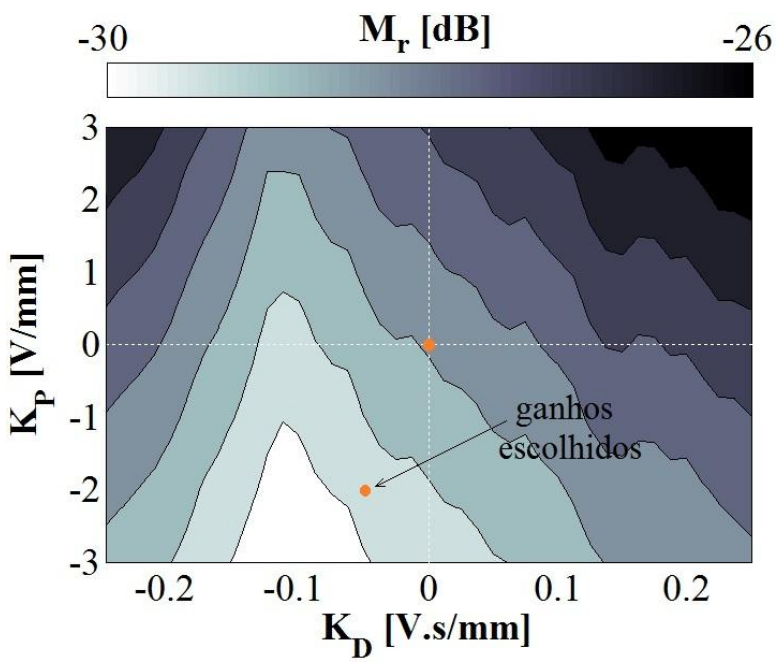

(d) $\Omega=2080 \mathrm{rpm}$

Figura 5.13: Valor esperado da amplitude do maior dos dois picos correspondentes ao $1^{\circ}$ modo de vibrar do sistema em função dos valores dos ganhos do controlador.

Implementado-se experimentalmente os ganhos escolhidos na Figura 5.13, os quais são os maiores possíveis de forma a não ocorrer saturação da porta de saída D/A da placa de aquisição, tem-se a comparação entre as FRFs do sistema (não controlado e controlado) apresentada na Figura 5.14 (uma vez que o pico de ressonância correspondente ao $2^{\circ}$ modo de vibrar do sistema não pode ser visualizado com clareza, não é possível verificar alguma 
influência da estratégia de controle para este modo, sendo, assim, a análise limitada ao primeiro modo). Os valores dos ganhos e da amplitude do maior dos dois picos de ressonância são sumarizados na Tabela 5.6.

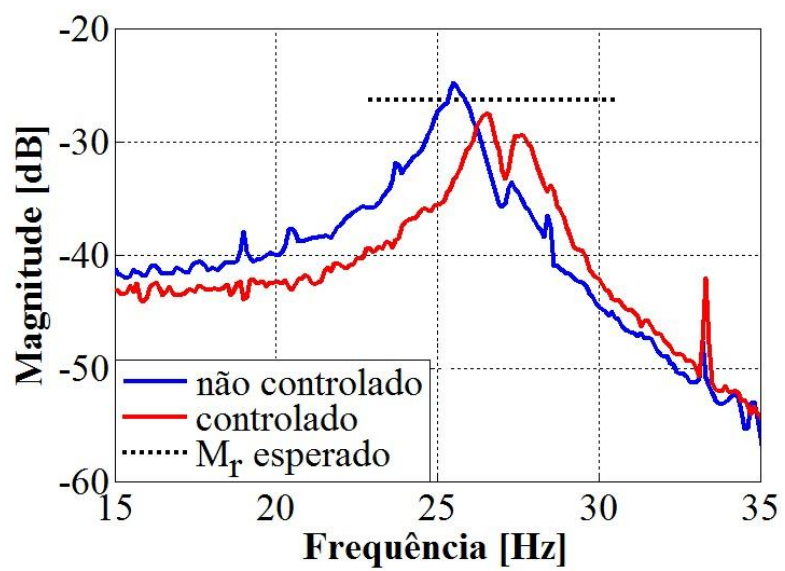

(a) $\Omega=280 \mathrm{rpm}$

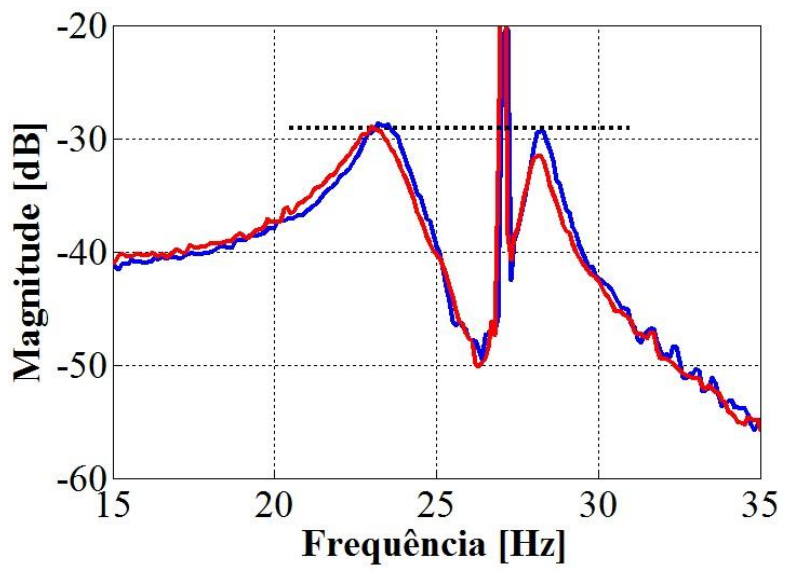

(c) $\Omega=1620 \mathrm{rpm}$

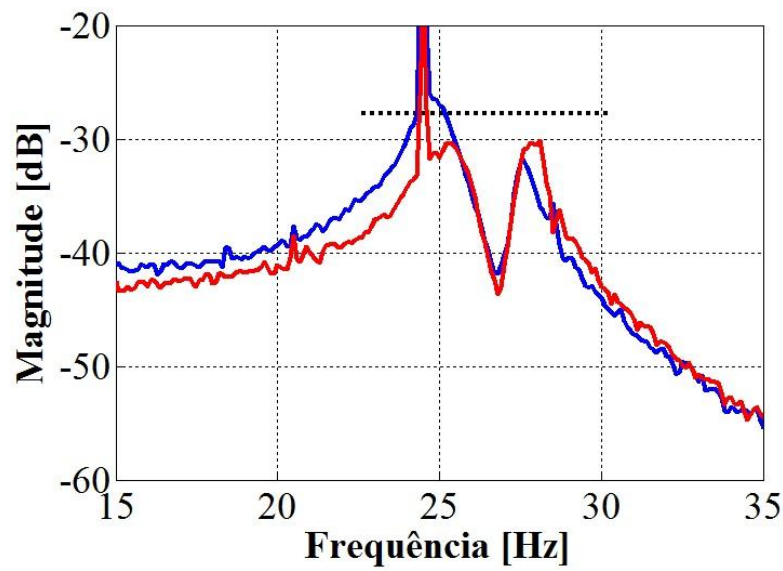

(b) $\Omega=740 \mathrm{rpm}$

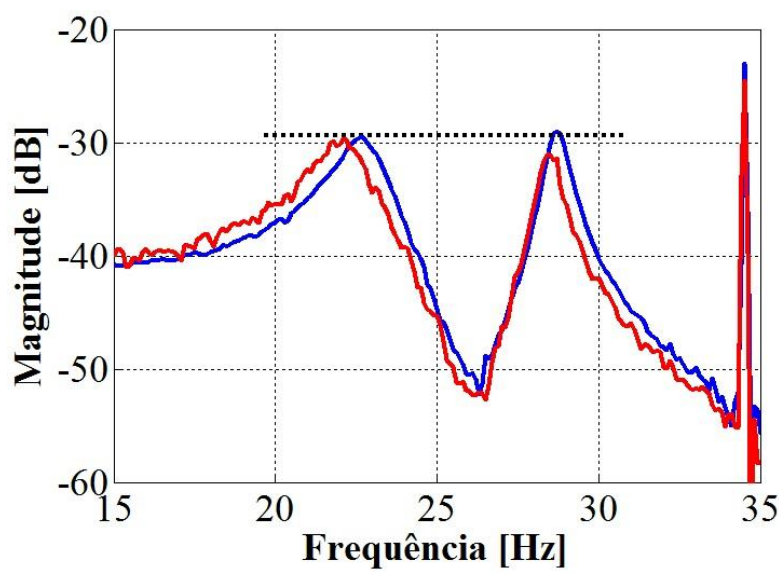

(d) $\Omega=2080 \mathrm{rpm}$

Figura 5.14: Comparação entre a amplitude do pico de ressonância na direção horizontal (sistema não controlado, controlado e valor esperado).

Tabela 5.6: Valores dos ganhos do controlador e amplitude do maior pico de ressonância.

\begin{tabular}{|c|c|c|c|c|c|}
\hline \hline $\begin{array}{c}\mathbf{\Omega} \\
{[\mathbf{r p m}]}\end{array}$ & $\begin{array}{c}\mathbf{K}_{\mathbf{D}} \\
{[\mathbf{V . s} / \mathbf{m m}]}\end{array}$ & $\begin{array}{c}\mathbf{K}_{\mathbf{P}} \\
{[\mathbf{V} / \mathbf{m m}]}\end{array}$ & $\begin{array}{c}\mathbf{M}_{\mathbf{r}} \text { não controlado } \\
{[\mathbf{d B}]}\end{array}$ & $\begin{array}{c}\mathbf{M}_{\mathbf{r}} \text { esperado } \\
{[\mathbf{d B}]}\end{array}$ & $\begin{array}{c}\mathbf{M}_{\mathbf{r}} \text { controlado } \\
{[\mathbf{d B}]}\end{array}$ \\
\hline 280 & 0,08 & $-1,0$ & $-25,09$ & $-26,34$ & $-27,53$ \\
\hline 740 & 0,05 & $-2,0$ & $-26,50$ & $-27,73$ & $-30,12$ \\
\hline 1620 & $-0,025$ & $-1,0$ & $-28,54$ & $-29,13$ & $-29,22$ \\
\hline 2080 & $-0,05$ & $-2,0$ & $-28,95$ & $-29,37$ & $-29,66$ \\
\hline
\end{tabular}


Observando-se a Figura 5.14, verifica-se que, para as velocidades subcríticas, o primeiro pico é maior que o segundo. Para a velocidade intercrítica, os dois picos têm aproximadamente a mesma amplitude e, por fim, para a supercrítica, observa-se uma inversão no comportamento da amplitude dos dois picos em relação ao observado para as velocidades subcríticas: o segundo pico torna-se maior que o primeiro (este fenômeno pode ser mais bem observado na Figura 4.18 (a) e (c)).

Além disso, analisando os gráficos da FRF não controlada e controlada observa-se, para todos os casos, uma relação conflitante entre a amplitude dos dois picos: o sistema de controle reduz a amplitude do maior; entretanto, em contrapartida, a amplitude do menor dos dois picos aumenta quando da implantação do controle PD.

Desta forma, pelo fato de a redução da amplitude de um pico implicar no aumento da amplitude do outro e, uma vez que, para as velocidades $\Omega=1620$ e $2080 \mathrm{rpm}$, a amplitude dos dois picos não difere significativamente, o controle PD se mostra pouco eficiente neste caso, sendo mínima a diferença entre os valores de $M_{r}$ não controlado e controlado.

Já para as velocidades $\Omega=280$ e $740 \mathrm{rpm}$, em que há grande diferença entre as amplitudes dos picos, o sistema de controle se faz efetivo, havendo, todavia, um erro considerável entre os valores estimados e medidos (Tabelas 5.6 e 5.7). Assim, como para o sistema com um disco, o valor deste parâmetro aumenta consideravelmente quando o sistema gira a velocidades mais próximas daquela em que ocorre a ressonância (para $\Omega=1620$ e 2080 rpm, não é possível verificar esta tendência do valor do erro, pois, para estas velocidades, os dois picos de ressonância têm amplitudes muito próximas, sendo o controle pouco efetivo).

Tabela 5.7: Redução percentual estimada e medida para o maior pico de ressonância e erro entre o valor medido em relação ao estimado.

\begin{tabular}{|c|c|c|c|}
\hline $\mathbf{\Omega}$ [rpm] & Redução estimada [\%] & Redução real [\%] & Erro [\%] \\
\hline \hline 280 & 13,4 & 24,5 & $-12,8$ \\
\hline 740 & 13,2 & 34,1 & $-24,1$ \\
\hline 1620 & 6,6 & 7,5 & $-1,0$ \\
\hline 2080 & 4,7 & 7,8 & $-3,3$ \\
\hline
\end{tabular}


A relação conflitante existente entre a amplitude dos dois picos sugere que os resultados obtidos para as FRFs controladas na Figura 5.14 não podem ser aprimorados de forma significativa, mesmo com o uso de atuadores mais potentes (a redução de um pico acarreta no aumento do outro). A Figura 5.15 ilustra o comportamento da magnitude de cada um dos dois picos individualmente em função dos ganhos do controlador, permitindo visualizar que a tendência de redução de ambos os picos de ressonância é a mesma para o ganho proporcional; entretanto, para o ganho derivativo, a tendência é sempre oposta: os valores deste ganho que atenuam um pico implicam, invariavelmente, no aumento do outro pico.
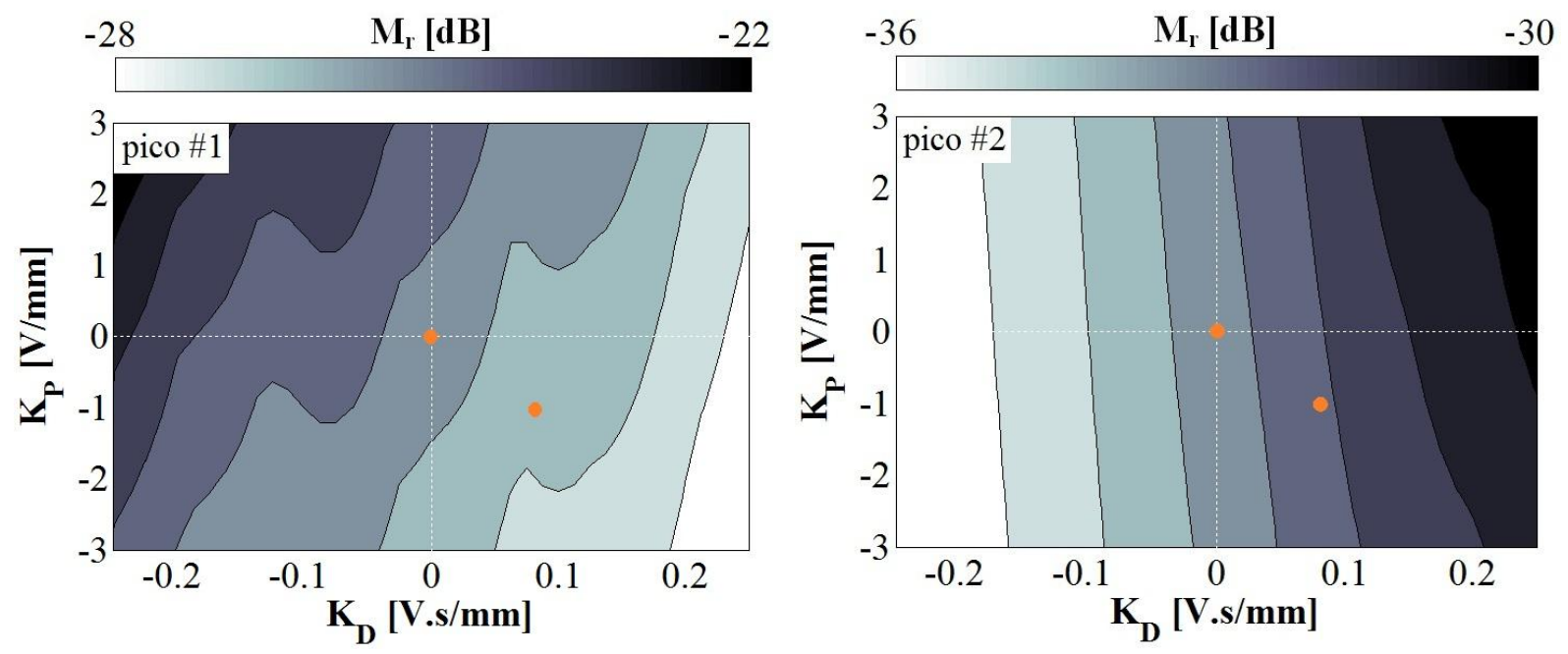

(a) $\Omega=280 \mathrm{rpm}$
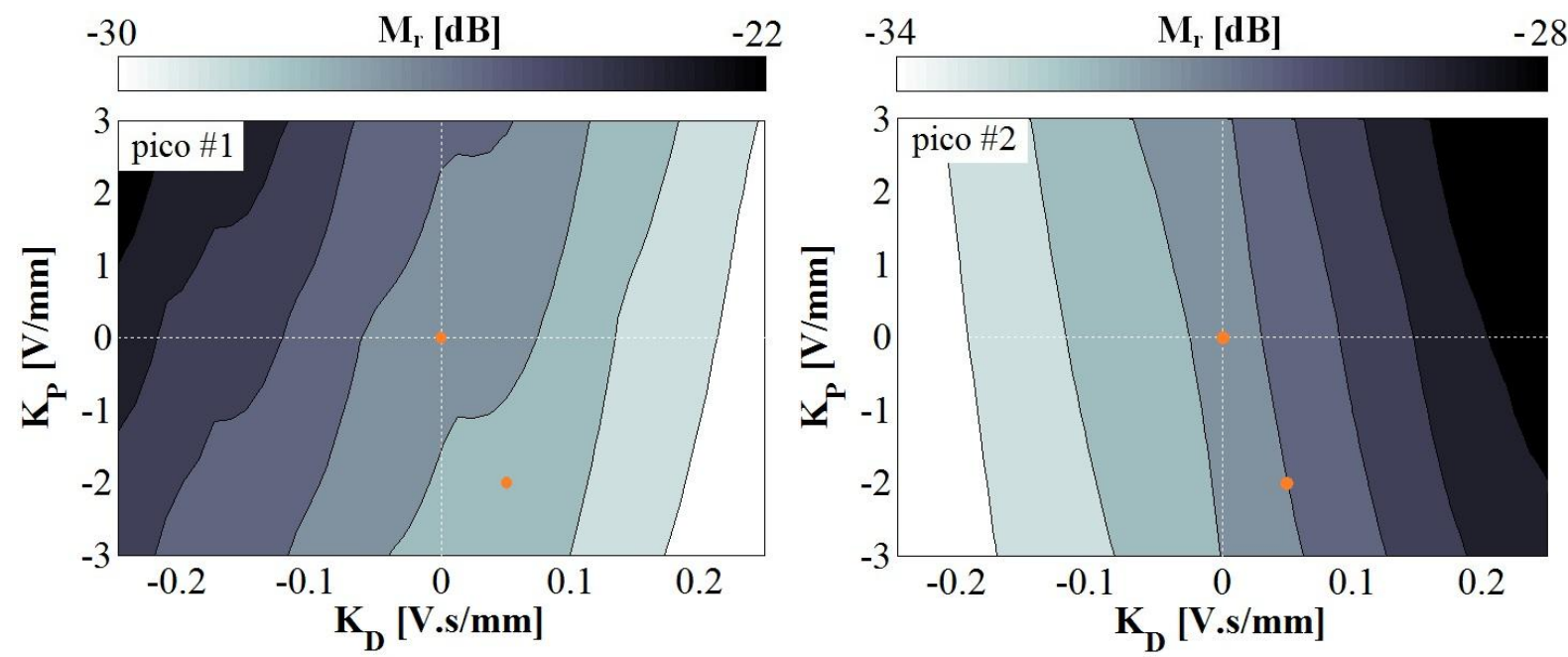

(b) $\Omega=740 \mathrm{rpm}$

Figura 5.15: Amplitudes do primeiro e segundo picos de ressonância correspondentes ao $1^{\circ}$ modo de vibrar do sistema em função dos valores dos ganhos do controlador. 

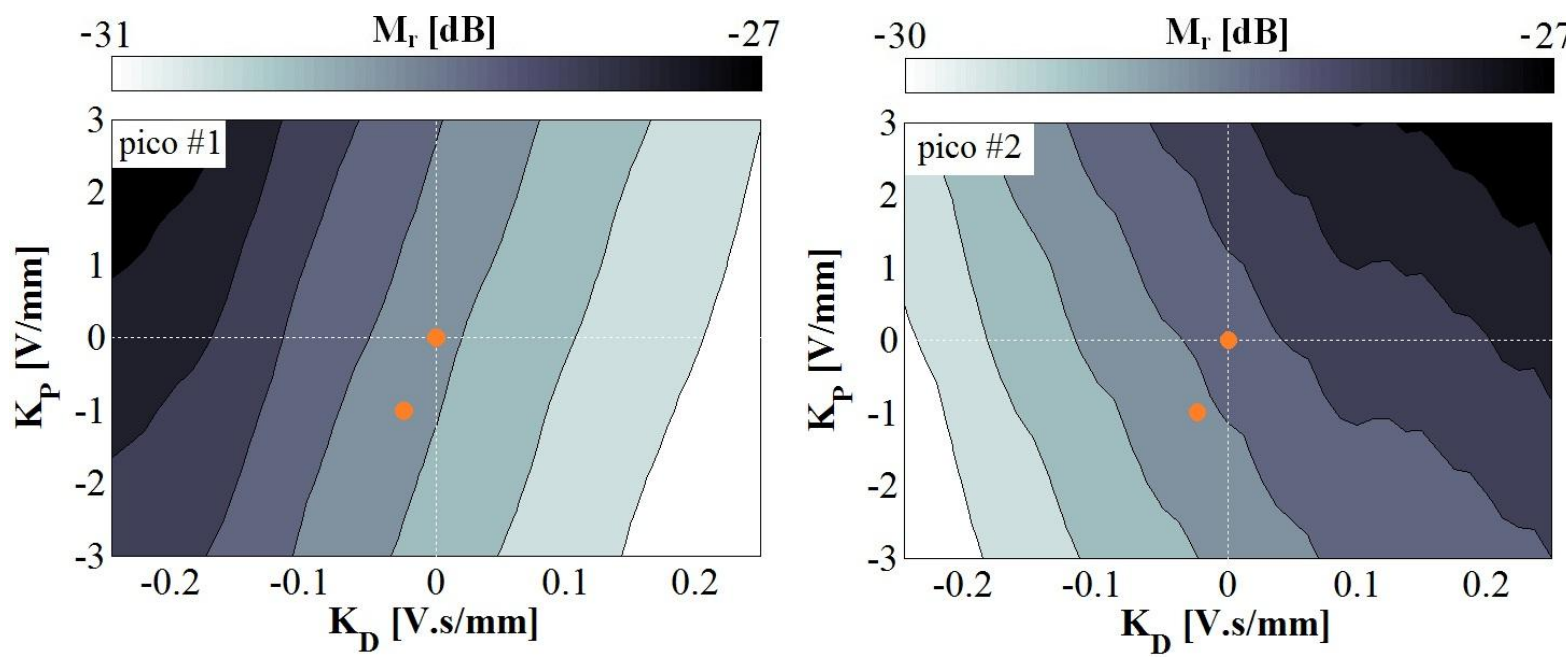

(c) $\Omega=1620 \mathrm{rpm}$
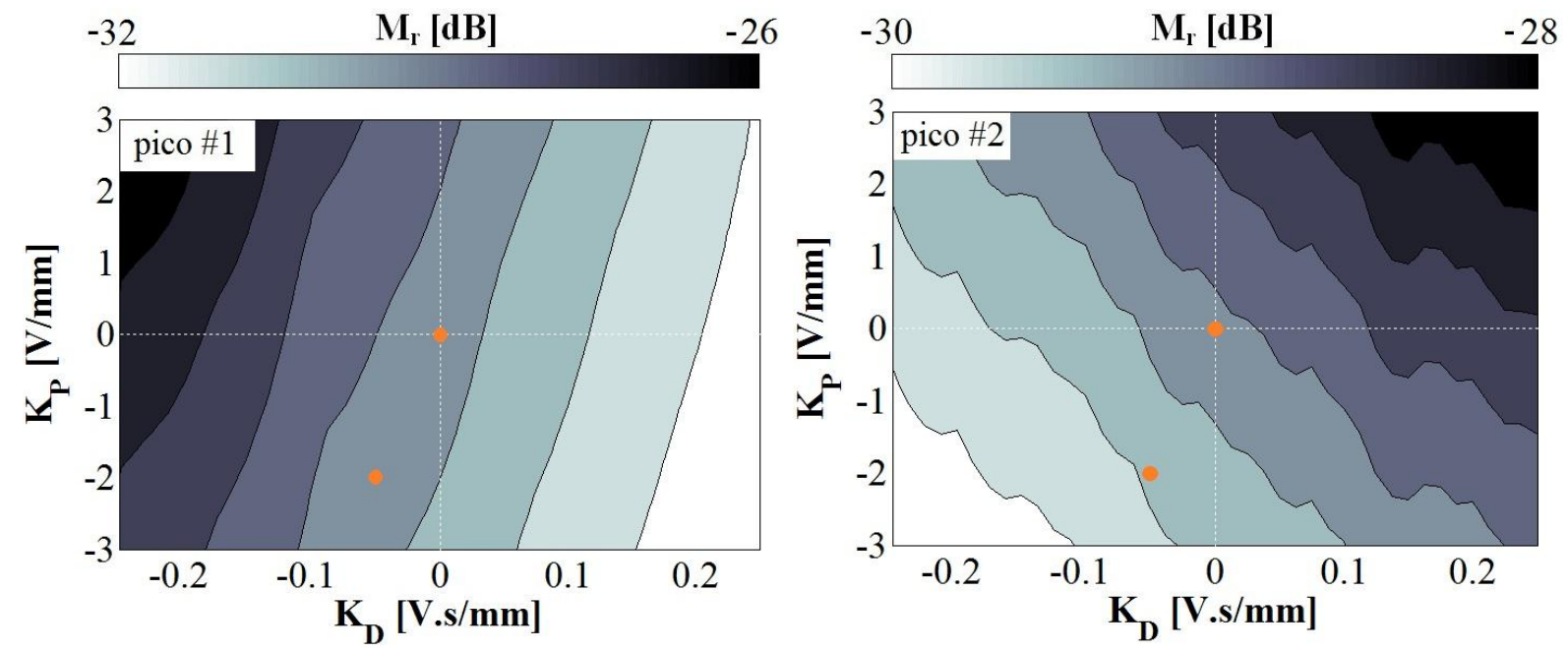

(d) $\Omega=2080 \mathrm{rpm}$

Figura 5.15: Amplitudes do primeiro e segundo picos de ressonância correspondentes ao $1^{\circ}$ modo de vibrar do sistema em função dos valores dos ganhos do controlador (cont.).

Uma interpretação para este efeito antagônico do ganho $K_{D}$ é o fato de a ação derivativa ser uma ação antecipativa, i.e., ela leva em conta a tendência do sistema. Observando-se a Figura 4.18, verifica-se que, para a direção horizontal, a tendência apresentada pela FRF do sistema é que o primeiro pico de ressonância diminui à medida que o segundo aumenta.

Os valores estimados para o pico \#1 e \#2 na Figura 5.15 são apresentados na Tabela 5.8. Novamente, verifica-se que quando há uma pequena variação na amplitude do pico, o erro da estimativa é pequeno (velocidades de $\Omega=1620$ e $2080 \mathrm{rpm}$ - Tabela 5.8). Quando a variação é significativa, o erro observado passa a ser considerável. Entretanto, apesar do erro 
entre o valor medido para cada um dos dois picos e o calculado, a tendência de variação sempre foi condizente com o observado na prática.

Além disso, quando a tendência estimada é de aumento da magnitude do pico, na prática, este aumento é sempre maior que o estimado e, nos casos em que a variação estimada é negativa, isto é, espera-se uma redução na amplitude do pico, a amplitude do pico é sempre menor que a estimada (ou seja, a redução real do pico é maior que a calculada).

Tabela 5.8: Amplitude do pico \#1: valores esperados e medidos.

\begin{tabular}{|c|c|c|c|c|c|c|}
\hline \hline $\begin{array}{c}\mathbf{\Omega} \\
{[\mathbf{r p m}]}\end{array}$ & $\begin{array}{c}\text { Não controlado } \\
{[\mathbf{d B}]}\end{array}$ & $\begin{array}{c}\text { Esperado } \\
{[\mathbf{d B}]}\end{array}$ & $\begin{array}{c}\text { Controlado } \\
{[\mathbf{d B}]}\end{array}$ & $\begin{array}{c}\text { Var. estimada } \\
{[\%]}\end{array}$ & $\begin{array}{c}\text { Var. real } \\
{[\%]}\end{array}$ & $\begin{array}{c}\text { Erro } \\
{[\%]}\end{array}$ \\
\hline 280 & $-25,09$ & $-26,34$ & $-27,53$ & $-13,4$ & $-24,5$ & $-12,8$ \\
\hline 740 & $-26,50$ & $-27,73$ & $-30,42$ & $-13,2$ & $-36,3$ & $-26,6$ \\
\hline 1620 & $-29,39$ & $-29,28$ & $-29,22$ & 1,3 & 2,0 & 0,7 \\
\hline 2080 & $-29,85$ & $-29,73$ & $-29,66$ & 1,4 & 2,2 & 0,8 \\
\hline
\end{tabular}

Tabela 5.9: Amplitude do pico \#2: valores esperados e medidos.

\begin{tabular}{|c|c|c|c|c|c|c|}
\hline \hline $\begin{array}{c}\mathbf{\Omega} \\
{[\mathbf{r p m}]}\end{array}$ & $\begin{array}{c}\text { Não controlado } \\
{[\mathbf{d B}]}\end{array}$ & $\begin{array}{c}\text { Esperado } \\
{[\mathbf{d B}]}\end{array}$ & $\begin{array}{c}\text { Controlado } \\
{[\mathbf{d B}]}\end{array}$ & $\begin{array}{c}\text { Var. estimada } \\
{[\mathbf{\%}]}\end{array}$ & $\begin{array}{c}\text { Var. real } \\
{[\%]}\end{array}$ & $\begin{array}{c}\text { Erro } \\
{[\%]}\end{array}$ \\
\hline 280 & $-33,60$ & $-31,63$ & $-29,47$ & 25,5 & 60,9 & 28,2 \\
\hline 740 & $-31,87$ & $-31,74$ & $-30,12$ & 1,5 & 22,3 & 20,5 \\
\hline 1620 & $-28,54$ & $-29,13$ & $-31,51$ & $-6,6$ & $-29,0$ & $-24,0$ \\
\hline 2080 & $-28,95$ & $-29,38$ & $-31,11$ & $-4,8$ & $-22,0$ & $-18,1$ \\
\hline
\end{tabular}

O fato de o controlador PD ter se mostrado limitado para o controle do $1^{\circ}$ modo de vibrar do sistema (comportamento conflitante para a ação derivativa), motiva a implantação de uma estratégia de controle que emprega apenas a ação proporcional (controle do tipo P). Embora este tipo de controlador não seja capaz de modificar o amortecimento do sistema, ele permite alterar sua rigidez, sendo, assim, também capaz de atenuar vibrações e, no caso, para este controle, a variação da magnitude dos picos de ressonância apresenta sempre a mesma tendência, i.e., $K_{P}<0$. Na próxima seção, um controlador P é implantado e os resultados são comparados (sistema não controlado e controle PD). 


\subsubsection{Comparação com um controle do tipo $P$}

Para um controle do tipo P, a tendência de variação da amplitude do pico é apresentada na Figura 5.16. Novamente, $M_{r}$ representa a amplitude do maior dos dois picos correspondentes ao primeiro modo de vibrar do sistema. Conforme esperado, tendo em vista a análise apresentada na Figura 5.15, a magnitude de $M_{r}$ reduz à medida que o valor do ganho proporcional decresce. Além disso, destaca-se que, para o controlador P, o sistema é estável para a faixa de valores $-42<K_{P}<8$ (Figura 5.12).

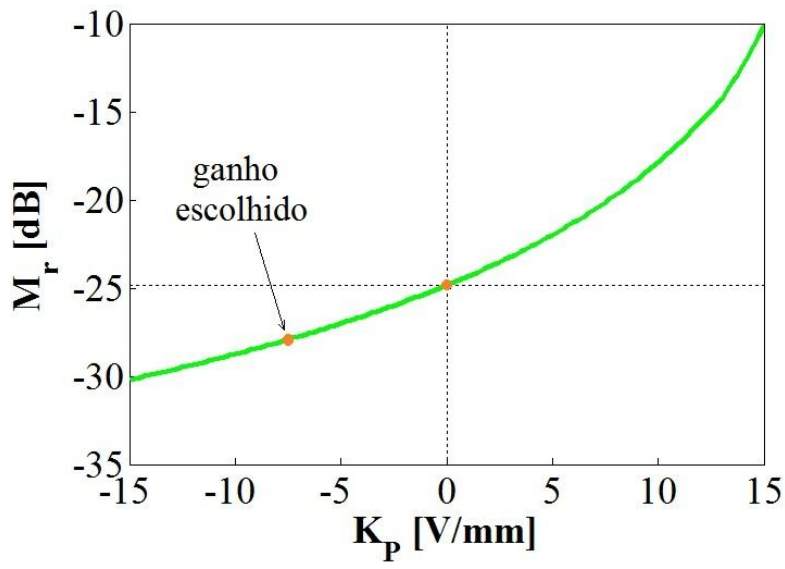

(a) $\Omega=280 \mathrm{rpm}$

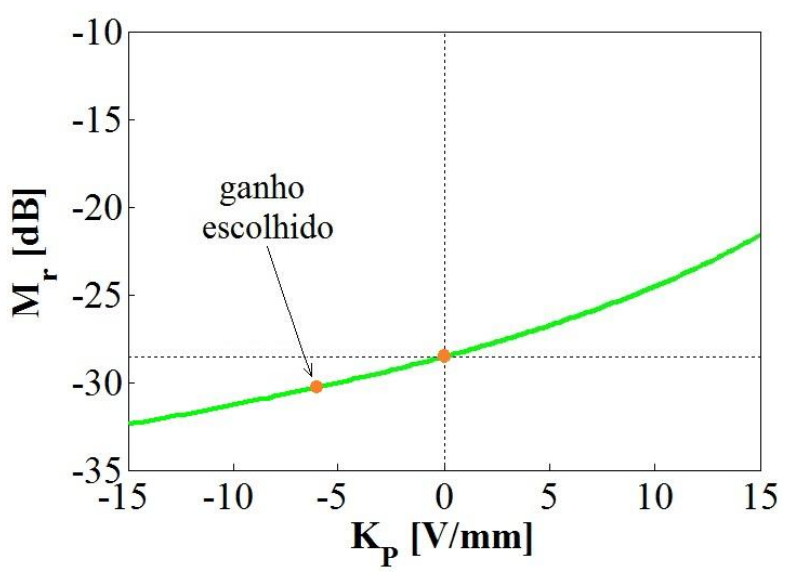

(c) $\Omega=1620 \mathrm{rpm}$

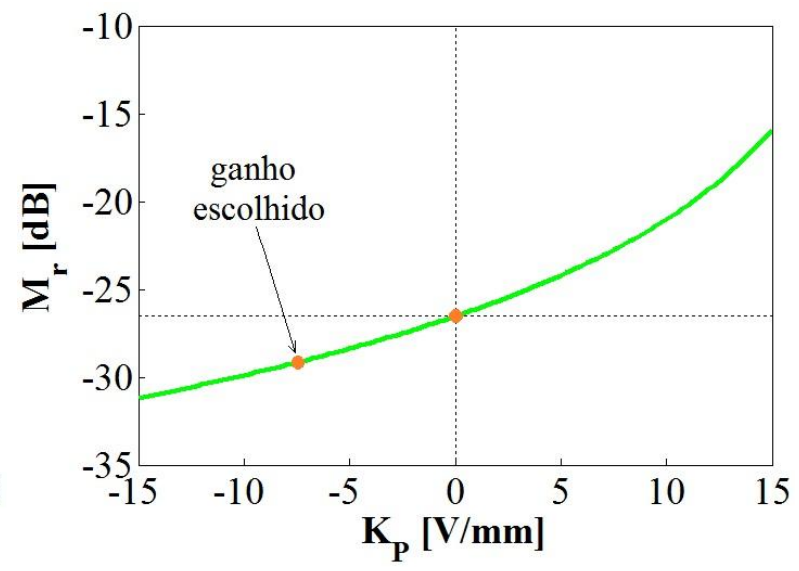

(b) $\Omega=740 \mathrm{rpm}$

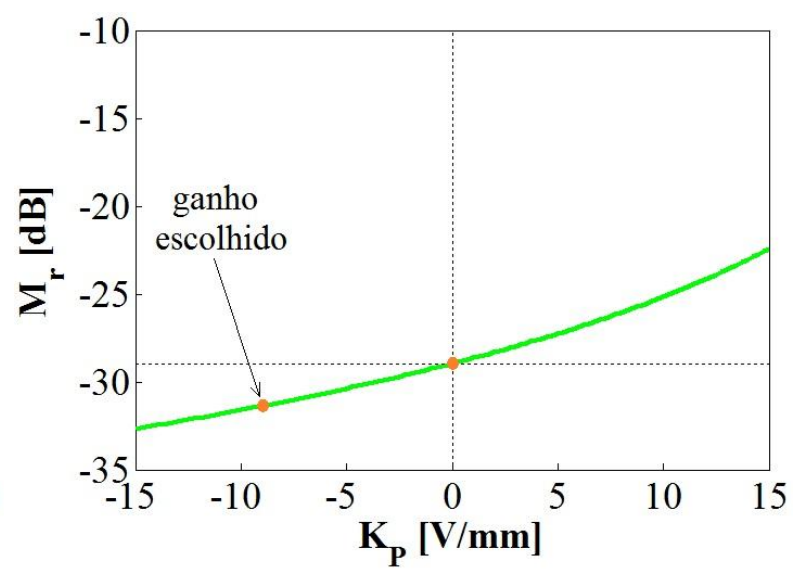

(d) $\Omega=2080 \mathrm{rpm}$

Figura 5.16: Valor esperado para o maior dos dois picos correspondentes ao $1^{\circ}$ modo de vibrar do sistema em função dos valores do ganho (controle do tipo P).

O valor escolhido para o ganho proporcional foi o maior possível de forma que não ocorresse a saturação da porta de saída D/A da placa de aquisição e os resultados obtidos para o controle P são comparados na Figura 5.17. A Tabela 5.10 sumariza os valores estimados 
para $M_{r}$ na Figura 5.16 e o valor medido experimentalmente para este parâmetro quando da implantação do controle.

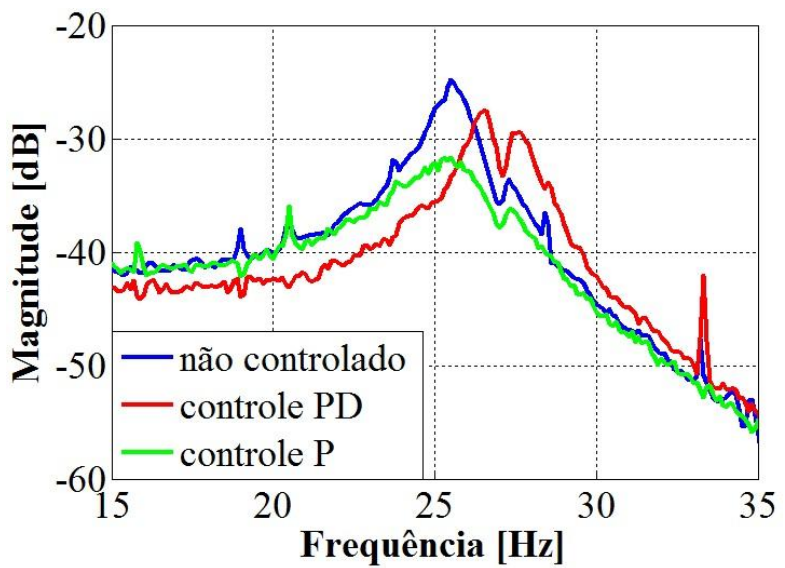

(a) $\Omega=280 \mathrm{rpm}$

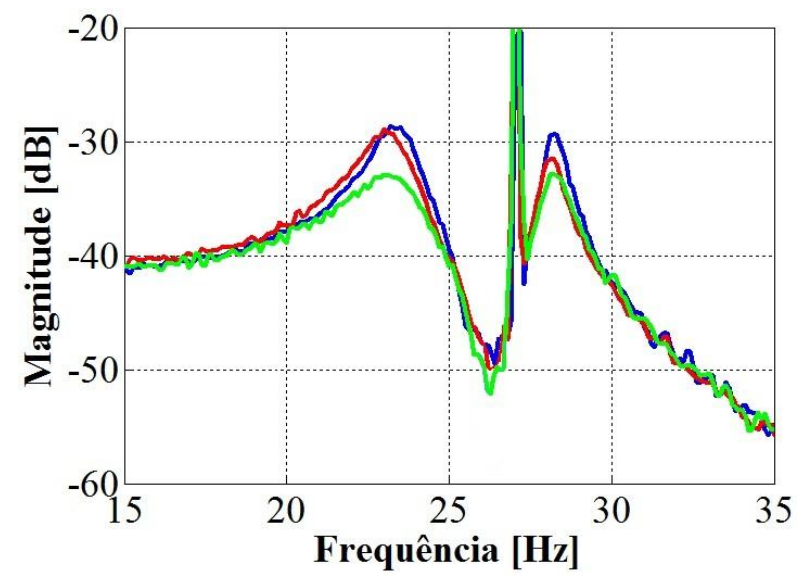

(c) $\Omega=1620 \mathrm{rpm}$

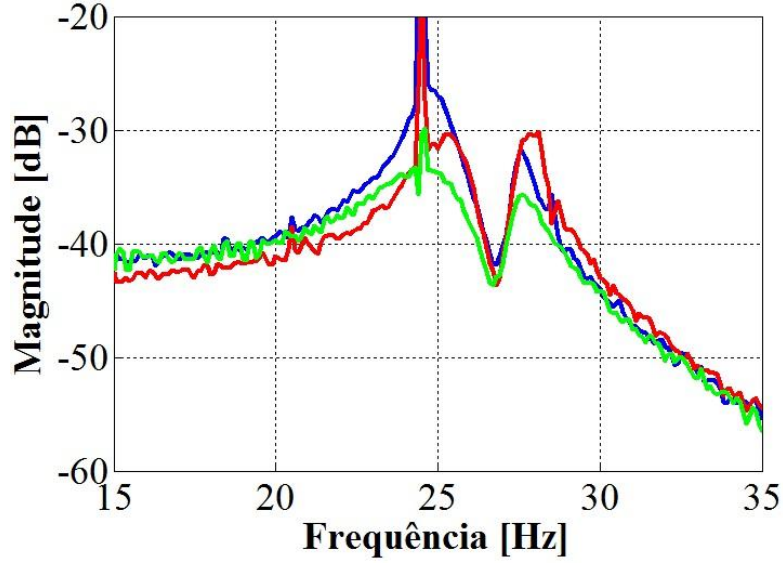

(b) $\Omega=740 \mathrm{rpm}$

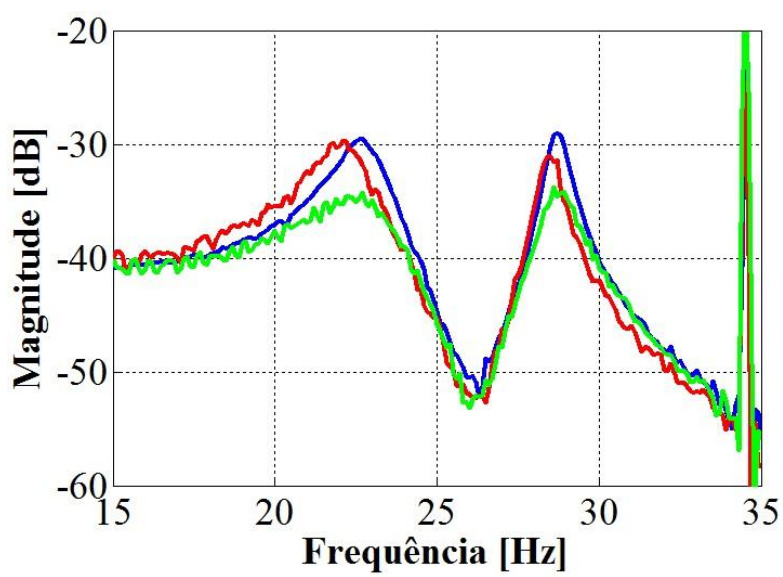

(d) $\Omega=2080 \mathrm{rpm}$

Figura 5.17: Comparação entre a amplitude do pico de ressonância na direção horizontal para o sistema não controlado e controlado (controle do tipo PD e P).

Observando-se a Figura 5.17, verifica-se, conforme esperado, que o controlador $\mathrm{P}$ foi capaz de atenuar a amplitude dos dois picos de ressonância, não apresentando o inconveniente do controlador PD de amplificar um dos picos e, uma vez que a ação derivativa não foi empregada, foi possível adotar-se valores mais elevados para o ganho proporcional em comparação com aqueles quando havia o ganho derivativo (Tabelas 5.6 e 5.10). Além disso, este controlador mostrou-se mais efetivo que o proporcional-derivativo do ponto de vista de atenuação de vibrações, especialmente para as velocidades de 1620 e $2080 \mathrm{rpm}$, em que a amplitude dos dois picos de ressonância é aproximadamente igual (Tabela 5.11). 
Tabela 5.10: Valor do ganho proporcional adotado para o controle do sistema e amplitude do maior pico de ressonância.

\begin{tabular}{|c|c|c|c|c|}
\hline $\begin{array}{c}\mathbf{\Omega} \\
{[\mathbf{r p m}]}\end{array}$ & $\begin{array}{c}\mathbf{K}_{\mathbf{P}} \\
{[\mathbf{V . s} / \mathbf{m m}]}\end{array}$ & $\begin{array}{c}\mathbf{M}_{\mathbf{r}} \text { não controlado } \\
{[\mathbf{d B}]}\end{array}$ & $\begin{array}{c}\mathbf{M}_{\mathbf{r}} \text { esperado } \\
{[\mathbf{d B}]}\end{array}$ & $\begin{array}{c}\mathbf{M}_{\mathbf{r}} \text { controlado } \\
{[\mathbf{d B}]}\end{array}$ \\
\hline \hline 280 & $-7,5$ & $-24,85$ & $-28,52$ & $-31,69$ \\
\hline 740 & $-8,0$ & $-26,00$ & $-30,29$ & $-33,58$ \\
\hline 1620 & $-6,0$ & $-28,70$ & $-30,29$ & $-32,80$ \\
\hline 2080 & $-9,0$ & $-28,95$ & $-31,36$ & $-34,16$ \\
\hline
\end{tabular}

Tabela 5.11: Comparação entre a amplitude do maior pico de ressonância para o sistema não controlado e controlado (controle do tipo PD e P).

\begin{tabular}{|c|c|c|c|c|c|}
\hline $\begin{array}{c}\mathbf{\Omega} \\
{[\mathbf{r p m}]}\end{array}$ & $\begin{array}{c}\mathbf{N a ̃ o} \text { controlado } \\
{[\mathbf{d B}]}\end{array}$ & $\begin{array}{c}\text { Controle PD } \\
{[\mathbf{d B}]}\end{array}$ & $\begin{array}{c}\text { Controle P } \\
{[\mathbf{d B}]}\end{array}$ & $\begin{array}{c}\text { Var. controle PD } \\
{[\%]}\end{array}$ & $\begin{array}{c}\text { Var. controle P } \\
{[\%]}\end{array}$ \\
\hline 280 & $-24,85$ & $-27,53$ & $-31,69$ & $-26,5$ & $-54,5$ \\
\hline 740 & $-26,00$ & $-30,12$ & $-33,58$ & $-37,8$ & $-52,1$ \\
\hline 1620 & $-28,70$ & $-28,87$ & $-32,80$ & $-1,9$ & $-37,6$ \\
\hline 2080 & $-28,95$ & $-29,66$ & $-34,16$ & $-7,8$ & $-45,1$ \\
\hline
\end{tabular}

Para as velocidades de 280, 740 e $2080 \mathrm{rpm}$, foi possível uma atenuação de $M_{r}$ em torno de $50 \%$ com o uso do controlador proporcional. Para $\Omega=1620 \mathrm{rpm}$, a redução foi menos expressiva devido à adoção de um valor menor para o ganho $K_{P}$ (ao girar a esta velocidade, o sistema vibra mais, sendo, assim, o deslocamento medido maior e, consequentemente, o valor adotado para o ganho do controlador deve ser menor, a fim de se evitar exceder a tensão de saturação).

Em relação ao erro, não se verificaram grandes variações de seu valor de acordo com a velocidade de rotação do eixo: em todos os casos analisados, o valor deste parâmetro esteve na faixa de -27 a $-32 \%$ (Tabela 5.12). Este fato reforça a hipótese de que a ação derivativa do MatLab Simulink não é capaz de derivar o sinal medido com precisão, pois, para o sistema com um disco, em que se adotou um controlador PD, o erro foi maior nas velocidades próximas a ressonância (as quais resultam em maior deslocamento, tornando uma imprecisão gerada pela ação derivativa mais expressiva), conforme mostrado pela Tabela 5.3. 
Tabela 5.12: Redução percentual estimada e medida para o maior pico de ressonância e erro entre o valor medido em relação ao estimado (controle do tipo P).

\begin{tabular}{|c|c|c|c|}
\hline \hline $\boldsymbol{\Omega}$ [rpm] & Redução estimada [\%] & Redução real [\%] & Erro [\%] \\
\hline 280 & 34,5 & 54,5 & $-30,6$ \\
\hline 740 & 39,0 & 58,2 & $-31,5$ \\
\hline 1620 & 16,7 & 37,6 & $-25,1$ \\
\hline 2080 & 24,2 & 45,1 & $-27,6$ \\
\hline
\end{tabular}

Também se destaca que o fato de haver um erro expressivo entre os valores estimados e medidos para $M_{r}$ (Tabelas 5.10 e 5.12), pode ser devido às correntes parasitas, responsáveis pela redução do pico de ressonância quando se compara o sistema parado e em movimento (Figuras 4.15 e 4.18): ao se simular o comportamento do rotor com a implantação do sistema de controle, este fenômeno não é computado, o que poderia implicar na discrepância observada entre os valores estimados (calculados através de simulação numérica) e os medidos para o pico de ressonância.

Uma vez conhecidas as influências do sistema de controle na direção horizontal, analisam-se as FRF do sistema para a direção vertical e para os deslocamentos medidos em ambas as direções pelos sensores \#2 (vide posicionamento dos sensores ilustrado na Figura 4.6). Para o deslocamento medido na direção vertical, têm-se as FRFs apresentadas pela Figura 5.18. Nota-se que, para esta direção, o segundo pico de ressonância é sempre maior que o primeiro (Figuras 4.18 (b) e (d)) e a tendência observada para os dois picos é a mesma: a amplitude de ambos aumenta à medida que a velocidade de rotação é maior. Acredita-se que pelo fato de ambos os picos apresentarem esta mesma tendência (maior amplitude para velocidades de rotação mais altas) tem-se que a implantação do controle PD, diferentemente para a direção horizontal, em que a atenuação de um pico implicava no aumento do outro, resultou na redução de ambos os picos (Figura 5.18).

Para a velocidade de $280 \mathrm{rpm}$, este efeito não é verificado, dada a distorção da forma do pico de ressonância (não permitindo uma averiguação precisa de sua magnitude); contundo, para as demais velocidades, é possível verificar que de fato ambos os picos foram atenuados. Todavia, apesar de não ter sido verificado o efeito conflitante causado pela ação derivativa (aumento de um pico implicar na redução do outro), o controlador $\mathrm{P}$, em 
comparação ao PD, novamente se mostrou mais eficiente (Tabela 5.13), tendo permitido uma atenuação de vibrações consideravelmente mais expressiva também na direção vertical.

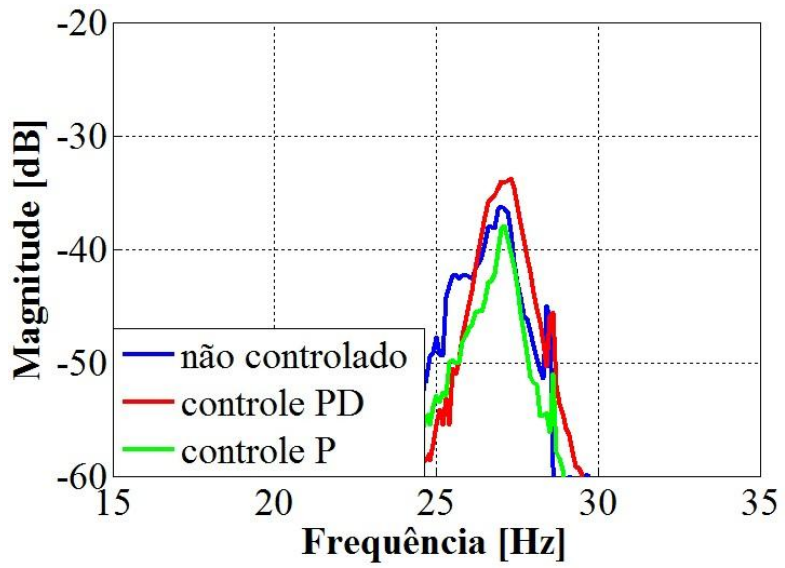

(a) $\Omega=280 \mathrm{rpm}$

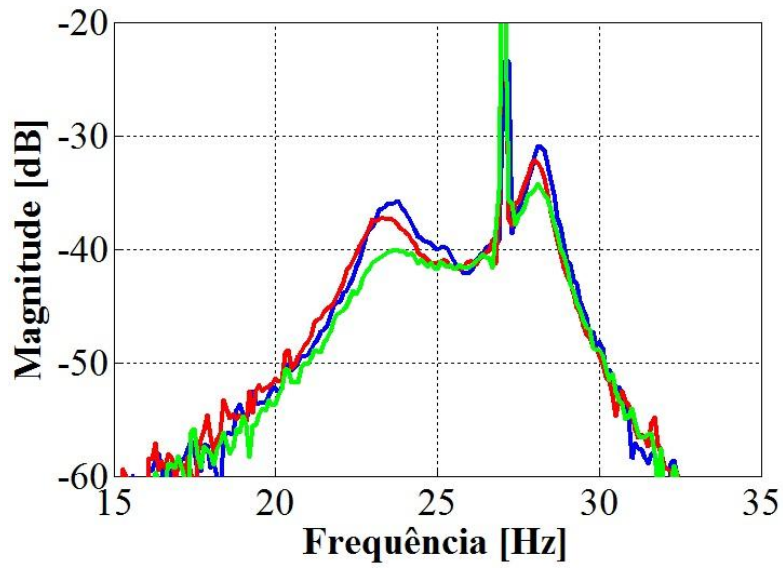

(c) $\Omega=1620 \mathrm{rpm}$

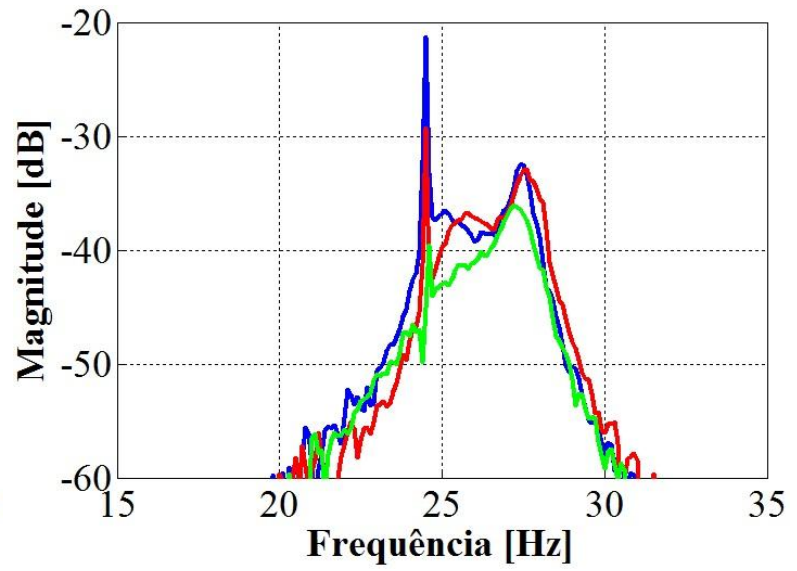

(b) $\Omega=740 \mathrm{rpm}$

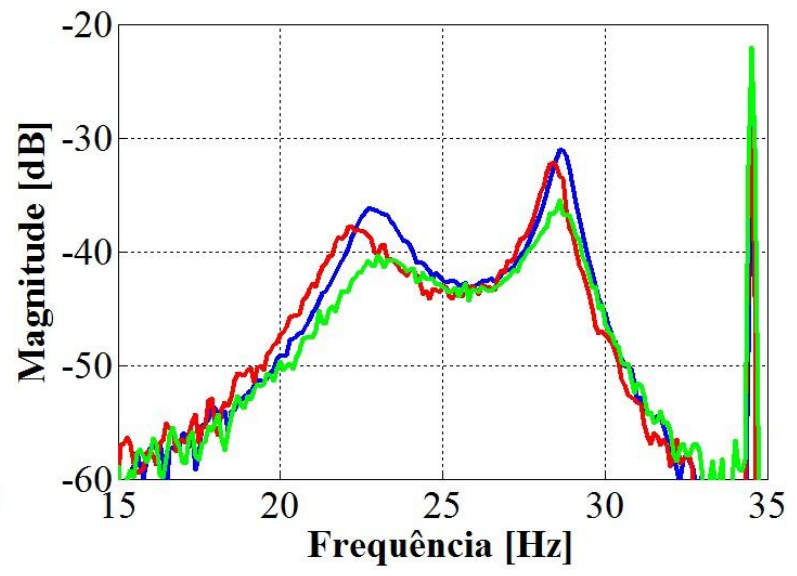

(d) $\Omega=2080 \mathrm{rpm}$

Figura 5.18: Comparação entre a amplitude do pico de ressonância na direção vertical para o sistema não controlado e controlado (controle do tipo PD e P) - sensor \#1.

Tabela 5.13: Comparação entre a amplitude do maior pico de ressonância para o sistema não controlado e controlado (controle do tipo PD e P) - direção vertical (sensor \#1).

\begin{tabular}{|c|c|c|c|c|c|}
\hline \hline $\begin{array}{c}\mathbf{\Omega} \\
{[\mathbf{r p m}]}\end{array}$ & $\begin{array}{c}\text { Não controlado } \\
{[\mathbf{d B}]}\end{array}$ & $\begin{array}{c}\text { Controle PD } \\
{[\mathbf{d B}]}\end{array}$ & $\begin{array}{c}\text { Controle P } \\
{[\mathbf{d B}]}\end{array}$ & $\begin{array}{c}\text { Var. controle PD } \\
{[\%]}\end{array}$ & $\begin{array}{c}\text { Var. controle P } \\
{[\%]}\end{array}$ \\
\hline 280 & $-36,27$ & $-33,80$ & $-37,97$ & 32,9 & $-17,8$ \\
\hline 740 & $-32,52$ & $-32,90$ & $-36,06$ & $-4,3$ & $-33,5$ \\
\hline 1620 & $-30,92$ & $-32,18$ & $-34,28$ & $-13,5$ & $-32,1$ \\
\hline 2080 & $-31,11$ & $-32,13$ & $-36,38$ & $-11,1$ & $-45,5$ \\
\hline
\end{tabular}


Para o deslocamento medido na direção horizontal pelo sensor \#2, têm-se as FRFs apresentadas pela Figura 5.19. Assim como para o deslocamento horizontal medido pelo sensor \#1, nota-se uma tendência oposta na variação dos picos de ressonância (a magnitude do primeiro diminui enquanto a do segundo cresce à medida que a velocidade de rotação aumenta). Da mesma forma, conforme observado na Figura 5.17, o controle PD resultou na atenuação do pico de maior amplitude e amplificação do menor amplitude, tendo sido o controlador P mais efetivo (Tabela 5.14).

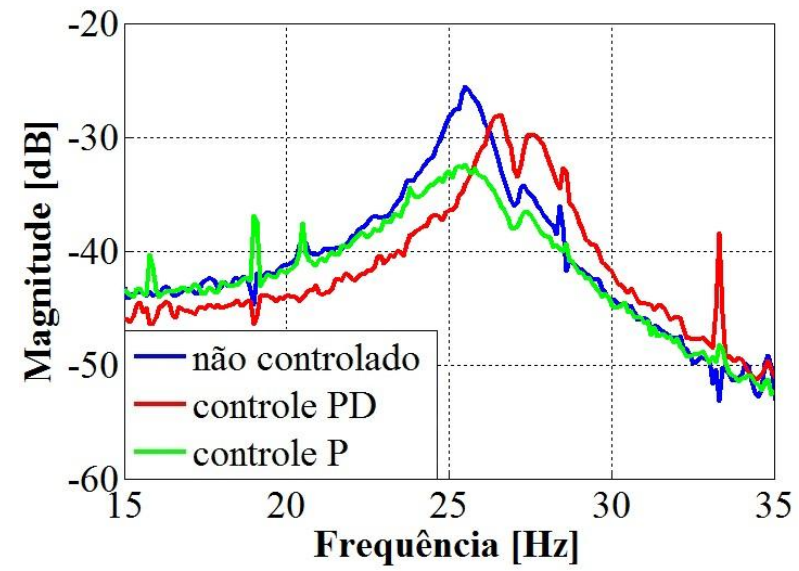

(a) $\Omega=280 \mathrm{rpm}$

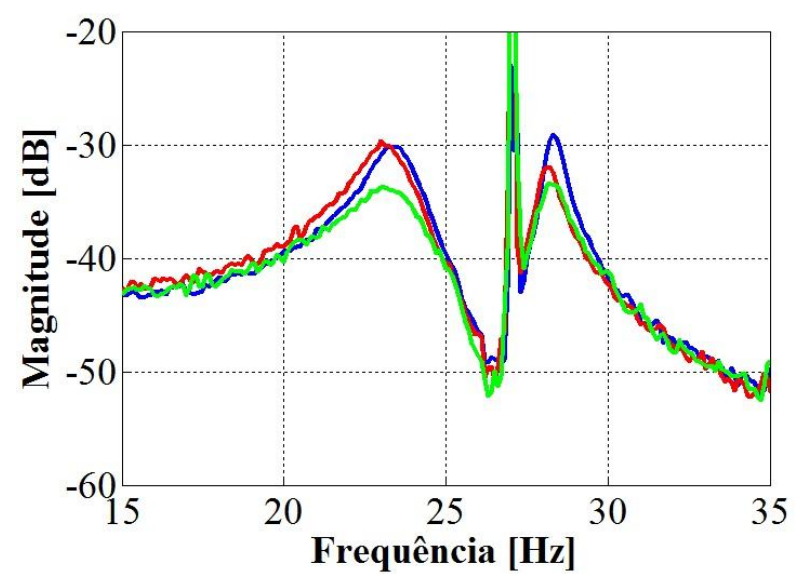

(c) $\Omega=1620 \mathrm{rpm}$

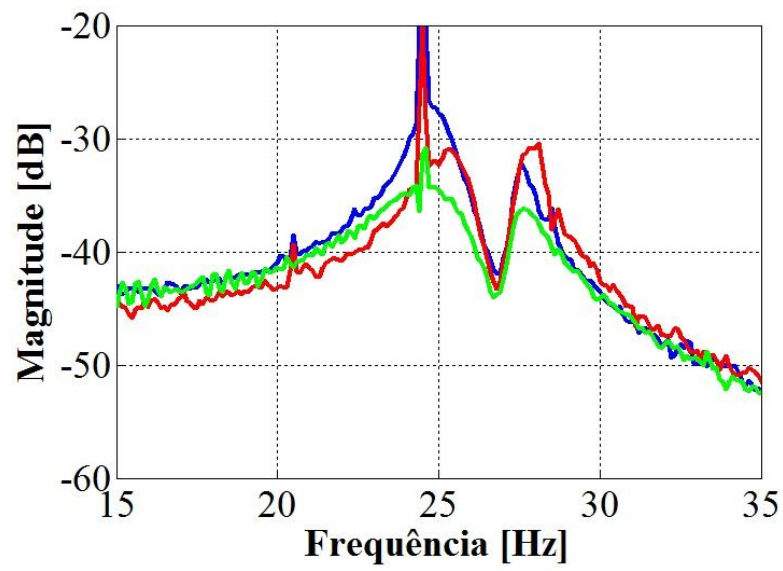

(b) $\Omega=740 \mathrm{rpm}$

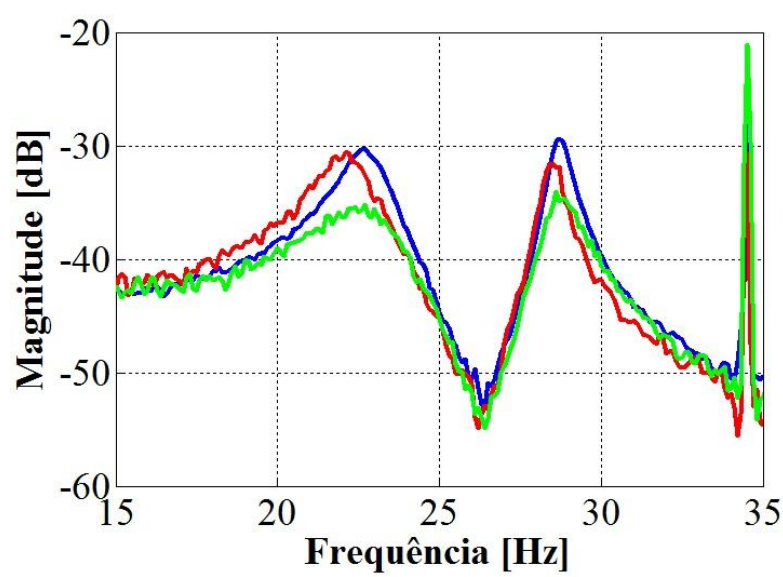

(d) $\Omega=2080 \mathrm{rpm}$

Figura 5.19: Comparação entre a amplitude do pico de ressonância na direção horizontal para o sistema não controlado e controlado (controle do tipo PD e P) - sensor \#2.

Finalmente, para o deslocamento medido na direção vertical pelo sensor \#2, têm-se as FRFs apresentadas pela Figura 5.20. Para esta direção, assim como verificado para o sensor \#1, acredita-se que pelo fato de a magnitude de os dois picos de ressonância apresentar a mesma tendência (suas amplitudes aumentam à medida que o rotor gira mais rapidamente), $\mathrm{o}$ controle PD se mostrou capaz de reduzir ambos os picos. Contudo, assim como para os deslo- 
camentos na direção horizontal e para o deslocamento na vertical medido pelo sensor \#1, maior atenuação de vibrações foi obtida com o controle P (Tabela 5.15).

Tabela 5.14: Comparação entre a amplitude do maior pico de ressonância para o sistema não controlado e controlado (controle do tipo PD e P) - direção horizontal (sensor \#2).

\begin{tabular}{|c|c|c|c|c|c|}
\hline $\begin{array}{c}\mathbf{\Omega} \\
{[\mathbf{r p m}]}\end{array}$ & $\begin{array}{c}\mathbf{N a ̃ o} \text { controlado } \\
{[\mathbf{d B}]}\end{array}$ & $\begin{array}{c}\text { Controle PD } \\
{[\mathbf{d B}]}\end{array}$ & $\begin{array}{c}\text { Controle P } \\
{[\mathbf{d B}]}\end{array}$ & $\begin{array}{c}\text { Var. controle PD } \\
{[\%]}\end{array}$ & $\begin{array}{c}\text { Var. controle P } \\
{[\%]}\end{array}$ \\
\hline \hline 280 & $-25,89$ & $-28,03$ & $-32,71$ & $-21,8$ & $-54,4$ \\
\hline 740 & $-27,21$ & $-30,86$ & $-34,27$ & $-34,3$ & $-55,6$ \\
\hline 1620 & $-29,13$ & $-29,63$ & $-33,39$ & $-5,6$ & $-38,8$ \\
\hline 2080 & $-29,38$ & $-30,61$ & $-34,93$ & $-13,2$ & $-47,2$ \\
\hline
\end{tabular}

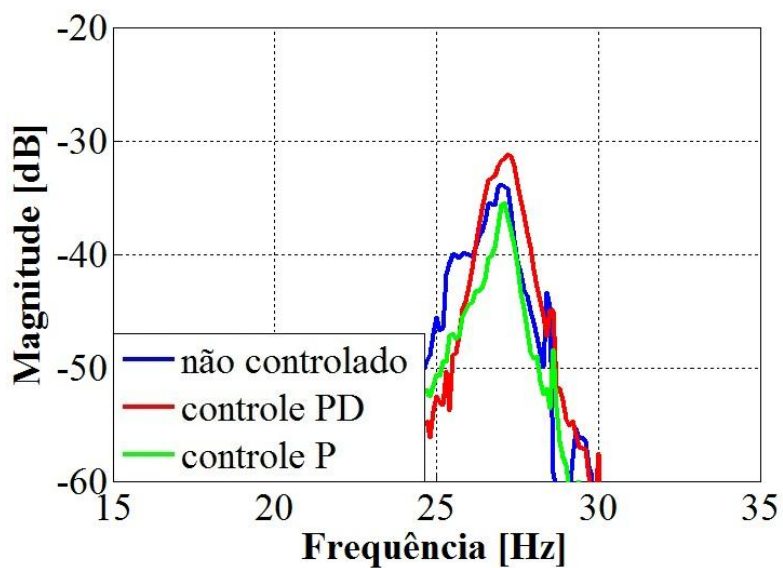

(a) $\Omega=280 \mathrm{rpm}$

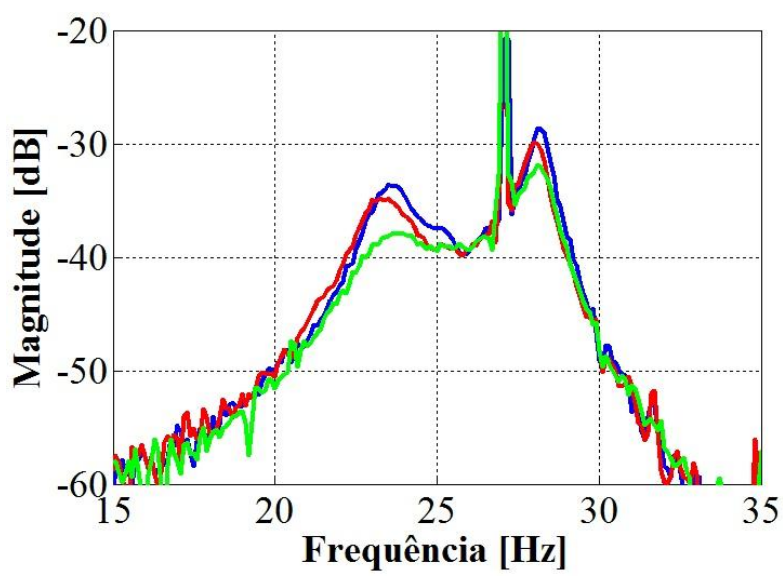

(c) $\Omega=1620 \mathrm{rpm}$

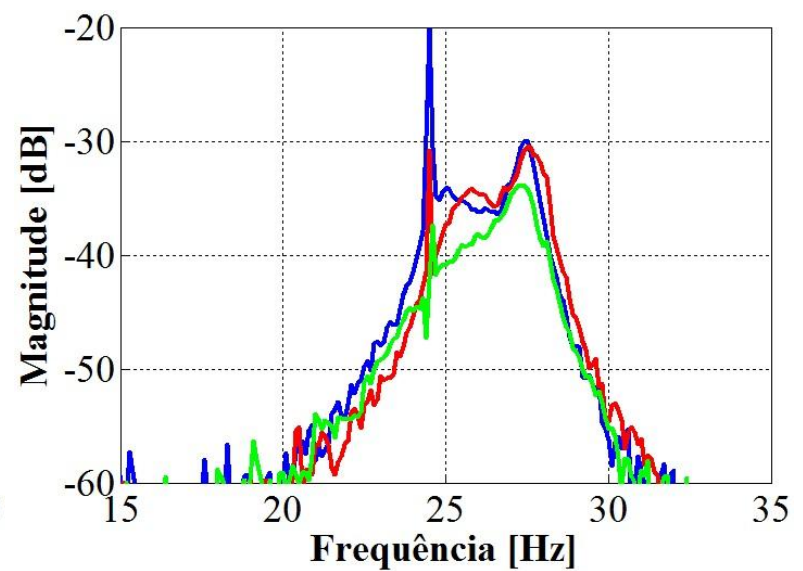

(b) $\Omega=740 \mathrm{rpm}$

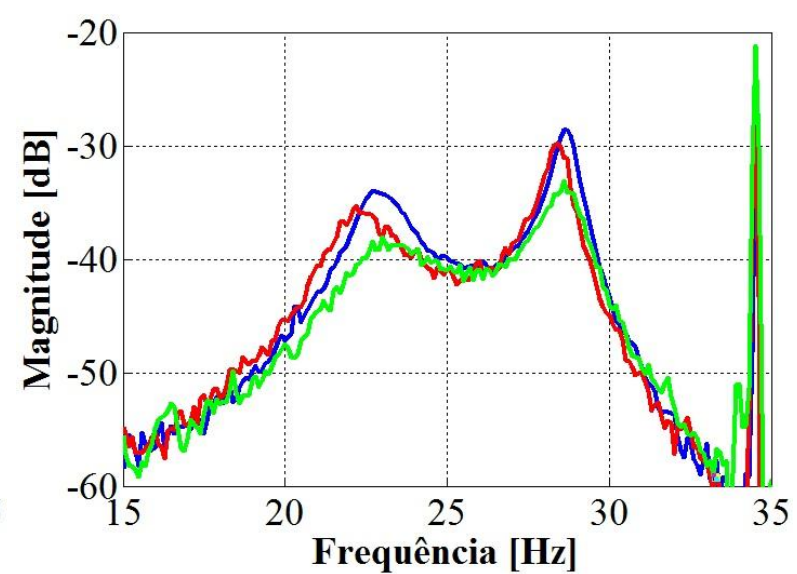

(d) $\Omega=2080 \mathrm{rpm}$

Figura 5.20: Comparação entre a amplitude do pico de ressonância na direção vertical para o sistema não controlado e controlado (controle do tipo PD e P) - sensor \#2. 
Tabela 5.15: Comparação entre a amplitude do maior pico de ressonância para o sistema não controlado e controlado (controle do tipo PD e P) - direção vertical (sensor \#2).

\begin{tabular}{|c|c|c|c|c|c|}
\hline \hline $\begin{array}{c}\mathbf{\Omega} \\
{[\mathbf{r p m}]}\end{array}$ & $\begin{array}{c}\text { Não controlado } \\
{[\mathbf{d B}]}\end{array}$ & $\begin{array}{c}\text { Controle PD } \\
{[\mathbf{d B}]}\end{array}$ & $\begin{array}{c}\text { Controle P } \\
{[\mathbf{d B}]}\end{array}$ & $\begin{array}{c}\text { Var. controle PD } \\
{[\%]}\end{array}$ & $\begin{array}{c}\text { Var. controle P } \\
{[\%]}\end{array}$ \\
\hline \hline 280 & $-33,90$ & $-31,23$ & $-35,52$ & 36,0 & $-17,0$ \\
\hline 740 & $-30,03$ & $-30,49$ & $-33,85$ & $-5,2$ & $-35,6$ \\
\hline 1620 & $-28,59$ & $-29,86$ & $-31,81$ & $-13,6$ & $-31,0$ \\
\hline 2080 & $-28,64$ & $-29,72$ & $-33,83$ & $-11,7$ & $-45,0$ \\
\hline
\end{tabular}

Os resultados apresentados na Figuras 5.17 a 5.20, em que foram comparadas uma estratégia de controle PD e $\mathrm{P}$, mostram que, na prática, apesar de contra-intuitivo, o controlador proporcional foi mais efetivo. Embora, em teoria, o controlador proporcionalderivativo seja mais eficiente que o proporcional do ponto de vista de atenuação de vibrações (uma vez que a ação derivativa permite aumento de amortecimento), a limitação existente dos valores máximos de seus ganhos que podem ser implementados na prática, devido à saturação da porta de saída da placa de aquisição, justifica a maior atenuação de vibrações obtida com o controlador proporcional (para o qual se pode adotar ganhos mais elevados).

\subsection{Comparação com o critério de estabilidade de Routh-Hurwitz}

Através da Decomposição-d, determinaram-se os ganhos estáveis de um controlador do tipo PD a partir da resposta em frequência de um sistema rotativo levantada experimentalmente. Tradicionalmente, dado um sistema linear e invariante no tempo (LTI) e um controlador, pode-se conhecer, a partir de seu modelo matemático, o conjunto de todos os ganhos do controlador que estabilizam o sistema em malha fechada por meio da aplicação do critério de estabilidade de Routh-Hurwitz (Routh, 1892; Hurwitz, 1895). A partir do polinômio característico do sistema em malha fechada, este critério permite calcularem-se condições necessárias e suficientes para que o sistema em malha fechada seja estável. Assim, é possível conhecerem-se as faixas de valores dos ganhos do controlador considerado que satisfazem este requisito.

Neste sentido, a fim de se comparar a Decomposição-d com o critério de RouthHurwitz, o qual é amplamente empregado no contexto da teoria de controle clássico (Dorf e Bishop, 2009), ajusta-se um modelo matemático à resposta do sistema com um disco obtida 
experimentalmente para a velocidade de rotação do eixo de $880 \mathrm{rpm}$. Através da tentativa e erro, determina-se que a FRF do sistema pode ser aproximada por um sistema de quarta ordem, cujos parâmetros são estimados com o auxílio da ferramenta ident do MatLab. A função de transferência (modelo ajustado) no domínio da variável de Laplace é dada pela Equação (5.2), e a Figura 5.21 apresenta uma comparação entre a resposta em frequência experimental para a velocidade considerada e a obtida através do modelo ajustado.

$$
P(s)=\frac{-9,2 \times 10^{-4} s^{2}-0,120 s-130}{4,858 \times 10^{-5} s^{4}+1,735 \times 10^{-2} s^{3}+1,542 s^{2}+308,501 s+7500}
$$

Tendo-se em mãos um modelo matemático, tem-se por objetivo comparar a região de estabilização obtida através da Decomposição-d para $\Omega=880 \mathrm{rpm}$ (região II da Figura 5.1) com uma região de ganhos estáveis no plano de ganhos do controlador calculada através do critério de estabilidade de Routh-Hurwitz. Uma vez que o modelo ajustado é bastante próximo da resposta medida experimentalmente, espera-se que este critério conduza a uma região de estabilização com o mesmo aspecto da apresentada na Figura 5.1 e que as curvas que a delimitam sejam aproximadamente idênticas às fronteiras da raiz real e complexa (RRB e CRB respectivamente).
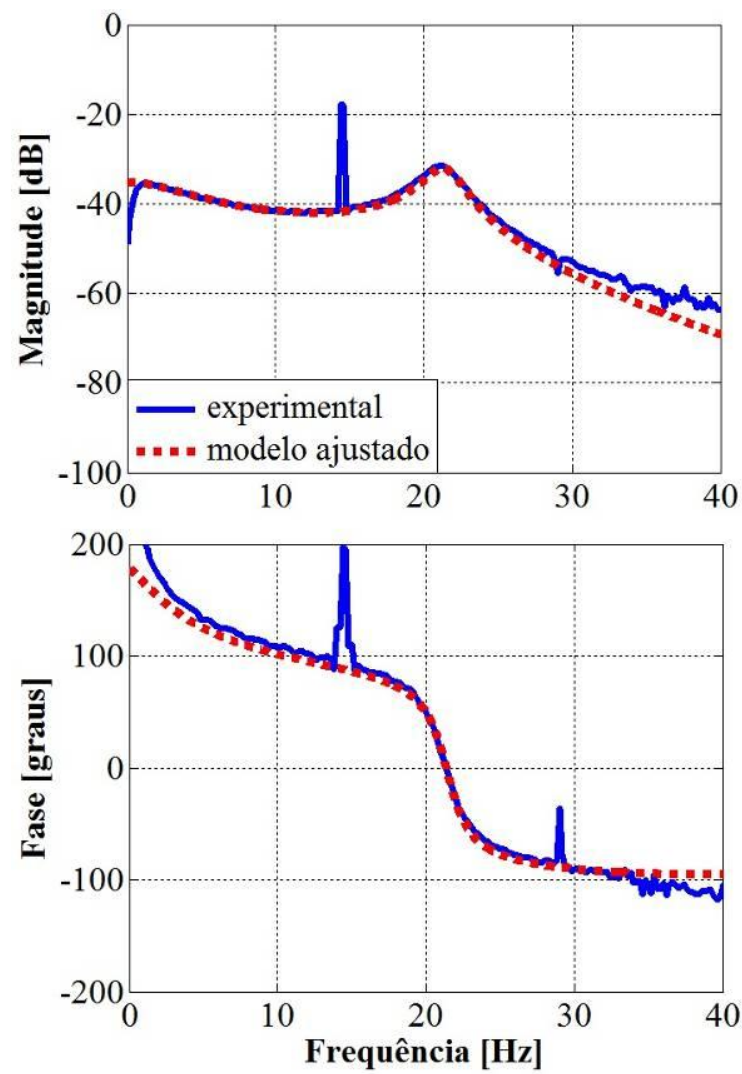

Figura 5.21: Comparação entre a FRF experimental e modelo ajustado $(\Omega=880 \mathrm{rpm})$. 
Denotando-se a Equação (5.2) conforme apresentado pela Equação (5.3)

$$
P(s)=\frac{n_{2} s^{2}+n_{1} s+n_{0}}{d_{4} s^{4}+d_{3} s^{3}+d_{2} s^{2}+d_{1} s+d_{0}}
$$

e, a partir do polinômio característico do sistema (definido pela Equação (3.9)), tem-se que o polinômio característico do sistema em malha fechada escrito no domínio s através da função de transferência ajustada empiricamente é dado pela Equação (5.4)

$$
\begin{gathered}
\pi(s)=d_{4} s^{4}+\left(d_{3}+K_{D} n_{2}\right) s^{3}+\left(d_{2}+K_{D} n_{1}+K_{P} n_{2}\right) s^{2}+ \\
+\left(d_{1}+K_{D} n_{0}+K_{P} n_{1}\right) s+\left(d_{0}+K_{P} n_{0}\right)
\end{gathered}
$$

Equivalentemente

$$
\pi(s)=\alpha_{4} s^{4}+\alpha_{3} s^{3}+\alpha_{2} s^{2}+\alpha_{1} s+\alpha_{0}
$$

A partir da Equação (5.5), tem-se a disposição de Routh-Hurwitz (Dorf e Bishop, 2009) apresentada na Tabela 5.16, cuja primeira coluna corresponde a cinco condições necessárias e suficientes para que o sistema em malha fechada seja estável (Equações (5.6) a $(5.10))$.

Tabela 5.16: Disposição de Routh-Hurwitz para o polinômio característico da Equação (5.5).

\begin{tabular}{|c|c|c|c|}
\hline$s^{4}$ & $\alpha_{4}$ & $\alpha_{2}$ & $\alpha_{0}$ \\
\hline$s^{3}$ & $\alpha_{3}$ & $\alpha_{1}$ & \\
\hline$s^{2}$ & $\frac{\alpha_{3} \alpha_{2}-\alpha_{1} \alpha_{4}}{\alpha_{3}}$ & $\alpha_{0}$ & \\
\hline$s^{1}$ & $\left(\frac{\alpha_{3} \alpha_{2}-\alpha_{1} \alpha_{4}}{\alpha_{3}}\right) \alpha_{1}-\alpha_{3} \alpha_{0}$ & & \\
\hline$s^{0}$ & $\alpha_{0}$ & & \\
\hline
\end{tabular}

$$
\begin{gathered}
d_{4}>0 \\
K_{D}>-\frac{d_{3}}{n_{2}} \\
\left(d_{3}+K_{D} n_{2}\right)\left(d_{2}+K_{D} n_{1}+K_{P} n_{2}\right)-d_{4}\left(d_{1}+K_{D} n_{0}+K_{P} n_{1}\right)>0 \\
{\left[\left(d_{3}+K_{D} n_{2}\right)\left(d_{2}+K_{D} n_{1}+K_{P} n_{2}\right)-d_{4}\left(d_{1}+K_{D} n_{0}+K_{P} n_{1}\right)\right] \alpha_{1}-\alpha_{3}^{2} \alpha_{0}>0}
\end{gathered}
$$




$$
K_{P}>-\frac{d_{0}}{n_{0}}
$$

Expandindo-se os termos das Equações (5.8) e (5.9), tem-se que as mesmas podem ser escritas de forma genérica conforme as Equações (5.11) e (5.12) respectivamente

$$
\begin{gathered}
\beta_{1} K_{D}^{2}+\left(\beta_{2} K_{P}+\beta_{3}\right) K_{D}+\beta_{4} K_{P}+\beta_{5}>0 \\
\gamma_{1} K_{D}^{3}+\left(\gamma_{2} K_{P}+\gamma_{3}\right) K_{D}^{2}+\left(\gamma_{4} K_{P}^{2}+\gamma_{5} K_{P}+\gamma_{6}\right) K_{D}+\left(\gamma_{7} K_{P}^{2}+\gamma_{8} K_{P}+\gamma_{9}\right)>0
\end{gathered}
$$

em que $\beta$ e $\gamma$ são constantes associadas aos parâmetros da função de transferência da planta.

A primeira condição (Equação (5.6)), a qual independe dos parâmetros do controlador, é verdadeira; as demais (Equações (5.7) a (5.10)), as quais são função dos ganhos proporcional e derivativo, são apresentadas graficamente no plano $\left(K_{D}, K_{P}\right)$, conforme a Figura 5.22. Assim, pode-se comparar este resultado, decorrente do critério de estabilidade de RouthHurwitz, com o obtido através da Decomposição-d (Figura 5.23).

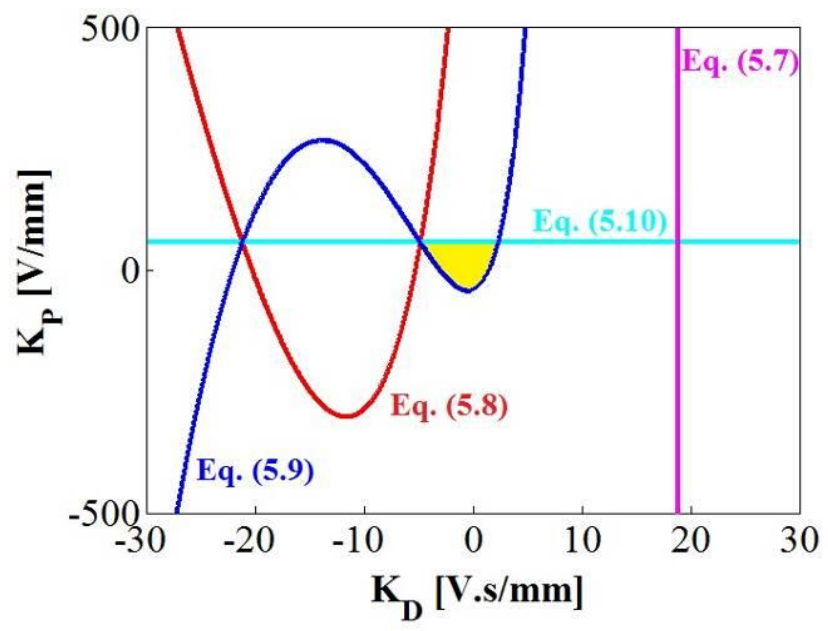

Figura 5.22: Representação gráfica das condições necessárias e suficientes para estabilidade do sistema em malha fechada calculadas a partir do critério de Routh-Hurwitz (a área hachurada corresponde à região de estabilização).

Observando-se a Figura 5.23, tem-se que a região de estabilização obtida em ambos os casos apresenta o mesmo aspecto, havendo uma pequena divergência entre a curva da CRB e a obtida através da Equação (5.9), o que se deve ao fato de esta última ter sido baseada em um modelo ajustado, cuja dinâmica é aproximadamente igual à do sistema medida experimentalmente (Figura 5.21). Este resultado é inédito na literatura, uma vez que não se verifica 
trabalhos anteriores que contemplem uma comparação entre regiões de estabilização calculadas através da Decomposição-d e do critério de estabilidade de Routh-Hurwitz, e as vantagens e desvantagens observadas entre ambas as técnicas são sumarizadas na Tabela 5.17.

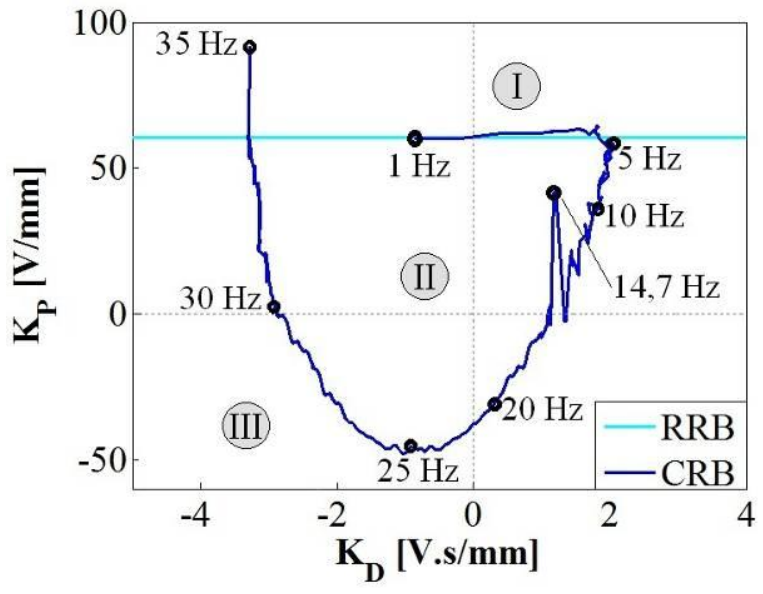

(a) Decomposição-d

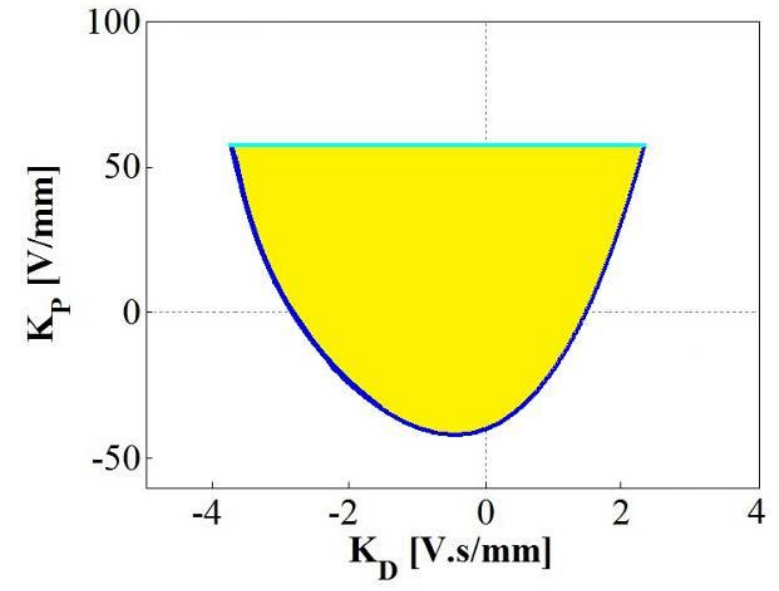

(b) Routh-Hurwitz

Figura 5.23: Comparação entre o resultado obtido através da Decomposição-d (baseado na resposta em frequência experimental do sistema) e o obtido através do critério de RouthHurwitz (baseado em um modelo ajustado) para $\Omega=880 \mathrm{rpm}$.

Tabela 5.17: Vantagens e desvantagens do critério de estabilidade de Routh-Hurwitz em relação à Decomposição-d para o cálculo dos ganhos estáveis de um sistema LTI.

\begin{tabular}{|c|c|c|}
\hline Técnica & Vantagens & Desvantagens \\
\hline $\begin{array}{c}\text { Critério de } \\
\text { estabilidade de } \\
\text { Routh-Hurwitz }\end{array}$ & $\begin{array}{l}\text { - Não requer teste de estabili- } \\
\text { dade para cada uma das regi- } \\
\text { ões obtidas (basta determinar a } \\
\text { intersecção entre as mesmas) }\end{array}$ & $\begin{array}{l}\text { - Requer um modelo matemático } \\
\text { da planta em estudo } \\
\text { - O cálculo da região de estabiliza- } \\
\text { ção é pouco prático }\end{array}$ \\
\hline Decomposição-d & $\begin{array}{l}\text { - Livre de modelos matemáticos } \\
\text { - Tende a ser mais precisa por } \\
\text { não ser baseada em hipóteses } \\
\text { simplificadoras (as quais são } \\
\text { inerentes no processo de mo- } \\
\text { delagem) } \\
\text { - Pode ser facilmente implemen- } \\
\text { tada através de um algoritmo }\end{array}$ & $\begin{array}{l}\text { - A resposta em frequência medida } \\
\text { restringe-se a uma faixa de fre- } \\
\text { quências limitada, podendo com- } \\
\text { prometer a efetividade (conjunto } \\
\text { de ganhos estáveis pode ser de- } \\
\text { terminado de forma parcial) } \\
\text { - Requer teste de estabilidade para } \\
\text { cada uma das regiões obtidas }\end{array}$ \\
\hline
\end{tabular}

Acredita-se que, embora a principal vantagem da Decomposição-d seja não requerer o modelo matemático da planta considerada, ela também se mostra mais interessante que o critério de Routh-Hurwitz nos casos em que o modelo do sistema é conhecido, pois conforme 
pode ser constatado ela pode ser facilmente implementada computacionalmente, ao contrário deste último, cuja aplicação para a determinação de regiões de estabilização no espaço de ganhos do controlador é pouco prática (em se tratando de um sistema de ordem mais elevada, este fato torna-se ainda mais evidente, uma vez que os termos presentes na disposição de Routh-Hurwitz apresentariam maior complexidade, demandando mais tempo por parte do projetista na determinação do conjunto de ganhos estáveis). Por fim, nos casos em que se têm medições de resposta em frequência muito ruidosas, pode ser interessante ajustar um modelo a FRF da planta e, em seguida, utilizar a Decomposição-d para o cálculo da região de estabilização a partir deste modelo, de forma que a efetividade desta técnica não seja comprometida. 



\section{Capítulo 6}

\section{Algoritmo de autoidentificação}

Neste capítulo, a técnica de controle estudada é implementada de forma automática para o sistema com dois discos por meio de um algoritmo (algoritmo de autoidentificação) que identifica a FRF do sistema e, a partir dela, obtém os ganhos ótimos do controlador (controle PD e P) visando redução do pico de ressonância. Este algoritmo é implementado através do aplicativo MatLab, sendo a aquisição da resposta e controle do sistema executados em tempo real através da ferramenta Simulink, e o cálculo dos valores dos ganhos estáveis que minimizam o pico de ressonância feito através de um código desenvolvido no editor do aplicativo.

Os resultados obtidos a cada operação realizada pelo algoritmo podem ser visualizados através de uma interface gráfica desenvolvida utilizando-se a ferramenta GUI e, desta forma, através de uma técnica para projeto de sistemas de controle livre de modelos matemáticos e de sua implementação de forma automática através do algoritmo de autoidentificação proposto, realiza-se o controle autônomo de vibrações do sistema rotativo para a configuração com dois discos utilizando-se um controlador do tipo PD e, posteriormente, um controlador P.

\subsection{Fluxograma do algoritmo}

O fluxograma do algoritmo de autoidentificação é ilustrado na Figura 6.1. Inicialmente, uma sub-rotina denominada FRF é executada (Figura 6.2). Ela é responsável por enviar aos atuadores eletromagnéticos o sinal chirp utilizado para excitar o sistema (Figura 4.11) e executar a aquisição de sua resposta (deslocamento do eixo) enquanto o sinal de excitação é transmitido. Tal procedimento é realizado em tempo real através da ferramenta 
Simulink (Figura 5.6) e, ao final de 40 s (período total de excitação), a FRF do sistema é calculada através do estimador $H_{1}(\omega)$ (Maia e Silva, 1997).

Identificada a resposta em frequência do sistema, uma sub-rotina denominada calculo_ganhos, responsável pela obtenção dos ganhos ótimos do controlador visando atenuação de vibrações, é executada (Figura 6.3). Embora ela calcule a região de estabilização do sistema, faz-se necessário conhecer de antemão os ganhos que estabilizam o sistema, pois o algoritmo não testa a estabilidade de cada uma das regiões de ganhos invariáveis calculadas através do Teorema 3.1 (Figuras 5.10 e 5.11), não sendo capaz de determinar os ganhos que estabilizam o sistema.

Uma vez que se têm em mãos os valores dos ganhos que estabilizam o sistema (determinados no Capítulo 5 - Figura 5.12), a sub-rotina calculo_ganhos determina o valor do pico de ressonância, $M_{r}$, em função dos mesmos. Em seguida, define-se uma faixa de valores para os ganhos, $\mathrm{K}_{\mathrm{D}_{-} \mathrm{TESTE}}$ e $\mathrm{K}_{\mathrm{P}_{-} \mathrm{TESTE}}$, e, para esta faixa, determinam-se os valores dos ganhos proporcional e derivativo que resultam na menor amplitude de $\mathrm{M}_{\mathrm{r}}$ (ganhos ótimos).

No caso, adota-se um passo de 0,025 para o vetor $\mathrm{K}_{\mathrm{D}_{-} \text {TESTE }}$ e de 0,5 para o vetor $\mathrm{K}_{\mathrm{P}_{-} \mathrm{TESTE}}$ para o controlador PD e um passo de 2 para o vetor $\mathrm{K}_{\mathrm{P}_{-} \text {TESTE }}$ para um controlador do tipo $\mathrm{P}\left(\mathrm{K}_{\mathrm{D}_{-} \mathrm{TESTE}}=0\right)$, pois, tendo-se em vista os valores dos ganhos escolhidos para o controlador no capítulo anterior, acredita-se que para essa magnitude de passo é possível determinar os ganhos mais apropriados de forma precisa realizando-se o menor número de iterações necessário.

Uma vez determinados os valores ótimos dos ganhos do controlador para uma faixa de ganhos, redefine-se esta faixa e o cálculo é refeito. O valor ótimo para os ganhos proporcional e derivativo é armazenado, respectivamente, nos vetores $\mathrm{K}_{\mathrm{D} \_ \text {отімо e }} \mathrm{K}_{\mathrm{P}_{-} \text {Oтімо }}$ (no caso de uma estratégia de controle $\mathrm{P}$, o vetor $\mathrm{K}_{\mathrm{D}_{-} \text {Oтाмо }}$ assume valores nulos). A posição em que estes ganhos são armazenados é a correspondente ao número da iteração realizada pela sub-rotina (definida pelo indexador aux2), sendo executadas ao todo 10 iterações, pois deste modo garante-se, com base nos testes realizados no capítulo anterior, que os ganhos ótimos calculados são suficientemente grandes a ponto de implicar na saturação do drive dos atuadores (sendo assim, desnecessário realizar um número maior de iterações, pois os ganhos obtidos não poderiam ser implementados na prática). 
Finalmente, executadas as sub-rotinas FRF e calculo_ganhos, os ganhos estáveis que otimizam o desempenho do sistema são conhecidos (os quais são armazenados em ordem crescente em termos de valor absoluto nos vetores $\mathrm{K}_{\mathrm{D}_{-} \text {отімо }}$ e $\left.\mathrm{K}_{\mathrm{P}_{-} \text {Oтімо }}\right)$. Os menores valores para os ganhos do controlador são então implementados e a sub-rotina FRF é executada novamente (Figura 6.1). Ao seu término, o valor máximo do sinal de controle é avaliado e, de modo a não saturar o drive dos atuadores $( \pm 10 \mathrm{~V}$ ), não deve exceder $6 \mathrm{~V}$ (o sinal de controle é somado ao de excitação, conforme diagrama da Figura 5.6, cuja amplitude é de 4 V).

Assim, caso o valor máximo do sinal de controle não ultrapasse $6 \mathrm{~V}$, os valores armazenados em $\mathrm{K}_{\text {D_OTIMO }}(2)$ e $\mathrm{K}_{\mathrm{P}_{-} \text {OTIMO }}(2)$ são implementados e sucessivas iterações são executa-

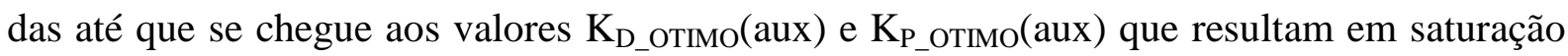
do drive. Calcula-se a média entre o valor dos ganhos situados nessa posição e na posição imediatamente anterior e avalia-se novamente a amplitude máxima da tensão de controle. Se esta for menor que $6 \mathrm{~V}$, o programa é finalizado; caso contrário, se a voltagem máxima for ultrapassada, atribuem-se os valores armazenados nos vetores $\mathrm{K}_{\text {D_otimo }}(\mathrm{aux}-1)$ e $\mathrm{K}_{\mathrm{P} \_ \text {OTIMO}}(\mathrm{aux}-1)$ para os ganhos do controlador e então o algoritmo é encerrado.

Desta forma, tem-se um algoritmo capaz de identificar a FRF do sistema rotativo e, a partir desta informação, calcular e implementar o valor máximo dos ganhos ótimos do controlador (PD ou P) que não resultam em saturação, assegurando, de forma automática, a estabilidade do sistema e maior atenuação possível de vibrações.

A fim de simplificar a visualização das operações envolvidas para o controle autônomo de vibrações do sistema rotativo, desenvolveu-se uma interface gráfica utilizando a ferramenta GUI do MatLab (Figura 6.4): ao pressionar o botão "iniciar", as etapas descritas na Figura 6.1 são executadas, sendo exibidas na área representada por eixos cartesianos, à medida que são calculadas, a FRF do sistema original, a sua respectiva região de ganhos estáveis, os valores do pico ressonância em função dos ganhos do controlador (representados na forma de curvas de nível) e a FRF do sistema controlado para cada valor dos ganhos implementado.

Ao final da execução do algoritmo, o usuário pode navegar entre os diferentes gráficos exibidos através dos botões contidos na aba "exibir gráficos", podendo, inclusive visualizar a "trajetória" realizada pelos ganhos do controlador (valores dos ganhos adotados em cada iteração da implantação do sistema de controle até que o sinal de controle atingisse o maior valor possível que não resultasse na saturação do drive). 


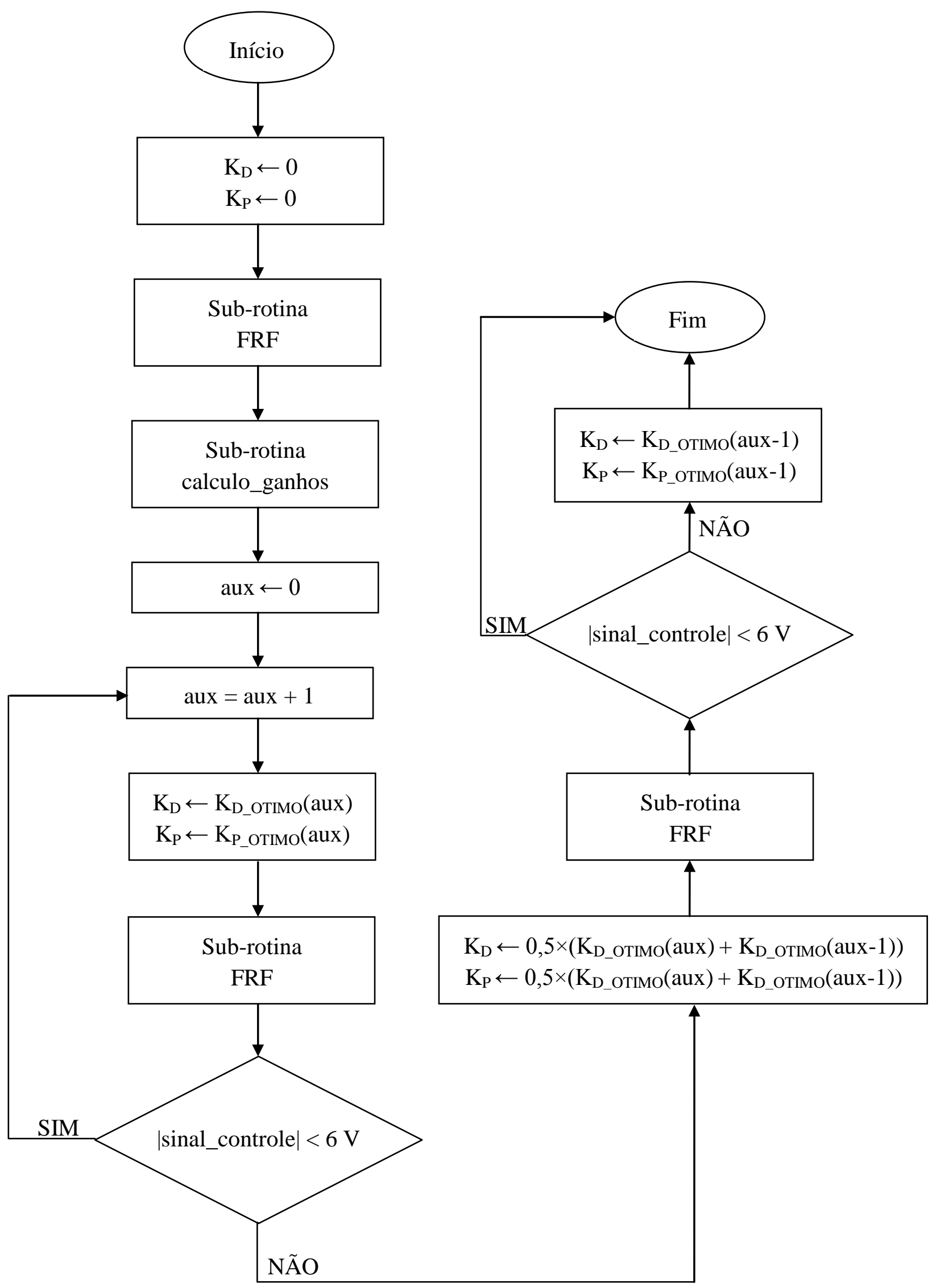

Figura 6.1: Fluxograma do algoritmo de autoidentificação. 


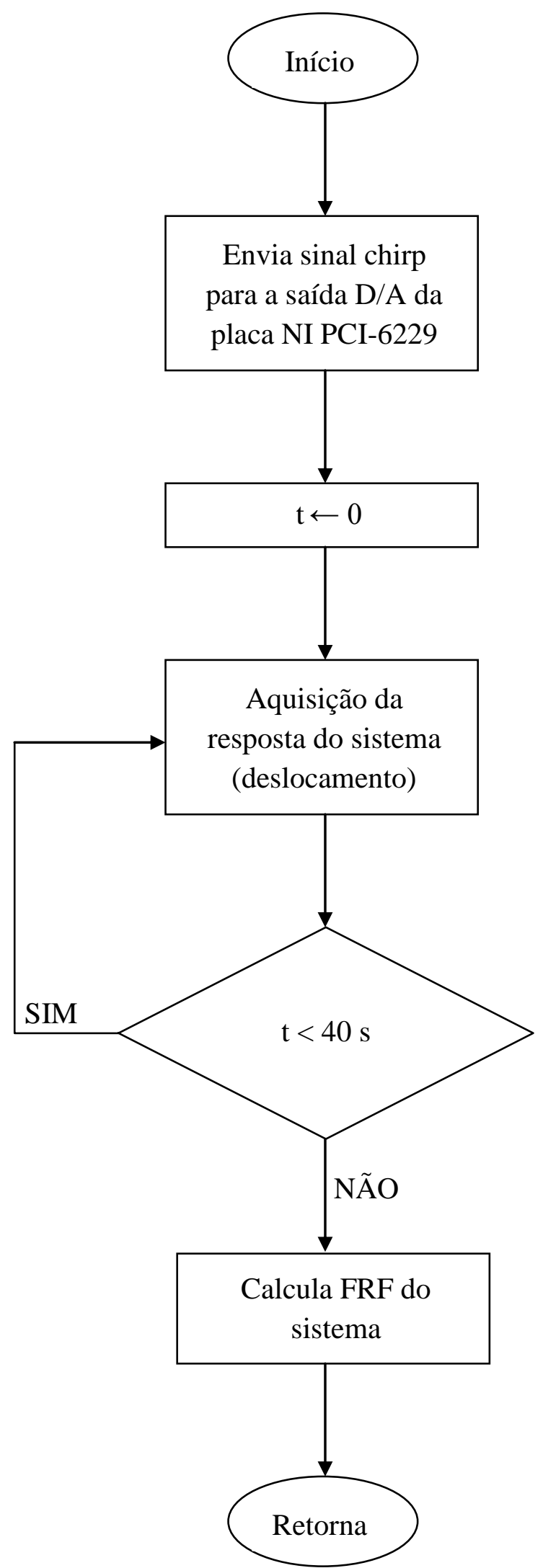

Figura 6.2: Fluxograma da sub-rotina FRF. 


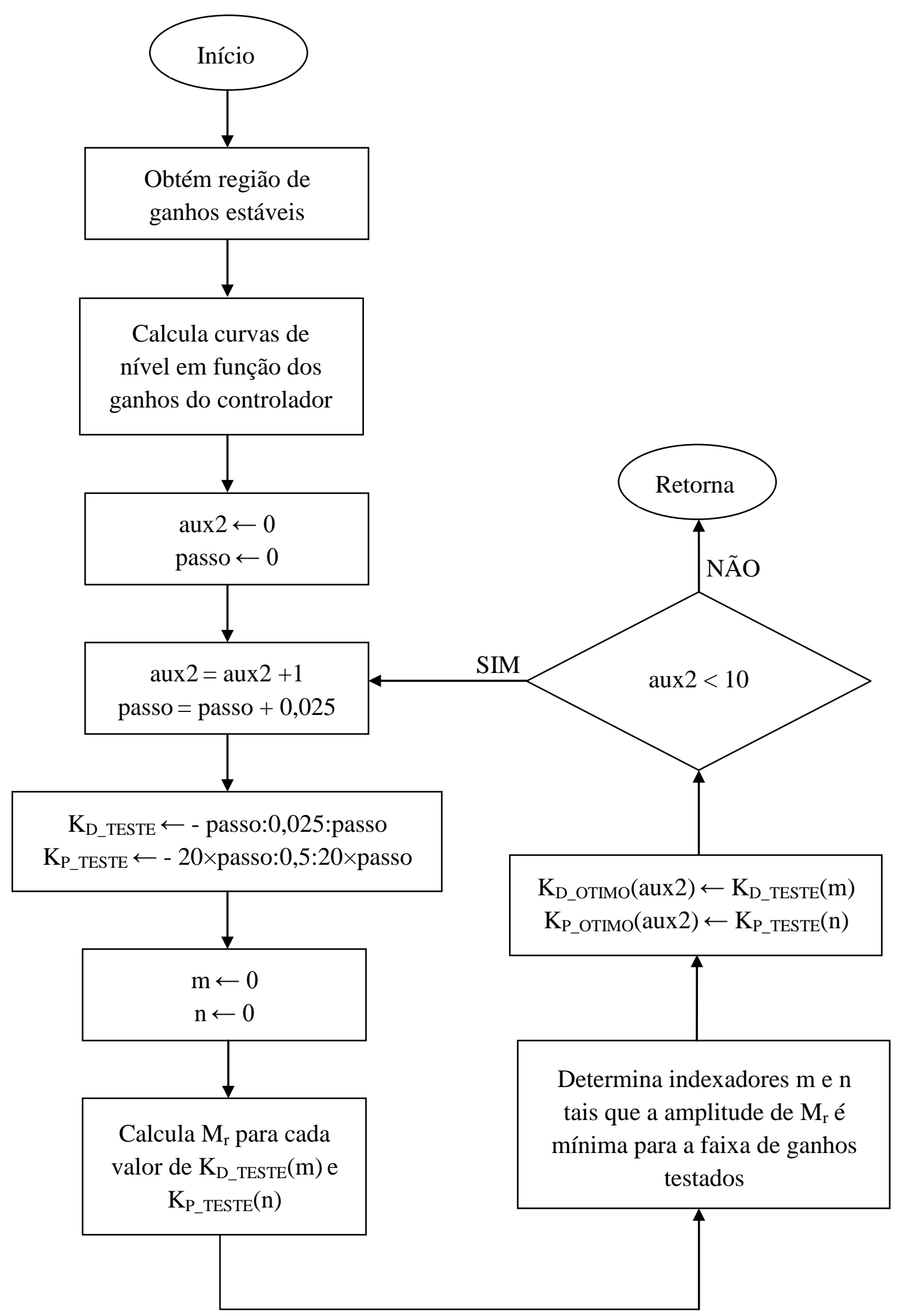

Figura 6.3: Fluxograma da sub-rotina calculo_ganhos. 


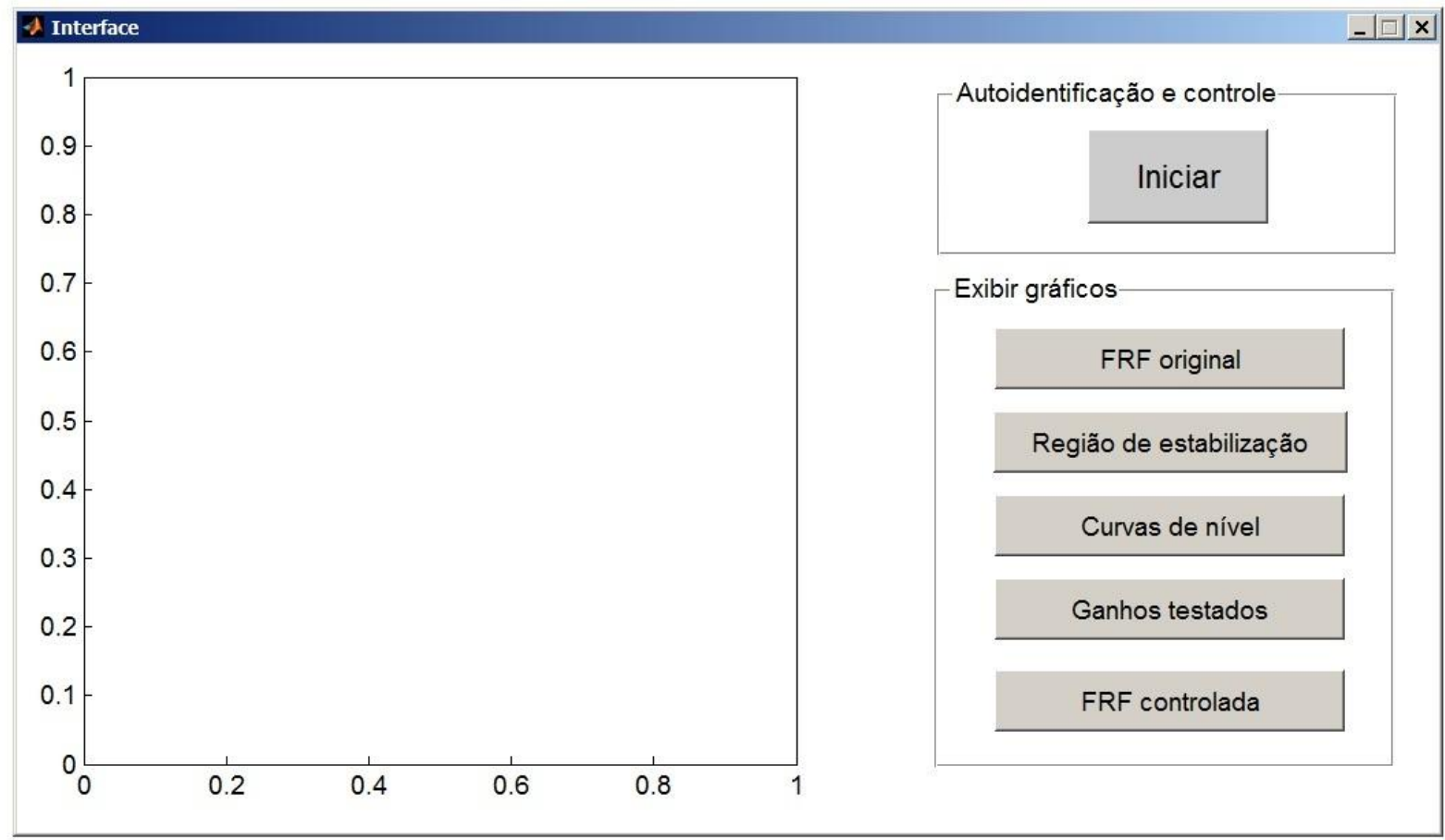

Figura 6.4: Interface gráfica do algoritmo de autoidentificação desenvolvida através da ferramenta GUI do MatLab.

\subsection{Controle autônomo de vibrações do sistema rotativo}

Nesta seção, o algoritmo desenvolvido é testado para as velocidades de rotação do eixo de 280 e $2080 \mathrm{rpm}$. Para $\Omega=280 \mathrm{rpm}$, a partir da identificação do sistema, têm-se os ganhos ótimos para os controladores PD e P implementados automaticamente conforme apresentado na Figura 6.5.

Para o controlador PD, foram realizadas 7 iterações até que os valores máximos dos ganhos do controlador que não resultassem em saturação do drive dos atuadores fossem atingidos (Tabela 6.1): quando $a u x=5$, o valor máximo de $6 \mathrm{~V}$ para a tensão de controle foi excedido; assim, calculou-se a média entre os ganhos correspondentes a este índice e ao índice imediatamente anterior (ponto \#6, Figura 6.5), o que também fez com que a voltagem máxima fosse ultrapassada. Logo, os valores adotados para os ganhos do controlador foram aqueles correspondentes ao índice imediatamente anterior ao que ocorreu a saturação ( $a u x=$ 4), conforme algoritmo ilustrado na Figura 6.1.

Já para o controlador proporcional, 5 iterações foram realizadas até que os valores máximos dos ganhos fossem atingidos (Tabela 6.1): quando $a u x=4$, o valor de $6 \mathrm{~V}$ para o sinal 
de controle foi ultrapassado, tendo sido verificada a tensão para o ganho correspondente à média entre o valor associado a esse índice e o imediatamente anterior (ponto \#5, Figura 6.5), de maneira, que desta vez, o valor máximo do sinal de controle não resultou na saturação do drive.

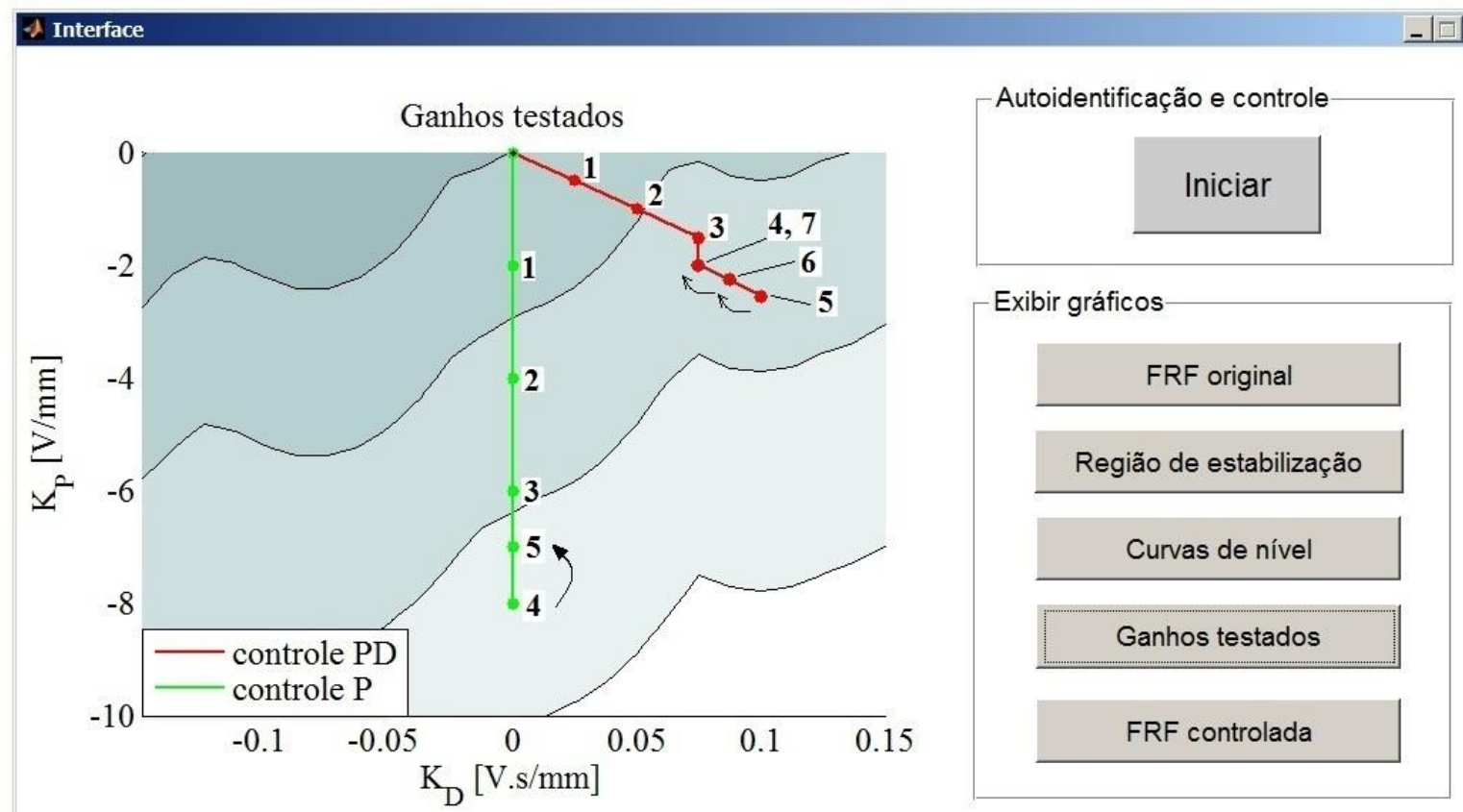

Figura 6.5: "Trajetória" realizada pelos ganhos do controlador (controle PD e P) a cada iteração realizada até que os valores máximos dos ganhos que não resultassem em saturação fossem atingidos $(\Omega=280 \mathrm{rpm})$.

Tabela 6.1: Valores dos ganhos do controlador para cada iteração realizada ( $\Omega=280 \mathrm{rpm})$.

\begin{tabular}{|c|c|c|c|}
\hline \multirow{2}{*}{ Iteração } & \multicolumn{2}{|c|}{ Controle PD } & Controle P \\
\cline { 2 - 4 } & $\mathbf{K}_{\mathbf{D}}$ [V.s/mm] & $\mathbf{K}_{\mathbf{P}}[\mathbf{V} / \mathbf{m m}]$ & $\mathbf{K}_{\mathbf{P}}$ [V/mm] \\
\hline \hline 1 & 0,025 & $-0,50$ & $-2,0$ \\
\hline 2 & 0,050 & $-1,00$ & $-4,0$ \\
\hline 3 & 0,075 & $-1,50$ & $-6,0$ \\
\hline 4 & 0,075 & $-2,0$ & $-8,0$ \\
\hline 5 & 0,1 & $-2,5$ & $-7,0$ \\
\hline 6 & 0,0875 & $-2,25$ & ----- \\
\hline 7 & 0,075 & $-2,0$ & ----- \\
\hline
\end{tabular}


A Figura 6.6 ilustra o princípio utilizado para cálculo dos ganhos ótimos empregado pela sub-rotina calculo_ganhos (Figura 6.3): tem-se um indexador (aux2) que representa a quantidade de intervalos analisados para determinação dos valores dos ganhos $K_{D}$ e $K_{P}$ que resultam no menor valor $\mathrm{M}_{\mathrm{r}} \mathrm{e}$, a cada iteração de aux2, o tamanho do intervalo aumenta (Tabela 6.2). Uma faixa de ganhos, $\mathrm{K}_{\mathrm{D}_{-} \mathrm{TESTE}} \mathrm{e} \mathrm{K}_{\mathrm{P}_{-} \mathrm{TESTE}}$, é analisada e os ganhos ótimos para

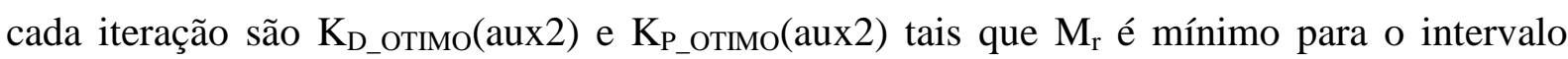
associado ao valor de aux2 considerado (para o controlador $\mathrm{P}$, o raciocínio é análogo, sendo

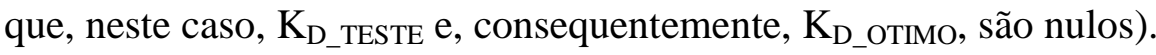

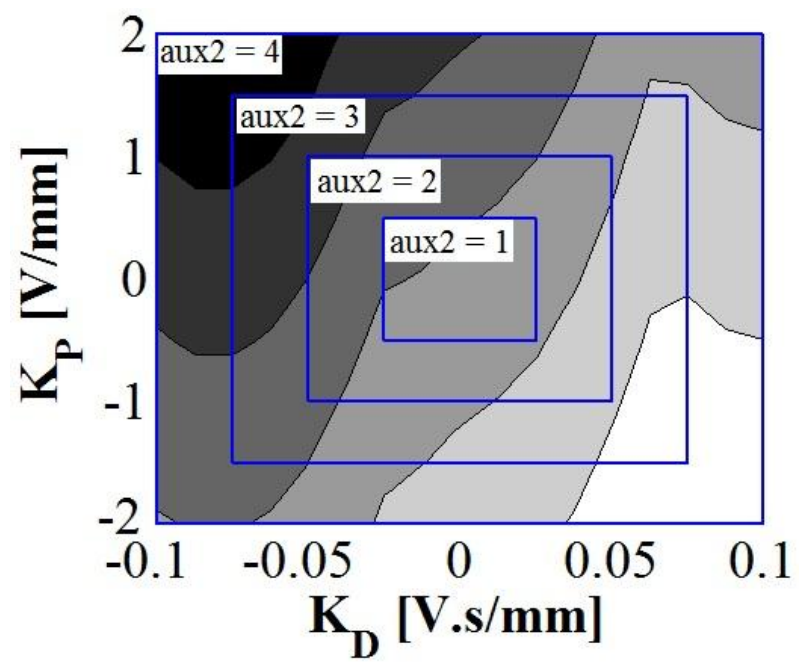

Figura 6.6: Faixas de ganhos analisadas pela sub-rotina calculo_ganhos quando da implantação do controle PD para $\Omega=280 \mathrm{rpm}$ (quatro primeiras iterações).

Tabela 6.2: Faixas de ganhos analisadas pela sub-rotina calculo_ganhos e valores ótimos para cada faixa quando da implantação do controle PD para $\Omega=280 \mathrm{rpm}$ (quatro primeiras iterações).

\begin{tabular}{|c|c|c|c|c|}
\hline aux2 & $\mathbf{K}_{\mathbf{D}_{-} \text {TESTE }}$ (passo 0,025) & $\mathbf{K}_{P_{-} \text {TESTE }}($ passo 0,5) & $\mathbf{K}_{\mathbf{D} \_ \text {отімо }}(\mathbf{a u x 2})$ & K户_отімо (aux2) \\
\hline 1 & $-0,025 \leq K_{D} \leq 0,025$ & $-0,5 \leq K_{P} \leq 0,5$ & 0,025 & $-0,5$ \\
\hline 2 & $-0,05 \leq K_{D} \leq 0,05$ & $-1 \leq K_{P} \leq 1$ & 0,05 & $-1,0$ \\
\hline 3 & $-0,075 \leq K_{D} \leq 0,075$ & $-1,5 \leq K_{P} \leq 1,5$ & 0,075 & $-1,5$ \\
\hline 4 & $-0,1 \leq K_{D} \leq 0,1$ & $-2 \leq K_{P} \leq 2$ & 0,075 & $-2,0$ \\
\hline
\end{tabular}


Para os ganhos correspondentes à última iteração realizada na Figura 6.5 (controle PD e P), i.e., aqueles que resultam na maior atenuação de vibrações possível, uma vez que equivalem aos maiores valores dos ganhos ótimos que não resultam na saturação do drive dos atuadores, tem-se as FRFs do sistema controlado autonomamente para o deslocamento medido pelo sensor \#1 apresentadas na Figura 6.7. Conforme verificado anteriormente, o controle PD, apesar de minimizar o maior pico, amplifica o de menor amplitude; e o controle $\mathrm{P}$, por sua vez, é capaz de reduzir ambos os picos, mostrando-se mais efetivo do que o controlador proporcional-derivativo.

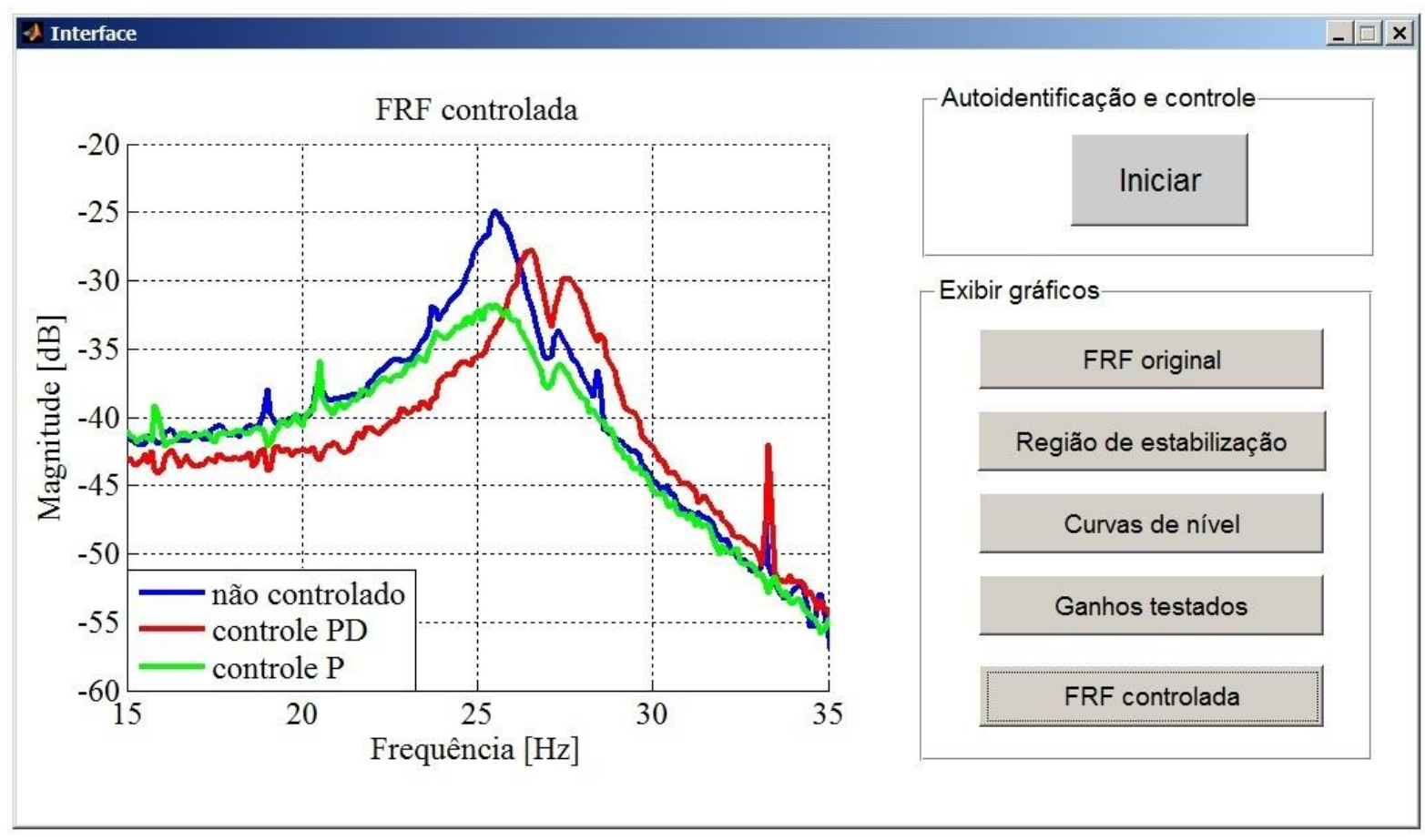

Figura 6.7: Comparação entre a amplitude do pico de ressonância na direção horizontal para o sistema não controlado e controlado autonomamente (controle PD e P) para $\Omega=280 \mathrm{rpm}$.

Analisando-se agora o funcionamento do algoritmo de autoidentificação para $\Omega=$ 2080 rpm, têm-se os ganhos ótimos para os controladores PD e P implementados automaticamente conforme apresentado na Figura 6.8 .

Para o controlador PD, foram realizadas 4 iterações até que os valores máximos dos ganhos do controlador que não resultassem em saturação do drive dos atuadores fossem atingidos (Tabela 6.3): quando $a u x=3$, o valor máximo de $6 \mathrm{~V}$ para a tensão de controle foi excedido; assim, calculou-se a média entre os ganhos correspondentes a este índice e ao ín- 
dice imediatamente anterior (ponto \#4, Figura 6.8), de maneira que, para esta ganho a voltagem máxima não fosse ultrapassada.

Já para o controlador proporcional, 6 iterações foram realizadas até que os valores máximos dos ganhos fossem atingidos (Tabela 6.3): quando $a u x=5$, o valor de de $6 \mathrm{~V}$ para o sinal de controle foi ultrapassado, tendo sido verificada a tensão para o ganho correspondente à média entre o valor associado a esse índice e o imediatamente anterior (ponto \#6, Figura 6.8), de maneira, que desta vez, o valor máximo do sinal de controle não resultou na saturação do drive.

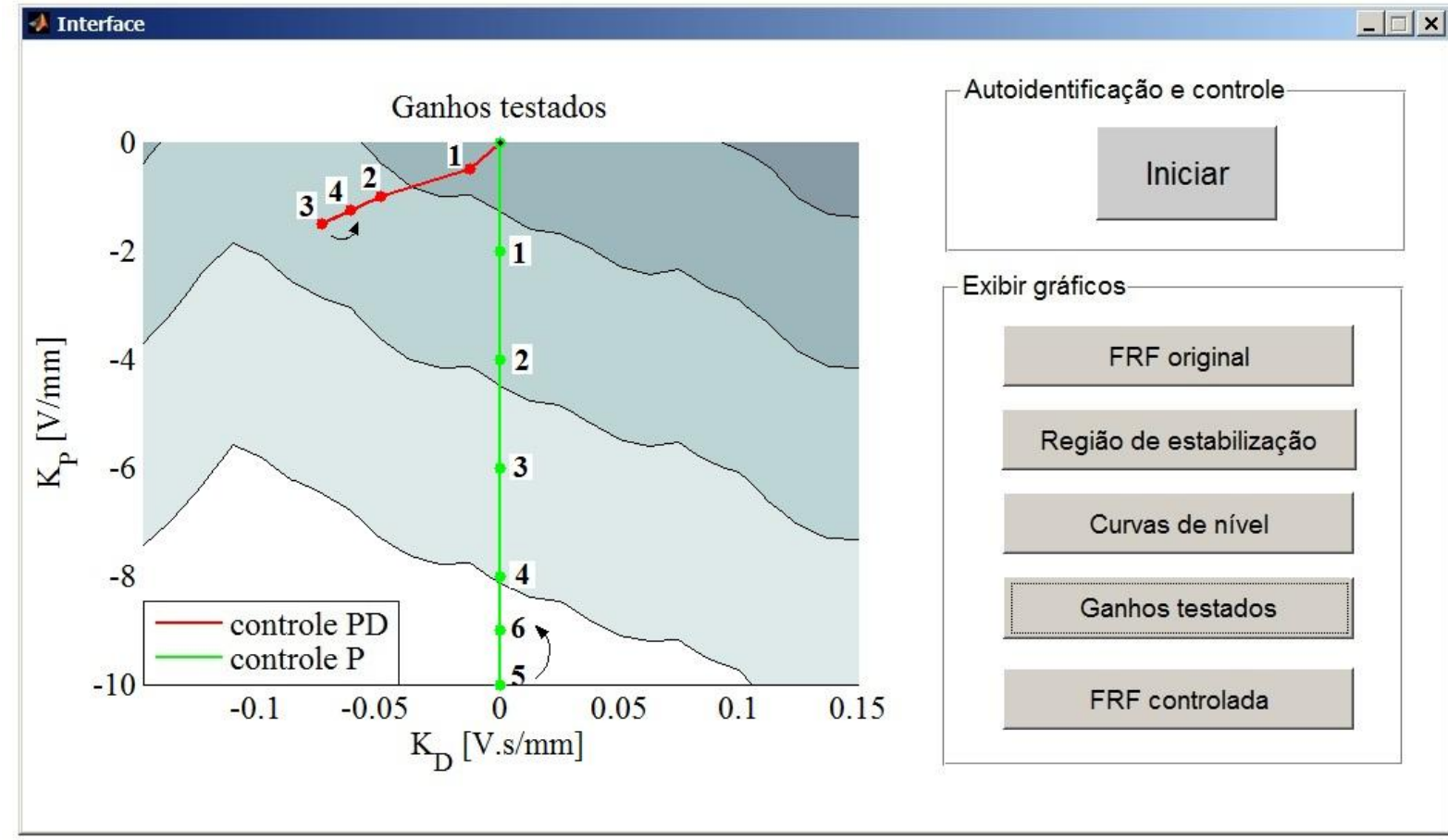

Figura 6.8: "Trajetória" realizada pelos ganhos do controlador (controle PD e P) a cada iteração realizada até que os valores máximos dos ganhos que não resultassem em saturação fossem atingidos $(\Omega=2080 \mathrm{rpm})$.

Assim, para os ganhos correspondentes à última iteração realizada na Figura 6.8 (controle PD e P), i.e., aqueles que resultam na maior atenuação de vibrações possível, uma vez que equivalem aos maiores valores dos ganhos ótimos que não resultam na saturação do drive dos atuadores, tem-se as FRFs do sistema controlado autonomamente para o deslocamento medido pelo sensor \#1 apresentadas na Figura 6.9. 
Tabela 6.3: Valores dos ganhos do controlador para cada iteração realizada $(\Omega=2080 \mathrm{rpm})$.

\begin{tabular}{|c|c|c|c|}
\hline \multirow{2}{*}{ Iteração } & \multicolumn{2}{|c|}{ Controle PD } & Controle P \\
\cline { 2 - 4 } & $\mathbf{K}_{\mathbf{D}}$ [V.s/mm] & $\mathbf{K}_{\mathbf{P}}$ [V/mm] & $\mathbf{K}_{\mathbf{P}}$ [V/mm] \\
\hline \hline 1 & $-0,0125$ & $-0,5$ & $-2,0$ \\
\hline 2 & $-0,05$ & -1 & $-4,0$ \\
\hline 3 & $-0,075$ & $-1,5$ & $-6,0$ \\
\hline 4 & $-0,0625$ & $-1,25$ & $-8,0$ \\
\hline 5 & ------ & ------ & $-10,0$ \\
\hline 6 & ------ & ----- & $-9,0$ \\
\hline
\end{tabular}

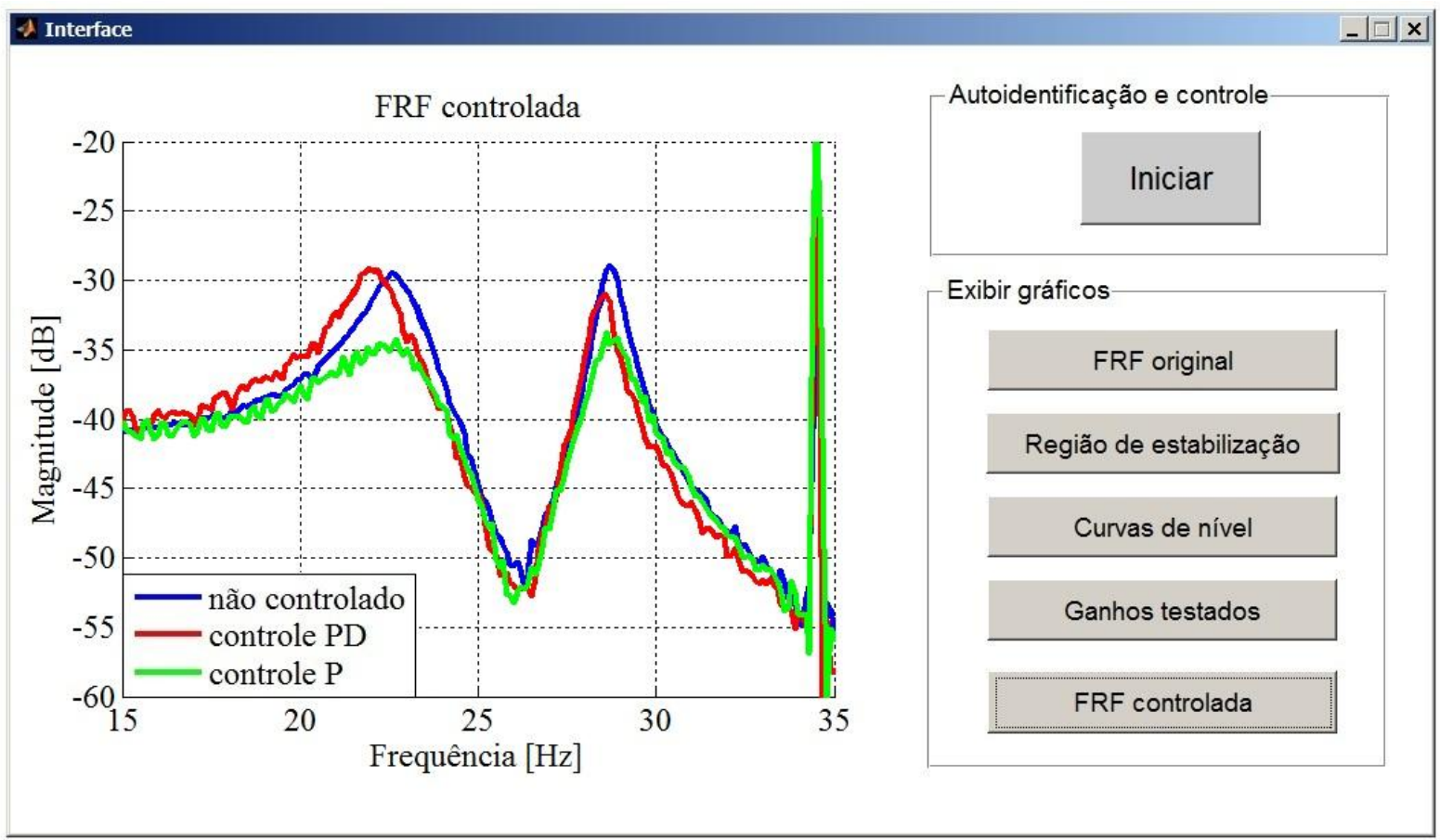

Figura 6.9: Comparação entre a amplitude do pico de ressonância na direção horizontal para o sistema não controlado e controlado autonomamente (controle PD e P) para $\Omega=2080 \mathrm{rpm}$.

A Tabela 6.4 sumariza os resultados obtidos para o controle autônomo do sistema às velocidades de 280 e $2080 \mathrm{rpm}$. Assim como verificado no Capítulo 5, o controle P se mostrou bem mais efetivo que o PD e, para o caso em que $\Omega=2080 \mathrm{rpm}$, pelo fato de ambos os picos terem valores de amplitudes muito próximos, o controle PD se mostra incapaz de atenuar de forma significativa a amplitude dos picos de ressonância. 
Tabela 6.4: Comparação entre a amplitude do maior pico de ressonância para o sistema não controlado e controlado autonomamente (controle PD e P).

\begin{tabular}{|c|c|c|c|c|c|}
\hline \hline $\begin{array}{c}\mathbf{\Omega} \\
{[\mathbf{r p m}]}\end{array}$ & $\begin{array}{c}\text { Não controlado } \\
{[\mathbf{d B}]}\end{array}$ & $\begin{array}{c}\text { Controle PD } \\
{[\mathbf{d B}]}\end{array}$ & $\begin{array}{c}\text { Controle P } \\
{[\mathbf{d B}]}\end{array}$ & $\begin{array}{c}\text { Var. controle PD } \\
{[\%]}\end{array}$ & $\begin{array}{c}\text { Var. controle P } \\
{[\%]}\end{array}$ \\
\hline 280 & $-24,85$ & $-27,61$ & $-31,57$ & $-27,2$ & $-53,9$ \\
\hline 2080 & $-28,95$ & $-28,93$ & $-34,16$ & 0,2 & $-45,1$ \\
\hline
\end{tabular}





\section{Capítulo 7}

\section{Conclusões}

Uma estratégia de controle livre de modelos matemáticos foi testada experimentalmente em um sistema rotativo, tendo sido obtidos, a partir de medições de resposta em frequência, em que os atuadores de um mancal magnético foram utilizados como fonte de excitação, os ganhos de um controlador PD que garantiam a estabilidade do sistema em malha fechada e, posteriormente, os seus valores que otimizavam o desempenho do sistema foram determinados, sendo a redução da amplitude do pico de ressonância utilizada como critério de desempenho.

Este tipo de abordagem para projeto de sistemas de controle é inédita no âmbito de sistemas rotativos e, além disso, representa uma contribuição para a área de sistemas de controle, uma vez que as técnicas de projeto de controladores a partir de resposta em frequência visando a obtenção de uma região de estabilização no espaço de ganhos do controlador são relativamente recentes, sendo poucos os trabalhos encontrados na literatura que a empregam experimentalmente.

Frente aos métodos tradicionais de projeto de controladores aplicados ao controle de vibrações em sistemas rotativos, esta metodologia, por não requerer o modelo matemático do sistema, contorna dificuldades de modelagem, permitindo a obtenção dos ganhos ótimos do controlador do ponto de vista de estabilidade e desempenho de forma simples, a partir de medições da resposta do sistema para uma entrada conhecida.

Para o sistema rotativo estudado, embora os atuadores utilizados tenham baixa capacidade atuação, conseguiu-se uma redução máxima de $25 \%$ e $35 \%$ do pico de ressonância 
para as configurações com um disco e dois discos respectivamente (controle PD), sendo que maior atenuação de vibrações poderia ter sido obtida com o uso de eletromagnetos mais potentes. Para a configuração com dois discos, verificou-se que a bipartição do pico de ressonância correspondente ao primeiro modo de vibrar do sistema, ocorrida em virtude do efeito giroscópico, resultou em dois picos cujas amplitudes apresentam tendências opostas para o deslocamento medido na direção horizontal (ao passo que um pico tende a diminuir com a rotação, o outro aumenta), tendo sido o controle do tipo proporcional-derivativo pouco efetivo neste caso, pois a ação derivativa resultou em um efeito conflitante em relação a minimização destes picos (embora ela atenuasse o de maior amplitude, amplificava o de menor amplitude).

Neste sentido, um controlador do tipo P foi implantado por ser capaz de atenuar ambos os picos de ressonância e, ao contrário do que se imaginava no início deste trabalho, este se mostrou mais eficiente que o controlador PD (tanto do ponto de vista de vibração na direção horizontal quanto na vertical), tendo sido alcançada uma redução máxima de $55 \%$ do pico de ressonância. $O$ fato de não haver o emprego da ação derivativa permitiu a adoção de valores mais elevados do ganho proporcional em comparação com aqueles adotados quando da utilização do controle proporcional-derivativo de modo a não ocorrer saturação da porta de saída D/A da placa de aquisição de dados, sendo, assim, o controle P mais efetivo que o PD e tendo as vantagens adicionais de não resultar em amplificação de ruídos e ser de implementação mais simples.

Em relação ao critério de desempenho estudado, a amplitude do pico de ressonância para o sistema em malha fechada foi estimada através de uma equação escrita em termos da FRF da planta e dos ganhos controlador. Embora tenha se verificado um erro considerável entre os valores estimados e os medidos na prática (chegando a uma diferença percentual máxima de $30 \%$ ), o comportamento previsto para a magnitude do pico em função dos ganhos foi correto em todos os casos: a tendência de variação do pico (aumento ou redução) estimada para valores crescentes ou decrescentes dos ganhos (por exemplo, a redução do pico à medida que $K_{P}$ decrescia) foi confirmada na prática.

Acredita-se que esse erro entre os valores estimados para o pico de ressonância e os seus valores reais seja devido às correntes parasitas, pois, quando o sistema em malha fechada é simulado em computador, este fenômeno não é computado. Uma alternativa seria tornar a porção do eixo situada entre os atuadores descontínua, inserindo-se nesta posição uma bucha 
constituída por lâminas de metal (mecanismo semelhante ao de transformadores). Desta forma, seria criado um gap entre as lâminas, impedindo a formação das referidas correntes. Assim, poder-se-ia avaliar a resposta do sistema sem a influência deste efeito e então se acredita que os valores medidos experimentalmente para o pico de ressonância seriam próximos aos estimados.

Em seguida, uma vez verificada a efetividade da técnica de controle estudada, automatizou-se o procedimento para sua implantação. Esta automatização foi feita através de um algoritmo (algoritmo de autoidentificação) implementado no software MatLab, em que a aquisição da resposta do sistema é executada em tempo real através da ferramenta Simulink. Uma vez obtida a resposta do sistema, um código desenvolvido no editor do aplicativo determina os ganhos estáveis que otimizam o comportamento do sistema.

Calculados estes ganhos, a ferramenta Simulink é novamente executada; desta vez, além de adquirir a resposta do sistema, ela também realimenta uma malha de controle. Novos valores para os ganhos são então implementados até que o critério de parada estabelecido seja atingido (tensão de controle atinge o máximo valor permitido de forma a não ocorrer saturação da porta de saída da placa de aquisição). Todos os passos executados pelo algoritmo de autoidentificação são executados de forma automática e os mesmos podem ser visualizados através da interface desenvolvida no ambiente GUI do aplicativo MatLab. Desta forma, temse um algoritmo que, a partir da identificação da resposta em frequência da planta e de uma estratégia de controle livre de modelos matemáticos, permite o controle autônomo das vibrações de um sistema rotativo.

Finalmente, destaca-se que, embora a técnica de controle estudada neste trabalho tenha sido aplicada a sistemas rotativos com 1 e 2 gdl, a mesma pode ser generalizada para sistemas com $\mathrm{N}$ modos de vibrar, desde que as restrições impostas pela Decomposição-d (sistemas lineares, invariantes no tempo e com uma entrada e uma saída) sejam atendidas. Do ponto de vista do critério de desempenho considerado, pode-se calcular a amplitude do maior dos picos de ressonância correspondentes aos $\mathrm{N}$ modos de vibrar do sistema, visando atenuação global do valor máximo da amplitude da resposta em frequência do sistema, ou pode-se selecionar um modo de vibrar específico, visando a atenuação apenas do pico associado a este modo (no caso deste trabalho, a métrica de desempenho em questão visava a redução apenas do $1^{\circ}$ modo de vibrar do sistema). 
Assim, acredita-se que a técnica de controle estudada neste trabalho, pioneiro no âmbito de projeto de sistemas de controle aplicados a sistemas rotativos visando o cálculo de regiões de estabilização a partir de medições de resposta em frequência, possa abrir novos horizontes para o projeto de controladores de máquinas rotativas, eliminando a etapa de modelagem do sistema. Além disso, o conceito de autoidentificação apresentado (algoritmo de autoidentificação) pode ser empregado no desenvolvimento de um mancal ativo inteligente visando, além de sustentação, o controle autônomo de vibrações de máquinas rotativas.

\subsection{Trabalhos futuros}

Os conceitos apresentados neste trabalho podem ser aperfeiçoados e aplicados de acordo com os seguintes passos visando o desenvolvimento de um mancal ativo inteligente capaz de controlar, de forma autônoma, vibrações em máquinas rotativas:

- utilizar como critério de desempenho uma norma de desempenho robusto; selecionando-se, dentro das regiões de estabilização, os ganhos que satisfazem esse requisito. Neste sentido, os resultados apresentados em Emami e Watkins (2009) podem ser úteis;

- atuar também na direção vertical, empregando atuadores que produzam forças nesta direção. Nesse caso, ter-se-ia um sistema com duas entradas e duas saídas, de modo que, dado o acoplamento entre as direções quando se tem o efeito giroscópico presente, o Teorema 3.1 não poderia ser aplicado, pois ele é válido somente para sistemas SISO. Assim, os resultados apresentados em Gryazina e Polyak (2006) podem ser úteis, pois a Decomposição-d é formulada para sistemas com duas entradas e duas saídas em termos da representação no espaço de estados do sistema, fazendo-se necessário reescrever esta formulação em termos da resposta em frequência do sistema, de modo que as suas regiões de ganhos estáveis possam ser obtidas a partir de uma metodologia livre de modelos matemáticos;

- excitar máquina rotativa suportada por mancais ativos utilizando os atuadores do próprio mancal, de forma a se obter suas FRFs, respectivas regiões de estabilização e ganhos que atenuam vibrações, a fim de projetar seu sistema de controle utilizando a metodologia de controle livre de modelos matemáticos estudada neste trabalho; 
- tornar um mancal ativo (como o conceito de mancal hidrodinâmico segmentado com sapatas móveis magnéticas apresentado) um componente inteligente: por meio de um sistema eletrônico embarcado e da implementação do algoritmo de autoidentificação em um microcontrolador, o mancal seria capaz, a partir de informações de deslocamento medidas por sensores de proximidade, de determinar os ganhos ótimos do controlador e implementá-los, sendo os mesmos reprojetados, automaticamente, à medida que as condições de operação da máquina rotativa suportada pelo mancal fossem modificadas, assegurando sustentação e controle autônomo de vibrações do rotor. 



\section{Referências bibliográficas}

Adams, M. L. (2001). Rotating machinery vibration. Marcel Dekker, New York.

Aenis, M., Knopf, E., Nordmann, R. (2002). Active magnetic bearings for the identification and fault diagnosis in turbomachinery. Mechatronics, Vol. 12, pp. 1011-1021.

Astrom, K. J., Wittenmark, B. (2008). Adaptive control. Marcel Dekker, New York.

Antsaklis, P. J. (1997). Inteligent control. John Wiley \& Sons, New York.

Beards, C. F. (1996). Structural vibration: analysis and damping. John Wiley \& Sons, New York.

Burdet, L. (2006). Active magnetic bearing design and characterization for high temperature applications. PhD Thesis, École Polytechnique Fédérale de Lausanne, Lausanne.

Buttini, T. M., Felscher, P., Nicoletti, R. (2011). PD controller synthesis based on frequency response of actuator-rotating systems. In Proc. $9^{\text {th }}$ International Conference on Vibrations in Rotating Machines, Darmstadt, Germany, pp. 1-9.

Buttini, T. M., Nicoletti, R. (2009). Direct synthesis from frequency response measurements applied to the controller design of a servo positioning system. In Proc. $20^{\text {th }}$ International Congress of Mechanical Engineering, Gramado, Brazil, pp. 1-7.

Buttini, T. M., Nicoletti, R. (2011). Rotor lateral vibration control: a stability and performance analysis based on a model-free approach. In Proc. $18^{\text {th }}$ International Congress on Sound and Vibration, Rio de Janeiro, Brazil, pp. 1-8.

Childs, D. W. (1993). Turbomachinery rotordynamics: phenomena, modeling and analysis. Jon Wiley \& Sons, New York. 
Dorf, R. C., Bishop, R. H. (2009). Sistemas de controle modernos. 11 ${ }^{\mathrm{a}}$ Ed., LTC, Rio de Janeiro.

Duan, G. R., Wu, Z. Y., Howe, D. (2001). Robust control of a magnetic-bearing flywheel using dynamical compensators. Transactions of the Institute of Measurements and Control, Vol. 23, No. 4, pp. 249-278.

Emami, T., Watkins, J. (2009). Robust performance characterization of PID controllers in the frequency domain. WSEAS Transactions on Systems and Control, Vol. 4, pp. 232-242.

Ewins, D. J. (1995). Modal testing: theory and practice. John Wiley \& Sons, New York.

Fadali, M. S. (2009). Digital control engineering: analysis and design. Elsevier, Burlington.

Frazer, R. A., Duncan, W. J. (1929). On the criteria for stability for small motions. In. Proc. of the Royal Society of London, pp. 642-654.

Fujisaki, Y., Oishi, Y., Tempo, R. (2004). Characterizations of fixed order stabilizing controllers. In Proc. 43rd IEEE Conference on Decision and Control, Atlantis, Paradise Island, Bahamas, pp. 5308-5309.

Furtado, R. M. (2008). Desenvolvimento de um atuador eletromagnético para excitação sem contato de sistemas rotativos. Tese de Doutorado, Universidade Estadual de Campinas, Campinas.

Gryazina, E. N., Polyak, B. T. (2006). Stability region in the parameter space: Ddecomposition revisited. Automatica, Vol. 42, pp. 13-26.

Gryazina, E. N., Polyak, B. T., Tremba, A. A. (2008). D-decomposition technique state-ofthe-art. Automation and Remote Control, Vol. 69, No. 12, pp. 1991-2026.

Gu, D. W., Petkov, P, Konstantinov, M. M. (2005). Robust control design with MatLab. Springer-Verlag, London.

Horst, H. G., Wolfel, H. P. (2004). Active vibration control of a high speed rotor using PZT patches on the shaft surface. Journal of Intelligent Material Systems and Structures, Vol. 15, pp. 721-728. 
Hurwitz, A. (1895). On the conditions under which an equation has only roots with negative real parts. Mathematische Annalen, Vol. 46, pp. 273-284.

Jinggong, L., Yali, X., Donghai, L. (2010). Calculation of PI controller stable region based on D-partition method. In Proc. International Conference on Control, Automation and Systems, Gyeonggi-do, Korea, pp. 2185-2189.

Kasarda, M. E. F. (2000). Overview of active magnetic bearing technology and applications. The Shock and Vibration Digest, Vol. 22, No. 2, pp. 91-99.

Keel, L. H., Bhattacharyya, S. P. (2005). Direct synthesis of first order controllers from frequency response measurements. In Proc. 2005 American Control Conference, Portland, USA, pp. 1192-1196.

Keel, L. H., Bhattacharyya, S. P. (2008). Controller synthesis free of analytical models: three term controllers. IEEE Trans. on Automatic Control, Vol. 53, No. 6, pp. 1353-1359.

Lallart, M. (2010). Vibration control. Sciyo, Rijeka.

Li, L., Shinshi, T., Shimokohbe, A. (2004). State feedback control for active magnetic bearings based on current change rate alone. IEEE Trans. on Magnetics, Vol. 40, pp. 3512-3517.

Li, Y., Sheng, A., Wang, Y. (2008). Synthesis of PID-type controllers without parametric models: a graphical approach. Energy Conversion \& Management, Vol. 49, pp. 23922402.

Maia, N. M. M., Silva, J. M. M. (1997). Theoretical and experimental modal analysis. Research Studies Press, London.

Mani, G., Quinn, D. D., Kasarda, M. (2006). Active health monitoring in a rotating cracked shaft using active magnetic bearings as force actuators. Journal of Sound and Vibration, pp. 454-465.

Moudgalya, K. M. (2007). Digital control. Jon Wiley \& Sons, New York.

Neimark, Y. I. (1948). Finding the parameter values that make automatic control system stable. Autom. and Telem., Vol. 9, pp. 190-203. 
Nicoletti, R. (2003). Mancais segmentados com lubrificação ativa - teoria, experimento e aplicação. Tese de Doutorado, Universidade Estadual de Campinas, Campinas.

Nicoletti, R. (2006). The proposed concept of active magnetic-pad journal bearings. In Proc. $5^{\text {th }}$ Brazilian Conference on Dynamics, Control and Their Applications, Guaratinguetá, Brazil, pp. 1-4.

Nicoletti, R., Santos, F. (2008). Control system design for flexible rotors supported by actively lubricated bearings. Journal of Vibration and Control, Vol. 14, pp. 347-374.

Noh, M. D., Maslen, E. H. (1997). Self-sensing magnetic bearings using parameter estimation. IEEE Trans. on Instrumentation and Measurement, Vol. 46, pp. 45-50.

Rehtanz, C. C. (2003). Autonomous systems and intelligent agents in power system control and operation. Springer-Verlag, Berlin.

Routh, E. J. (1892). Dynamics of a system of rigid bodies. Macmillan, New York.

Saeki, M. (2007). Properties of stabilizing PID gain set in parameter space. IEEE Transactions on Automatic Control, Vol. 52, pp. 1710-1715.

Schammass, A., Herzog, R., Buhler, P., Bleuler, H. (2005). New results for self-sensing active magnetic bearings using modulation approach. IEEE Trans. on Control Systems Technology, Vol. 13, No. 4, pp. 509-516.

Schweitzer, G. (1998). Magnetic bearings as a component of smart rotating machinery. In Proc. $5^{\text {th }}$ International Conference on Rotordynamics, Darmstadt, Germany, pp. 3-15.

Schweitzer, G., Maslen, E. H. (2009). Magnetic bearings: theory, design and application to rotating machinery. Springer-Verlag, Heidelberg.

Siljak, D. D. (1969). Nonlinear systems: the parameter analysis and design. John Wiley \& Sons, New York.

Silva, C. W. (2007). Vibration damping, control and design. CRC Press, New York.

Simões, R. C., Steffen Jr., V., Hagopian, J. D., Mahfoud, J. (2007). Modal active vibration control of a rotor using piezoelectric stack actuators. Journal of Vibration and Control, Vol. 13, pp. 45-64. 
Sokolov, A. A. (1946). A criterion of stability for linear regulated systems with distributed parameters. Engineering Overview, Vol. 2, pp. 3-26.

Sung, S. W., Lee, J., Lee, I. B. (2009). Process identification and PID control. Jon Wiley \& Sons, New York.

Tao, G. (2003). Adaptive control design and analysis. John Wiley \& Sons, New Jersey.

Ulbrich, H. (1993). Haben active lagerungen zukunft. In Proc. Schwingungen in Rotierenden Maschinen II, Wiesbaden, Deutschland, pp. 18-27.

Ulbrich, H. (1998). Active vibration control of rotors. In Proc. $5^{\text {th }}$ International Conference on Rotordynamics, Darmstadt, Germany, pp. 16-31.

Vance, J. M., Zeidan, F., Murphy, B. (2010). Machinery vibration and rotordynamics. John Wiley \& Sons, New Jersey.

Vishnegradsky, I. (1876). Sur la theorie generale des regulateurs. Compt. Rend. Acad. Sci., Vol. 83, pp. 318-321.

Viveros, H. P., Buttini, T. M., Nicoletti, R. (2011). Frequency response attenuation of rotating system using hydrodynamic bearing with electromagnetic actuators. In Proc. $21^{\text {th }}$ International Congress of Mechanical Engineering, Natal, Brazil, pp. 1-7.

Yang, X., Xu, B., Chiu, M. S. (2011). PID controller design directly from plant data. Ind. Eng. Chem. Res., Vol. 50, pp. 1352-1359.

Yu, C. C. (2006). Autotuning of PID controllers. Springer-Verlag, London.

Zutavern, Z. S., Childs, D. W. (2008). Identification of rotordynamics forces in a flexible rotor system using magnetic bearings. Journal of Engineering for Gas Turbines and Power, Vol. 130, No. 2, pp. 1-6. 